Portland State University

PDXScholar

Winter 2-20-2014

\title{
Mapping Sociocultural Values of Visitors on the Olympic Peninsula, Washington
}

\author{
Alexa North Todd \\ Portland State University
}

Follow this and additional works at: https://pdxscholar.library.pdx.edu/open_access_etds

Part of the Place and Environment Commons, and the Recreation, Parks and Tourism Administration Commons

Let us know how access to this document benefits you.

\section{Recommended Citation}

Todd, Alexa North, "Mapping Sociocultural Values of Visitors on the Olympic Peninsula, Washington" (2014). Dissertations and Theses. Paper 1637.

https://doi.org/10.15760/etd.1636

This Thesis is brought to you for free and open access. It has been accepted for inclusion in Dissertations and Theses by an authorized administrator of PDXScholar. Please contact us if we can make this document more accessible: pdxscholar@pdx.edu. 
Mapping Sociocultural Values of Visitors on the Olympic Peninsula, Washington

by

Alexa North Todd

A thesis submitted in partial fulfillment of the requirements for the degree of

\author{
Master of Science \\ in \\ Geography
}

\author{
Thesis committee: \\ Joseph Poracsky, Chair \\ David Banis \\ Rebecca McLain \\ Hunter Shobe
}

Portland State University 2014 


\begin{abstract}
Contested land-management plans make spatial data about values that people attach to the landscape necessary for federal land management. The study area for this project is the Olympic Peninsula, Washington, an area that is divided by a complex mosaic of land jurisdictions, including public lands administered by the National Park Service, National Forest Service, and Washington State, as well as interspersed tribal and private landholdings surrounding the perimeter. During the summer of 2012, I collected map and survey data from visitors at fourteen popular destinations around the Olympic Peninsula, including visitor centers, campgrounds, trail access points, and a ferry. Three research objectives were evaluated in my thesis: 1) determine a general typology of visitors, 2) understand what values and activities visitors associate with places in the peninsula, and 3) compare visitor data with resident data from the Human Ecology Mapping Project (HEM), a collaboration between the US Forest Service Pacific Northwest Research Station, the Institute of Culture and Ecology, and Portland State University.

Analysis using ArcGIS included density and density hot spot calculations for a composite of the data as well as subsets based on types of visitors and individual values and activities. A majority of the participants were older males with higher education. Results indicate that visitors with different levels of familiarity spend time in different parts of the Peninsula. Aesthetic, recreation, and wilderness are the values most often included in the survey; hiking, non-cardio recreation, and sociocultural are the activity groups most often included in the survey. Visitors primarily mark places in Olympic
\end{abstract}


National Park. Visitors, including those who live locally, responded in strikingly different ways than residents who participated in HEM. This research produced expected results that not only substantiate knowledge about specific places in the Olympic Peninsula, but also support theories about environmental cognition. 


\section{Acknowledgements}

Thank you to many people who contributed to my thesis: David Banis (Center for Spatial Analysis and Research, Portland State University) for his collaboration and advice on this research; Mazamas and Portland State University Department of Geography for funding the data collection; Rebecca McLain (Institute for Culture and Ecology) and Lee Cerveny (U.S. Forest Service (USFS)) for their support and insights; Joe Poracsky and Hunter Shobe for their support and input on my thesis; Karin Waller and Jon Franczyk for assisting data collection on the Washington State Ferry (WSF); and many USFS, National Park Service, and WSF employees for additional help and support in the field. 


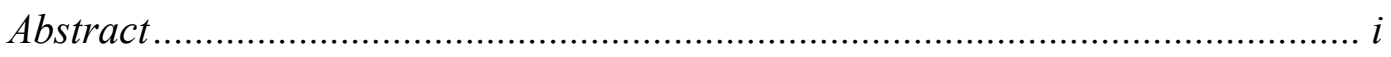

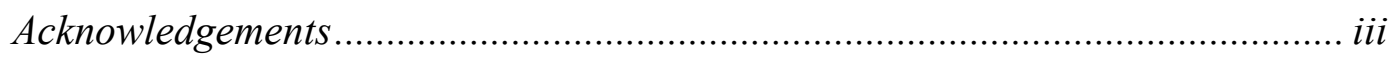

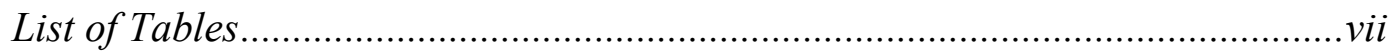

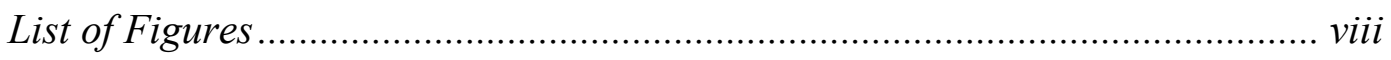

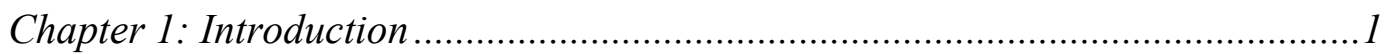

1.1 Purpose

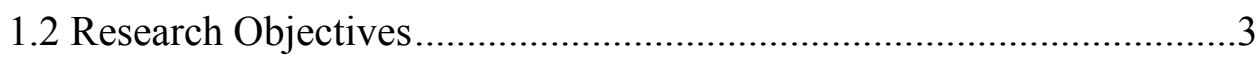

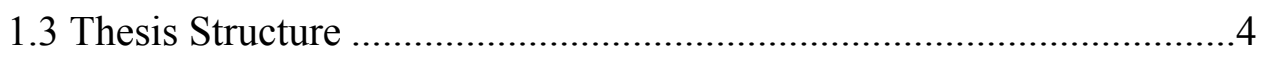

Chapter 2: Geography of the Olympic Peninsula, WA......................................... 6

Chapter 3: A History of Conflicting Interests.......................................................

3.1 Logging in the Olympic Peninsula ...................................................10

3.2 Recreation in the Olympic Peninsula......................................................13

3.3 Wilderness in the Olympic Peninsula ................................................16

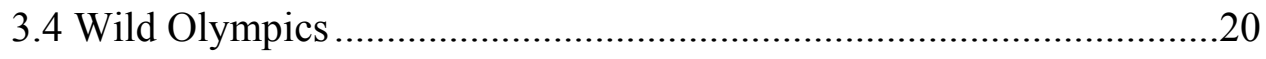

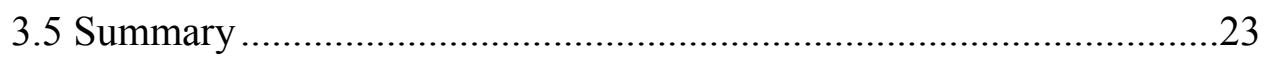

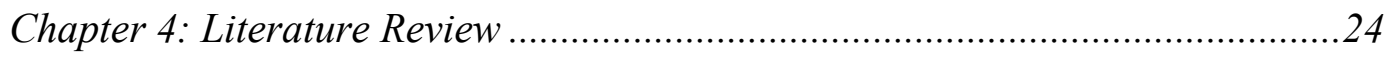

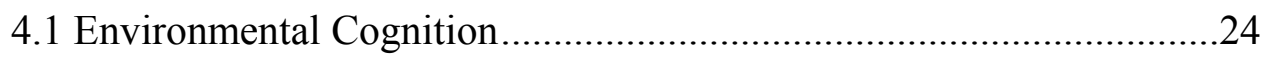

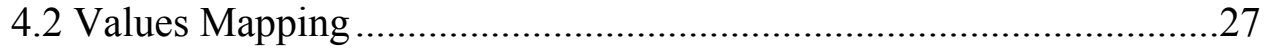

4.3 Human Ecology Mapping Project.........................................................31

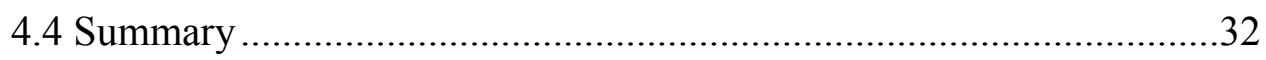

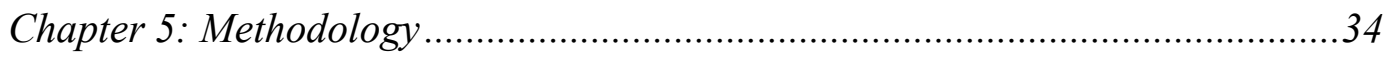

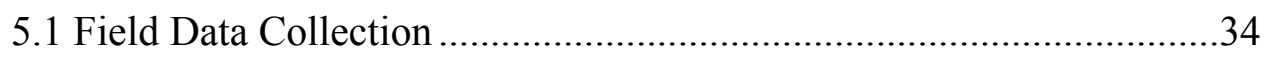




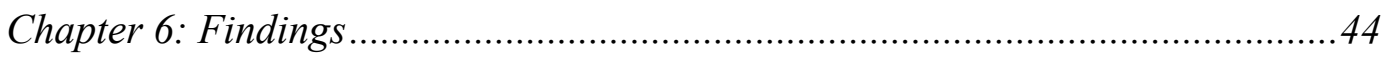

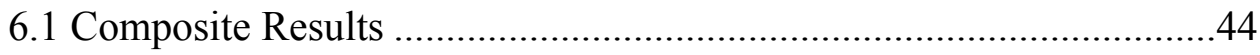

6.2 Visitors to the Olympic Peninsula .................................................48

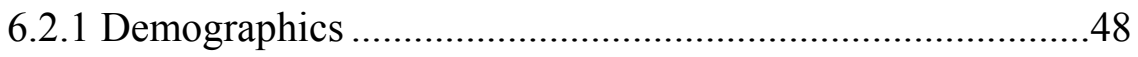

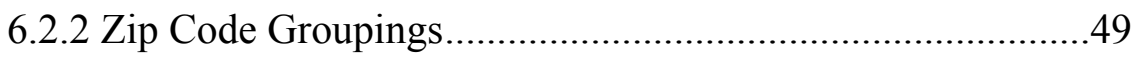

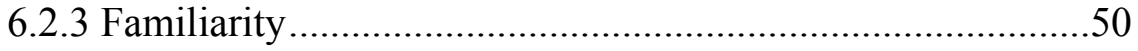

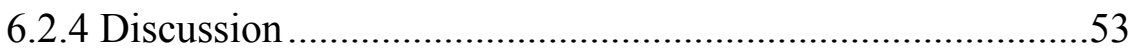

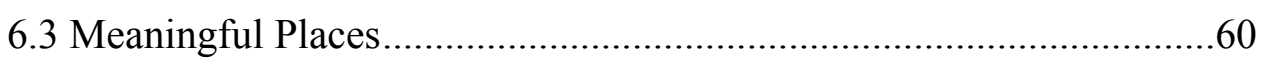

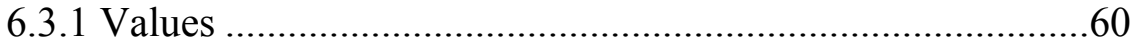

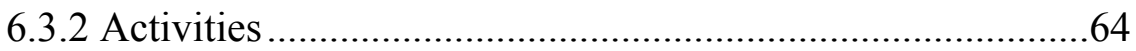

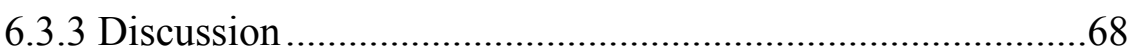

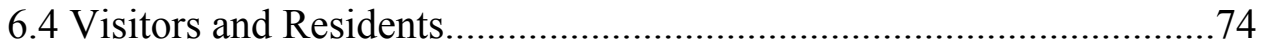

6.4.1 Comparison of Visitors and Residents..............................74

6.4.2 Combination of Visitor and Resident Data.........................76

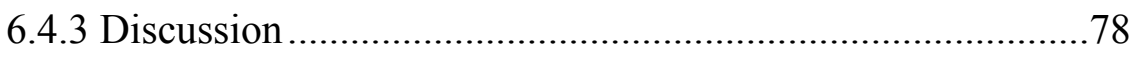

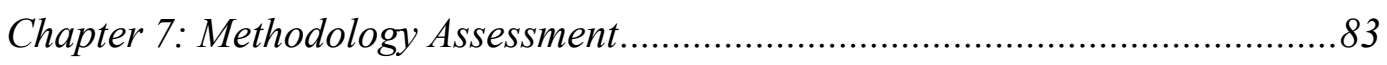

7.1 Random Surveys versus Workshops...........................................83

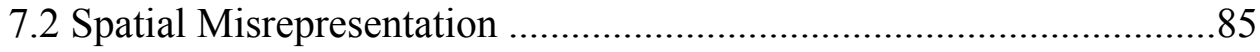

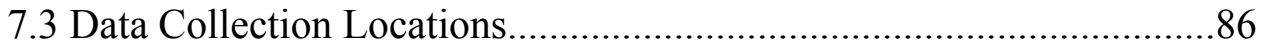

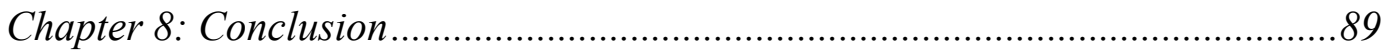

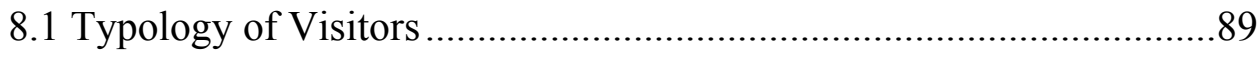

8.2 Values and Activities in the Olympic Peninsula...............................90

8.3 Comparison of Visitors and Residents...........................................91

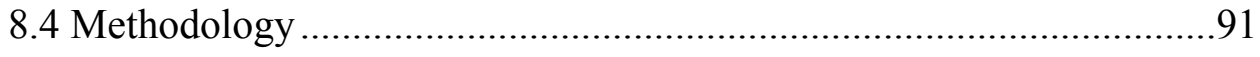

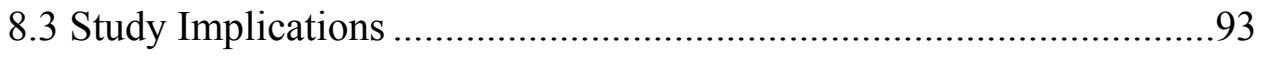




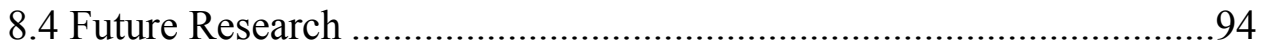

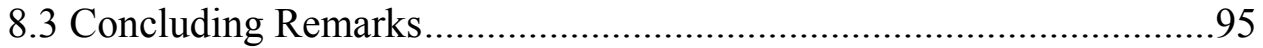

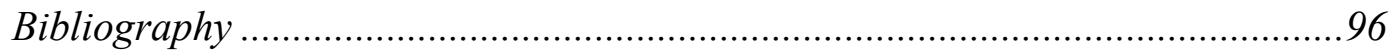

Appendices

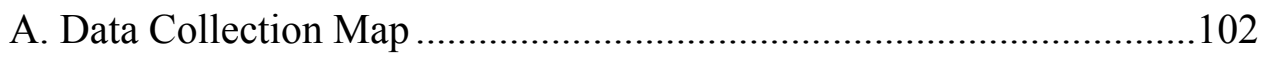

B. Data Collection Questionnaire: Values Mapping..................................103

C. Data Collection Questionnaire: Demographics.....................................104 


\section{List of Tables}

Table 1. Members of Wild Olympics ............................................................22

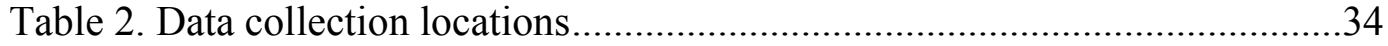

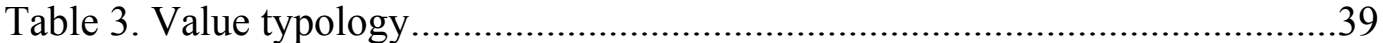

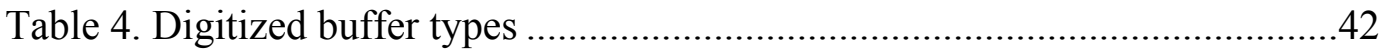

Table 5. Data collection location results........................................................45

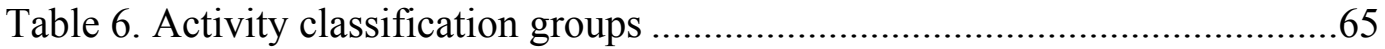

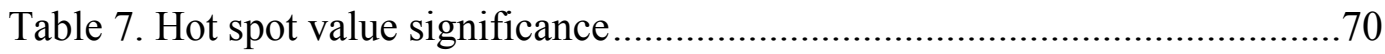




\section{List of Figures}

Figure 1. Photos of Wild Olympics political signs ............................................2

Figure 2. Maps of the Olympic Peninsula elevation and precipitation................... 7

Figure 3. General reference map of the Olympic Peninsula ..................................9

Figure 4. Photos representing past and present logging ...................................20

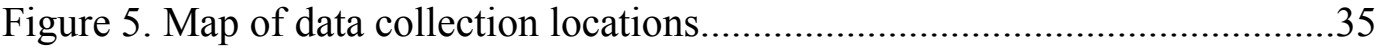

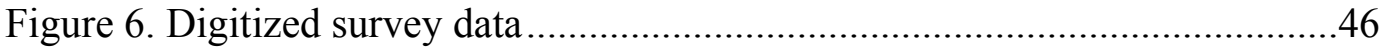

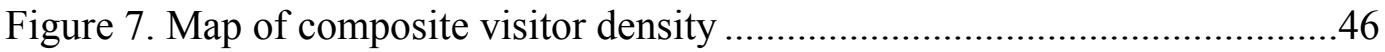

Figure 8. Map of composite visitor density hot spots ....................................47

Figure 9. Charts of the visitor demographic results ..........................................48

Figure 10. Maps of visitor density hot spots by zip code groups ........................50

Figure 11. Chart of visitor familiarity results ..............................................51

Figure 12. Chart of visitor familiarity results by data collection location .............52

Figure 13. Maps of visitor density hot spots by familiarity ................................53

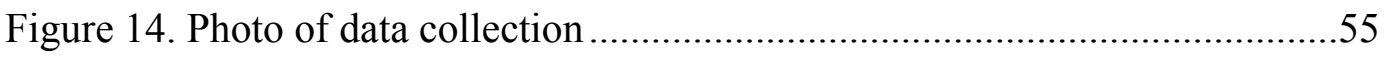

Figure 15. Chart of visitor familiarity results by land jurisdiction ......................58

Figure 16. Chart of visitor value percentages ...............................................61

Figure 17. Maps of visitor value density hot spots ........................................62

Figure 18. Chart of visitor activity group percentages ....................................64

Figure 19. Maps of visitor activity density hot spots ......................................67

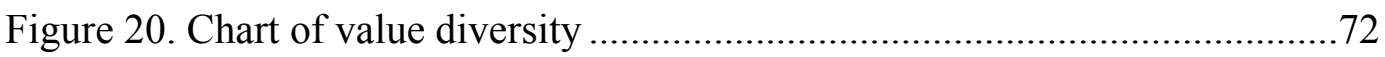

Figure 21. Maps showing all visitor and resident value density hot spots ............75

Figure 22. Chart comparing visitor and resident value percentages .....................76

Figure 23. Map of composite visitor and resident density hot spots ....................77

Figure 24. Chart of combined visitor and resident value percentages..................78

Figure 25. Maps showing local visitor and resident value density hot spots.........80

Figure 26. Chart comparing local visitor and resident value percentages .............81

Figure 27. Charts of the Bainbridge Island visitor demographic results ...............88 


\section{Chapter 1: Introduction}

Highway 101 is the main and only route that circles the Olympic Peninsula, Washington. Filling the narrow two-lane road are logging-trucks piled high with logs, various sizes of campers and sport utility vehicles, some towing boats, and many other recreational vehicles. Along either side of the highway signs are posted for state and federal recreation sites; reservation attractions, especially casinos and fireworks; and local businesses such as ice cream shops, restaurants, and boutiques. Political signs calling for support of "Wild Olympics" are strategically placed in clearings by the roadway. Surrounding the highway on the east and north sides of the Peninsula are mature forests and spectacular views of the Hood Canal, the Strait of Juan de Fuca, and Crescent Lake.

Dispersed along Highway 101 on the west side of the Peninsula are small towns and buildings and patches of harvested forests at different stages of growth, from clearcuts to young trees. Wooden signs identify these as 'working forests,' and provide information regarding when the trees were planted and harvested. In front of rural homes and businesses, red signs stand out against the green of the vegetation making declarative accusations against "Wild Olympics" (Figure 1). The juxtaposition of views of the natural landscape on the Olympic Peninsula as both a utilitarian resource and essential beauty demonstrate the conflict of interests that makes management of this land challenging. 

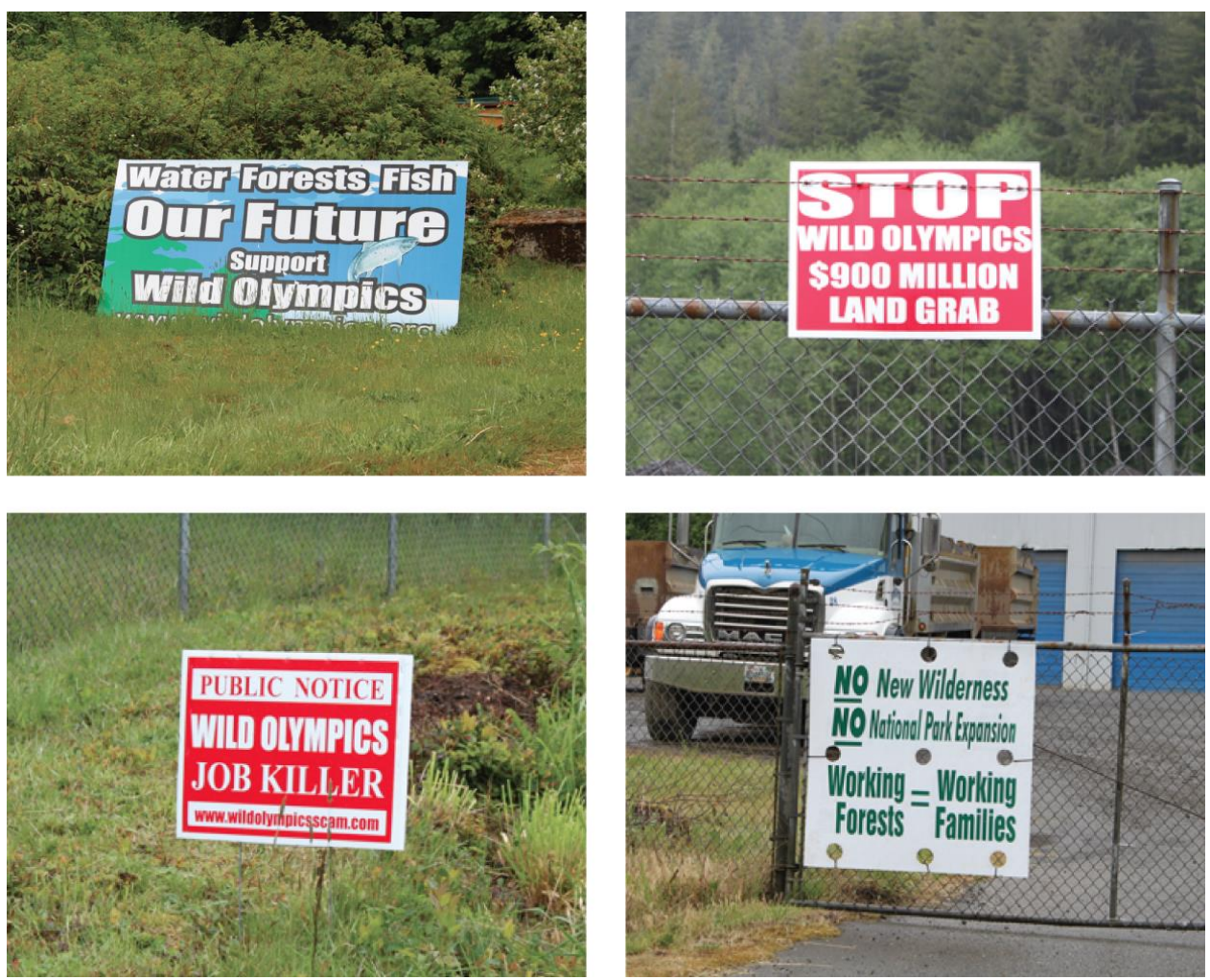

Figure 1. Photos of Wild Olympics political signs posted alongside Highway 101 in the Olympic Peninsula.

\subsection{Purpose}

Management of natural landscapes, like those of the Olympic Peninsula, is a difficult undertaking, made even more complex by the presence of humans. In addition to biophysical data, natural area management requires data about people, their attitudes toward the physical environment, what they value about it, and how they interact with it. However, the diverse behavior and independent actions that characterize those people are not easy to define or measure.

In response to the need for sociocultural data to integrate with biophysical data for planning, the US Forest Service's (USFS) Pacific Northwest Research Station and the Institute for Culture and Ecology initiated the Human Ecology Mapping Project (HEM). 
Between 2010 and 2011, a series of workshops were held for residents of the Olympic Peninsula that focused on identifying places with personal meaning to locals. This sociocultural data is useful for informing land management decision-making regarding how residents relate to natural areas in the Olympic Peninsula. If management is aware of the activities in and attitudes about specific places, potential conflicts may by prevented and areas receiving heavy usage can get adequate attention.

While resident data is a crucial sociocultural aspect of the Olympic Peninsula, visitors make up the majority of people using the natural environment. Visitors and local recreationists influence policies and practices of federal land management. According to US Forest Service researchers, Farnum and Kruger $(2008,41)$, the "most important stakeholder in land-management [is] the public." Much of the land in the Olympic Peninsula is federally or state owned and managed, so understanding both the resident and visitor perceptions of the Peninsula is essential for developing management plans that take into account their values.

\subsection{Research Objectives}

My research compliments the HEM data representing the local perspective with survey data collected from visitors to the Olympic Peninsula. By surveying visitors from a variety of locations, I aimed to map and analyze the ways in which people perceive the landscape as well as their activities. This research supports the following objectives:

1. Develop a typology of visitors that varies from residents of the region who might be frequent users of public lands to one-time tourists driving around the peninsula. 
2. Understand the nature and intensity of activities of visitors and the values they attach to the landscape.

3. Compare the values and activities of visitors with those of residents.

Information about how human activities and values relate to places and land management jurisdictions in the Olympic Peninsula can provide a more nuanced understanding of multiple-use issues and aid problem solving.

\subsection{Thesis Structure}

In chapter 2, I describe the study area - the Olympic Peninsula in Washington State - in terms of its physical structure and human habitation patterns. Chapter 3 provides a short history of federal land-management with special attention to its effects on the Olympic Peninsula. The chapter is divided into four main sections that break the timeline into periods with different major policy influences: logging, recreation, wilderness, and climate change.

I evaluate relevant literature that has influenced my research in Chapter 4. This literature review is thematically structured and starts with the general theory of environmental cognition, followed by a summary of methods used for values mapping research, and finally describing the Human Ecology Mapping Project, which is the foundation for my research. In Chapter 5, I detail my methodology of data collection and analysis.

In Chapter 6, I present the findings from my research in four sections (composite of all visitor data, demographics, values and activities, and a comparison of visitors to residents), including a focused discussion for each of the research objectives. I evaluate 
what effects the methodology has on the results in Chapter 7. In Chapter 8, the conclusion, I answer the research objectives, state the research implications, and suggest future research. 


\section{Chapter 2: Geography of the Olympic Peninsula, WA}

"The mountains seem to rise from the edge of the water, on both sides, in steep ascent to the line of perpetual snow, as though nature had designed to shut up this spot for her safe retreat forever..."

- Governor Eugene Semple (McNulty 2009, 14)

The Olympic Peninsula is located in western Washington State with saltwater on three sides - the Pacific Ocean on the west, the Strait of Juan de Fuca on the north, and Puget Sound on the east. The 6,500 square miles of the Peninsula are dominated by the Olympic Mountains (Figure 2) and mid-latitude rain forest (Chickowski 2009). Because the steep Olympic mountain range traps moisture from the Pacific Ocean, the western side of the Peninsula is the wettest environment in Washington State with over two hundred inches of rain a year (Whitesell 2004). Contrasting with the moisture rich landscape west of the Olympic Mountains is the rain shadow in the northeast portion of the Peninsula that receives as little as fifteen inches of rain annually. 

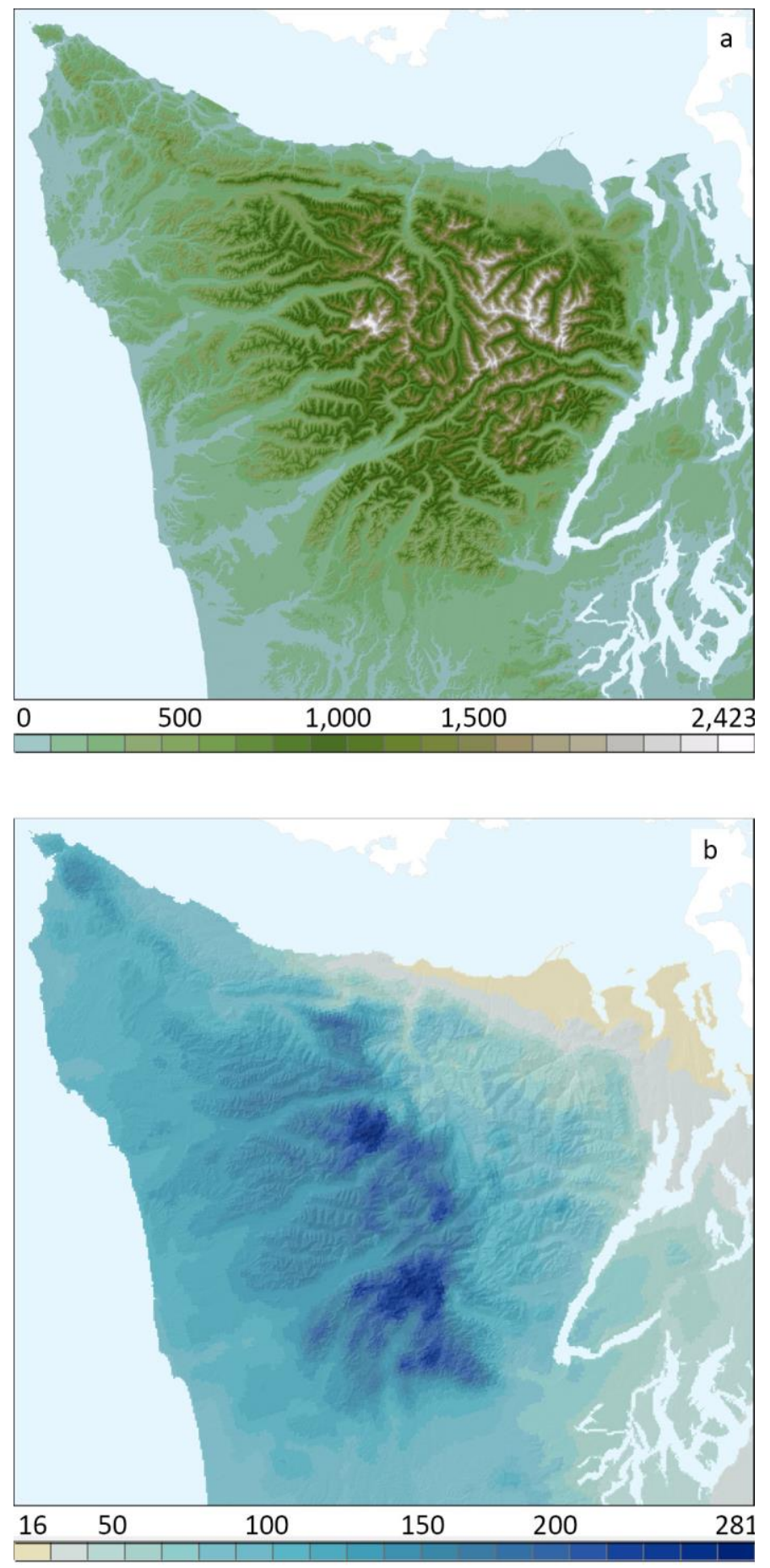

Figure 2. Maps of the Olympic Peninsula showing (a) elevation in meters and (b) precipitation in inches. 
The Olympic Mountains were shaped during the Ice Age at a time when the Peninsula was covered by the Cordilleran ice sheet (McNulty 2009). Remnants of the ice sheet exist today as 266 glaciers in the Olympic Mountains (McNulty 2009). When the ice receded, about 13,000 years ago, people migrated into habitable areas of the Peninsula (Wray 2002, McNulty 2009). It wasn't until the late 1700s when European traders and explorers began traveling to the Peninsula and making land claims (Wray 2002). Several native tribes still inhabit the Olympic Peninsula including the Hoh, Quinault, Skokomish, Klallam, S'Klallam, Quileute, and Makah (Wray 2002).

Since the arrival of Europeans in the late 18th century, the environment has been dramatically transformed by logging with only 50 percent of the forest remaining unaltered - predominantly forested areas located in the rugged mountainous interior (Wood 2000). The northern west coast of the Peninsula has also been preserved as wild land. Today a complex mosaic of land jurisdictions divides the Olympic Peninsula, and includes public lands administered by the National Park Service, National Forest Service, and Washington State, as well as interspersed tribal and private landholdings surrounding the perimeter (Figure 3). 


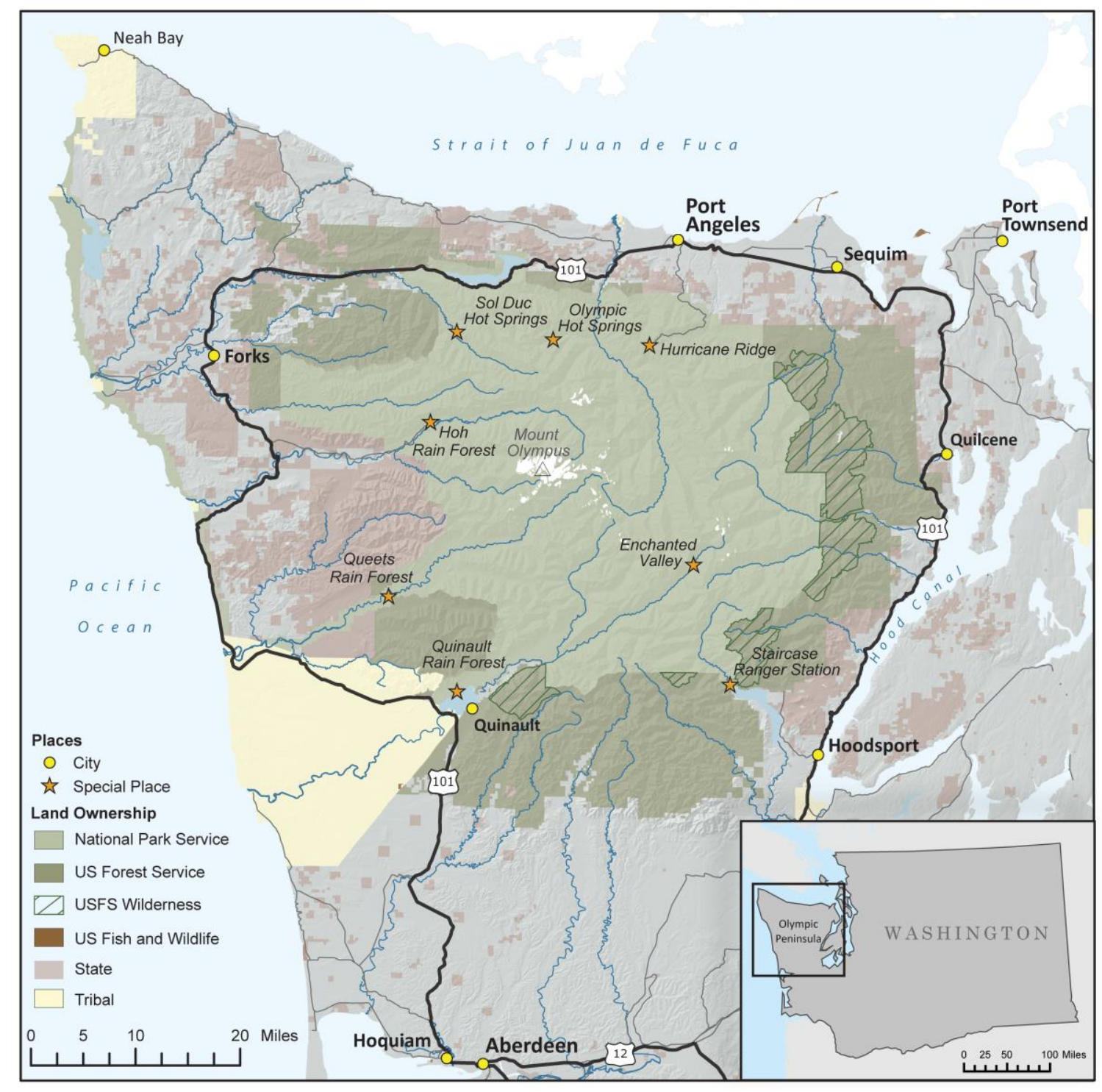

Figure 3. General reference map of the Olympic Peninsula (adapted from McLain 2013b). 


\title{
Chapter 3: A History of Conflicting Interests
}

The Olympic Peninsula was first recognized for its great stands of old-growth forests in the latter part of the $18^{\text {th }}$ century and has been a contested landscape since the establishment of federal forest reserves at the end of the $19^{\text {th }}$ century. As the nation developed and transportation improved during the early $20^{\text {th }}$ century, the forest reserves were managed for shared use with recreational opportunities. Environmental concerns arose throughout the $20^{\text {th }}$ century that called for conservation of the forestlands. Today growing awareness of the effects of changing climate conditions is the source of controversial policy proposals. These timeless disagreements stem from people's varying relationships with the environment and mixed expectations for land management in the Olympic Peninsula.

\subsection{Logging in the Olympic Peninsula}

\begin{abstract}
"When the natural resources of any nation become exhausted, disaster and decay in every department of national life follow as a matter of course...The planned and orderly development and conservation of our natural resources is the first duty of the United States."
\end{abstract}

- Gifford Pinchot, The Fight for Conservation (1910, 4-20)

In the Pacific Northwest, old growth forests were a dominant source of income for settlers during the $19^{\text {th }}$ century. Despite the importance of timber, these forests were not regulated until the Forest Reserve Act was passed in 1891 in order to correct "indiscriminate grazing and timber-cutting" (Wilkinson 1992, USDA 1997). President Grover Cleveland established the Olympic National Forest in 1897. At about two million acres, it was the largest reserve established as part of the Forest Reserve Act. Shortly thereafter, the Forest Service funded a three-year survey of the Olympic National Forest 
and found that 83 percent of the reserve was covered by merchantable timber (USGS 1902). People working in the logging industry aggressively criticized President Cleveland for placing restrictions on the use of these timber resources (Morgan 1955).

The shift of the Forest Service towards more sustainable methods of harvesting began with the influence of Gifford Pinchot in the beginning of the 20th century. Pinchot became chief of the Division of Forestry in the Department of Agriculture in 1898 and worked with President Theodore Roosevelt to set aside three quarters of the current National Forest System (Wilkinson 1992). This federal control of timberland was strongly opposed by the timber industry, which was accustomed to indiscriminate cutting and little federal oversight.

At the start of the $20^{\text {th }}$ century several federal acts were passed to protect the environment from resource extraction impacts, as there was increasing public concern over the effects of "logging, mining, and farming on fragile watershed lands" (USDA 1997). The Antiquities Act of 1906 was passed authorizing the President to establish national monuments for federal protection (Stipe and Lee 1997). Shortly afterwards in 1909, after years of public pressure to protect Roosevelt elk habitat in the Olympic Peninsula, President Roosevelt established the Mount Olympus National Monument preserving 750,000 acres within the central part of the Olympic Peninsula to be managed by the Forest Service (Whitesell 2004). The Weeks Act in 1911 allowed the government to "purchase land in the watershed of navigable streams for watershed protection and timber production and provided authority for the Secretary of Agriculture to designate such lands for permanent retention as National Forests" (USDA 1997). 
Federal policies reflected growing awareness of the finiteness of natural resources. Pinchot pushed for policy that considered the longevity of timber harvest because he believed "conservation of natural resources is the basis, and the only permanent basis, of national success" (Pinchot 1910, 91). These ideas are reflected in an article published in 1911 by The Morning Leader, a newspaper local to the Olympic Peninsula, which promoted the Olympic Peninsula for its timber harvest potential while emphasizing the importance of responsible policy:

\begin{abstract}
"There is no portion of the United States so far back in its development, which can begin to compare in tangible wealth in material resources with the Olympic Peninsula...If permitted free and untrammeled development, under an intelligent policy which aims to promote the utilization of its resources, there is no part of the civilized world which would be more attractive than the Olympic Peninsula... No finer bodies of timber are to be found in the world...It should be utilized under some rational and intelligent system of forestry. The matured timber is not improving, but rather deteriorating year by year...If the matured timber were cut under proper forestry regulations, with every encouragement lent to the growth of the new forest as fast the old one is cut, the timber region will furnish a perpetual supply of timber for generations yet unborn."
\end{abstract}

The influence of Pinchot is apparent in this article with the emphasis on "intelligent policy" and "proper...regulations" that are necessary for timber resources to sustain livelihoods into the distant future. Management of trees was seen as necessary to prevent timber from deteriorating into what today we might call old-growth forest. It was believed that natural resources could not be sustained without human intervention.

Not only did people believe forests needed management by humans, but they also needed protection from destruction by humans. According to Western Forester, E. T. Allen (1911), "conservation...does not mean non-use of ripe timber, but...protecting it from useless waste and destruction, and replacing it by reforestation when it is used." To foresters during the early $20^{\text {th }}$ century, conservation meant proper use of forests - today we might refer to this as sustainability - and not using natural resources was viewed as 
wasteful. Timber was the greatest source of income for the Olympic Peninsula and the State Trust Lands were (and still are) a source of tax revenue for state and county government services such as public schools and state prisons (Allen 1911).

\subsection{Recreation in the Olympic Peninsula}

"...many of the most controversial issues in the parks involve external threats, in which resource development in adjacent national forests affects the parks."

- Charles F. Wilkinson, Crossing the Next Meridian (1992, 118)

Beginning in the early $20^{\text {th }}$ century, a demand for recreation on public lands coincided with increased accessibility to transportation (specifically automobiles and trains) and brought attention to the lack of necessary tourism and recreational infrastructure. The National Park Service Organic Act of 1916 established the National Park Service as a separate bureau in the Department of the Interior (Miles 2000). According to the Act, the purpose of National Parks "is to conserve the scenery and the natural and historic objects and the wild life therein and to provide for the enjoyment of the same in such manner and by such means as will leave them unimpaired for the enjoyment of future generations." This mission broadened the application of land management beyond conservation to make natural areas accessible for public use.

This change in priorities to accommodate visitors meant roads needed to be built for public access to and management of natural areas. Highway 101 circling the perimeter of the Olympic Peninsula was completed in 1932. Starting in 1933, the Civilian Conservation Corps (CCC), a New Deal program initiated by President Franklin Delano Roosevelt, was stationed in several locations around the Peninsula, including 
Humptulips, Lake Cushman, Quilcene, and Elwha (NPS). By 1934, the CCC had constructed twenty-two miles of roads on Forest Service lands (NPS).

The addition of recreationists to public lands meant forests were not solely valued for their timber resources. Throughout the 1930s, the US Forest Service and the National Park Service competed for control of national lands, basing their arguments on their ability to manage wilderness appropriately (Whitesell 2004). Robert Marshall, an advocate for wilderness, was the head of Forest Service's Division of Recreation and Lands from 1937 to 1939 . During this time Forest Service policy was influenced by Marshall's appreciation for virgin forestland and land was set aside to be free of resource extraction (Marshall 1933).

The debate about managing the natural resources in the Olympic Peninsula is apparent in a proposal from the Emergency Conservation Committee (ECC) in 1934 for Olympic National Park. The main arguments made in support of this National Park include: 1) Mount Olympus National Monument had been reduced in size by the Forest Service and no longer served its purpose as a sanctuary for the Roosevelt elk; 2) the Olympic Peninsula was home to some of the best and only wildlife, primeval forests, lakes and watersheds, and scenery that needed protection from hunters, development, and timber harvesting; 3) the Forest Service was "backed by the lumber and grazing interests" and did not protect or manage the well-being of the forests or watersheds; 4) the forests were more valuable for park purposes than for their timber; and 5) the National Park would bring in tourism that would more than compensate for the loss of resource extraction. The closing statement of this proposal explicitly addressed a conflict of interest between local and national political concerns (ECC 1934): 
"[T]he Olympic National Forest does not belong either to the Forest Service or to the local residents of that part of the State of Washington. It belongs to the American people as a whole. The preservation of such a magnificent animal as the Roosevelt Elk is a matter of interest to the whole nation, in fact to the whole world. It is vastly more important than the privilege of a few residents to hunt on the lands which the American nation, not the residents of the Peninsula, owns. The same reasoning applies to preserving in its natural scenic beauty a reasonable amount of the primeval forest, and to protecting against diversion to private use of the especially beautiful spots that the public owns and should be free to enjoy. We believe that all this opposition can be successfully fought and overcome as soon as it is realized that the Olympic Park is a national, not a local question."

After years of debate, Olympic National Park was established in 1938 by Franklin D. Roosevelt, and as recommend by a NPS study, the park would remain as wilderness, even if that meant limited access by roads (Miles 2000). The establishment of this roadless park was significant during a time when roads were rapidly being built on federal lands.

After World War II there was a dramatic increase in visitors to federal land reserves (Whitesell 2004). In response to increased interest in recreation during the 1950s, the Forest Service adopted a "multi-use" management strategy. Superintendent Overly of Olympic National Park devised the 1952 Master Plan around his outlook of "parks are for people." The plan involved recreational developments including campgrounds, trails, and skiing slopes (Miles 2000). In 1960 Congress passed the Multiple-Use Sustained-Yield Act that "recognized recreation as a proper use of the national forest" (Wilkinson 1992, 137). An increase of visitors to the national forests brought attention to unwelcome clear-cuts and scrutiny to the Forest Service (Wilkinson 1992). 


\subsection{Wilderness Conservation in the Olympic Peninsula}

"The root of the problem, of course, was that the public had become too large for the wilderness... development, and then popularity, constituted the first two threats to wilderness..."

- Roderick Nash, Wilderness and the American Mind (1982, 337-339)

More people visiting natural areas meant greater impact on the environment, and concern for the degradation of valued natural areas provoked revision to federal landmanagement practices. Nash $(1982,290)$ describes the challenge to land management as the "changing geographical and intellectual conditions had altered for Americans the meaning of both wilderness and civilization." Shifting cultural priorities from ease of access to conservation of undeveloped wilderness resulted in disputes over federal landmanagement. In the Olympic Peninsula, a proposal in the early 1950s for a road along the west coast met opposition from the public who believed that the coast should remain as wilderness. President Eisenhower ameliorated the conflict in 1953 by adding the northern part of the coast to Olympic National Park for preservation (Whitesell 2004).

Congress passed the Wilderness Act in 1964 to place greater restrictions on use within designated wilderness areas. Over nine million acres from National Forests that were previously designated wild areas became the foundation of the National Wilderness Preservation System (Wilkinson 1992). This reserve system was formed, “...to assure that an increasing population, accompanied by expanding settlement and growing mechanization, does not occupy and modify all areas within the United States...leaving no lands designated for preservation and protection in their natural condition...to secure for the American people of present and future generations the benefits of an enduring resource of wilderness." Wilderness is defined by the Act as federal land that is preserved 
in its natural state without development or habitation by people and "has outstanding opportunities for solitude or a primitive and unconfined type of recreation" (Wilderness.net).

In 1965, the Land and Water Conservation Fund (LWCF) Act was passed that earmarked funds to purchase land for present and future Americans to enjoy recreationally (USDA 1997). The National Environmental Protection Act (NEPA) was passed early in 1970 to establish a national standard for studying environmental impacts prior to planning, and by the end of the year the Environmental Protection Agency was established to regulate NEPA (Lindstrom 2011). According to the first administrator, William D. Ruchelshaus, “[a]n environmental ethic is needed. Each of us must begin to realize our own relationship to the environment. Each of us must begin to measure the impact of our own decisions and actions on the quality of air, water, and soil of this nation" (Wisman 1985). Legislative acts, such as the Wilderness Act, LWCF, and NEPA, reflected a shift in the cultural understanding of federal lands and a broadened appreciation of the unaltered environment.

NEPA mandates that for every management plan there must be an environmental impact statement with a period for public comments prior to making final decisions. Inclusion of the public in decision-making broadened the influence of citizen groups in policy-making. According to Wilkinson $(1992,147)$, "since the early 1970s, virtually every reform in public lands forest management has been sparked by citizens' suits holding the Forest Service to its statutory obligations." Non-profit environmental organizations, including the Wilderness Society, Sierra Club, and the Mountaineers, 
increased their capacity and developed "powerful moral and political" campaigns that helped gain support and funding (Proctor 1996, 278).

The National Forest Management Act (NFMA) of 1976 mandated a decrease in clear-cutting, regulated where timber could be harvested, incorporated sustained-yield management, and created standards for maintaining watershed health, biodiversity, and scenic beauty (Wilkinson 1992). Influential to the passing of NFMA was the Church Report by the Public Lands Subcommittee in 1972 that asserted where timber should not be harvested: "highly scenic land, land with fragile soils, land with low reforestation potential, and land where reforestation or environmentally acceptable harvesting would be uneconomical" (Wilkinson 1992, 142).

A new Wilderness Act was passed in 1984 and additional wilderness reserves were established in the national forests throughout Washington State (Whitesell 2004). Five wilderness areas were designated in the Olympic National Forest, including Buckhorn, Wonder Mountain, The Brothers, Mt Skokomish, and Colonel Bob Wildernesses. In 1988, 95 percent of Olympic National Park was designated the Olympic Wilderness (Wilderness.net).

Not everyone was supportive of these environmental protection measures. President and Chief Operating Officer of the Mountain States Legal Foundation, William Perry Pendley (1995, 30-31) argued that environmental extremists were waging war on the West by making "bogus excuse[s] for putting an end to timber harvesting." $\mathrm{He}$ asserted that "national forests were meant to be managed to meet the nation's need for wood products" and "there is today a full-scale assault against the use of the abundant timber resources" that has "devastating consequences." Pendley understood 
environmental conservation as theft of land and livelihood from local people who rely on resource extraction to survive.

President Bill Clinton implemented the Northwest Forest Plan (NWFP) in 1994 in response to conflict between environmentalists and federal agencies over the effect of logging practices on endangered key species and watersheds (Whitesell 2004). The NWFP was informed by management plans developed by each National Forest and Bureau of Land Management district in 1990. According to the Olympic National Forest Plan (USDA 1990), the key issues are: scenery, recreation, old-growth forest, timber harvest level, sediment, fish habitat, wildlife habitat, unroaded areas, and wild and scenic rivers. The variety of issues that the Forest Service addresses demonstrates the change in land management from a focus on resource extraction to forest restoration (Buttolph et al. 1996).

Even though the NWFP provided guidance for moving forward, the resulting plan was heavily contested. Proctor (1998) evaluates the conflict between proponents for and against the NWFP to better understand the root of the issue. While arguments are based around 'wilderness' or 'ancient forests,' he concludes that the real issue needing to be evaluated is what values these concepts are supporting. Proctor $(1998,297)$ writes, "Making moral sense of these places entails embracing the paradox that they are both social constructions and realities that transcend social constructions." Federal laws that affect land-use change the perceived meaning of places as well as their physical structure.

Restrictions on logging of national forest lands as a result of the NWFP threatened the livelihoods of many people in timber-dependent communities and the rate of unemployment increased. In the 1990s, several programs were initiated by the 
Columbia-Pacific Resource Conservation and Development Council to provide timber workers with training, skills, and work in habitat restoration, special forest products, and wood products production and marketing activities (McDonald and McLain 2003). Still, many people had to move to find work elsewhere. The timber industry continues to harvest logs from State Trust Lands and private timber lands in the Olympic Peninsula, but as a vestige of its bountiful past (Figure 4).
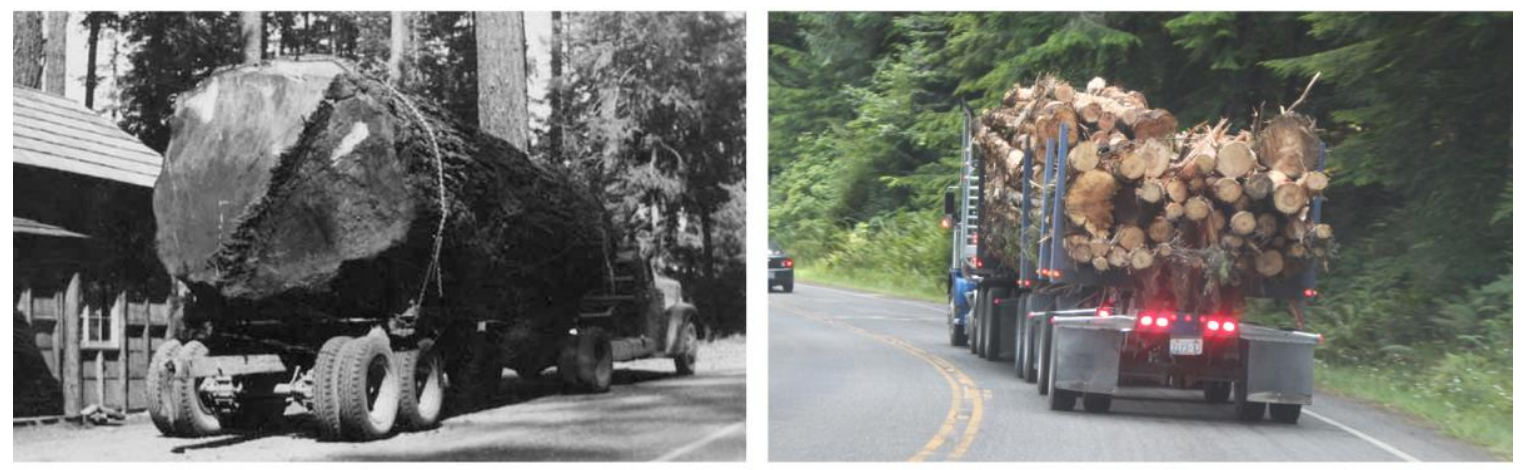

Figure 4. Photos representing past and present logging: images of logging trucks near Lake Crescent in the Olympic Peninsula, (on the left) a massive tree carried by a truck in 1939 and (on the right) a truck full of small trees in 2012 demonstrate the change in logging in the last half century (left photo by Boyd ca. 1939; right photo by the author in 2012).

\subsection{Wild Olympics}

"Washington's forests have been - and continue to be - contested and coveted by many competing groups and individuals."

- Center for the Study of the Pacific Northwest

Since the end of the $20^{\text {th }}$ century, environmental policy has been influenced by an increasing concern for the consequences of climate change. Addressing the impacts to the environment at a global scale first became a political priority during the 1990s when the US participated in international negotiations with the United Nations as a partner in the 
Framework Convention on Climate Change (Gerrard 2007). In July of 1997, the Clinton Administration developed the White House Initiative on Global Climate Change to raise awareness and gain support from the public on climate change issues (Oberthur and Ott 1999). At the end of that year, an International Climate Convention was held in Japan in order to develop the Kyoto Protocol, committing developed countries to pursuing reduction of greenhouse gases (Gerrard 2007). Although the next US President, George W. Bush, did not support the international proposal, domestic policy measures were enacted to accomplish the same ends.

Recognition of the significance of climate change is evident in federal research programs that were established to inform policy and promote public awareness as early as 1978. Such programs include the US Global Change Research Program, the National Commission on Energy Policy, and the EPA's State and Local Climate Change Program (Gerrard 2007). Public information about the threat of climate change has strengthened the cause of environmental groups and increased support for conservation.

A recent proposal for altering land-use designation in the Olympic Peninsula is based on predictions of climate change, and has re-ignited controversy between resident timber harvesters and proponents for conservation (Wild Olympics). The "Wild Olympics" campaign is led by a coalition of ten organizations (Table 1), working to protect watersheds in the Olympic Peninsula. The draft plan calls for extension of the Olympic National Park boundaries around designated rivers in order to conserve habitat for fish and wildlife as global climate change threatens native species (Wild Olympics). According to Wild Olympics, "Park additions will protect the integrity of one of our 
country's premiere ecological preserves; restore salmon and wildlife habitat; and offer increased opportunities for recreation, education, and solitude."

Table 1. List of coalition members leading the Wild Olympics campaign.

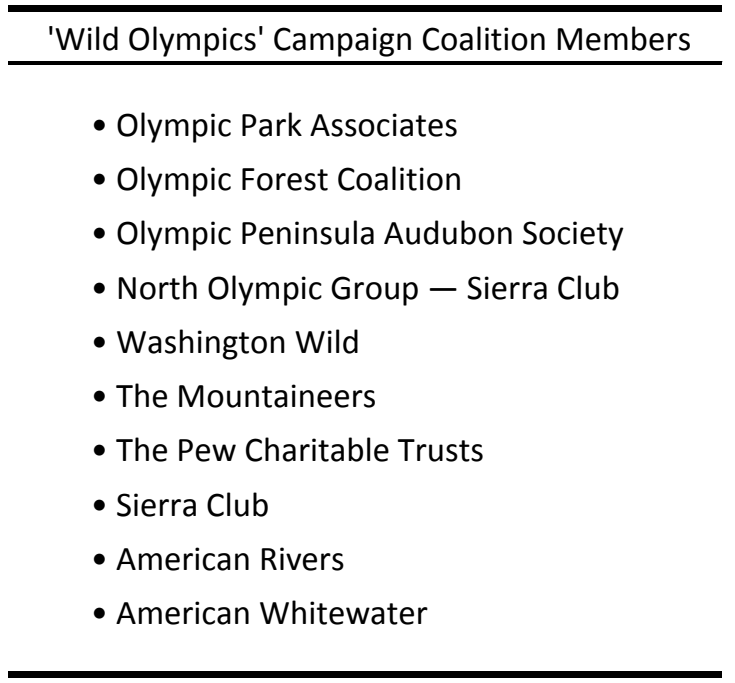

In opposition to Wild Olympics, the "Anti-Wild Olympics" campaign was initiated in 2011. The Anti-Wild Olympics campaign protests the transfer of Department of Natural Resources Trust lands to National Park and Wilderness because, according to Clallam County Republican Party Chairman, Dick Pilling, it means "up to 225 jobs and millions in annual tax revenue would be lost” (Ollikainen 2011). As seen printed on signs alongside Highway 101 (Figure 1), some opponents view the proposal as an unjust federal 'land grab'. Other arguments against the Wild Olympics proposal include loss of accessibility to wilderness areas and lack of government funds to manage additional land. 


\subsection{Summary}

Continued controversy over public land management on the Olympic Peninsula demonstrates the need for additional information about human uses and values of public lands. Since the public can have a strong influence on policy drafting, land-management planning not only requires information about the physical properties of the land and its habitat, but also qualitative information regarding where people go, what they do there, and the meanings they associate with these places. By improving managers' awareness of activity and attitudes regarding places in the Olympic Peninsula, potential conflicts may by prevented and places receiving heavy usage can get adequate attention. 


\section{Chapter 4: Literature Review}

As seen in the history of land management in the Olympic Peninsula, land-use conflicts can be limited to the existence of different perspectives about how the land should be used. Because human motivation, values, and attitudes influence policy goals, to solve land management problems it is necessary to understand the ways people think about place (Tuan 1974). Sense of place research attempts to explain how people interpret the space around them and what personal meaning certain places hold. Recent studies attempt to integrate environmental values with other spatially referenced datasets for analysis using geographic information system (GIS) technology. This thematic review of the relevant literature begins with general theory of environmental cognition and concludes with specific methodologies of values mapping that relate to my research.

\subsection{Environmental cognition}

Values mapping is founded on theory about how humans perceive the environment, or environmental cognition, which was developed in the $20^{\text {th }}$ century by scholars, including Yi Fu Tuan, Rachel and Stephen Kaplan, and Anne Buttimer. Tuan (1974) defines perception as how people sense the physical environment around them. Since the environment contains much more detail than a human can comprehend at one time, a person necessarily recognizes certain qualities and ignores the rest. What a person observes in the environment is determined by purposeful activity that ascribes meaning to the space. As space acquires meaning from personal interaction, people create places (Tuan 1974; Buttimer 1980; DeLyser 2001; Cresswell 2004). 
According to DeLyser (2001), landscapes gain meaning not only from sensory experiences but also from actualizing social memory and cultural ideas. Perception is a personal response to input from the senses that is guided by cultural knowledge. The value assigned to place is unique in each human mind and is formed through a combination of memory (past experiences), information/knowledge, expectations, personality and sociocultural context. Certain aspects of an individual's unique perception are shared with groups (Gould 1973; Tuan 1974).

Environmental cognition theory identifies experience of place as a basis for differing perspectives of place. Cultural knowledge shapes a place through experiences over time. Cresswell (2004) describes contrasting theories on place as social constructs that differ as to whether places influence social identity or political processes shape place meanings. Tuan (1974) describes the different experiences of visitors and "natives" that influence their understanding of natural areas. Visitors (especially tourists) form their perspective using their "eyes to compose pictures." The native perspective is more complex and formed through physical experience of living on the land.

Buttimer (1980) evaluates place based on this tension between inside and outside perspectives. Insiders understand a place from their intimate experience and outsiders are informed by conventional descriptions. Several issues arise from this contrast in place experience. The "insider's trap" is understanding places based on everyday life without recognizing its broader spatial or social context. In contrast, the "outsider's trap" is the abstract interpretation of places based on images and ideas. Problems may occur when these limited views of places are taken for granted. When external knowledge informs 
change in land-use, the associated meanings insiders have developed of place may be challenged and this provokes territorial resistance. If a landscape attracts attention from outsiders as a tourist destination, a shift in power dynamics can occur as the function of the place adjusts to suit visitors (Lippard 1999 in Oakes and Price 2008).

Because natural landscapes (i.e., mountains, deserts, and oceans) exist at a scale far greater than that of our human existence, they tend to elicit an emotional response. This emotional connection to natural landscapes is translated into environmental values (Tuan 1974). A person's environmental values develop as a function of cultural identity. As they are closely linked with personal identity, environmental values inform strong ethics of right and wrong that can be the source of conflict in natural area landmanagement (Proctor 1996).

To understand the problem of conflicting environmental values in landmanagement decision-making, Proctor (1998) analyzes public commentary on the Northwest Forest Plan Draft Supplementary Environmental Impact Statement. After categorizing the positions and justifications expressed in the commentary, Proctor concludes that public opinions are based on strong environmental values; they contain conflicts between interests that reflect differing attitudes, but are essential for creating viable environmental management solutions. Manfredo et al. (2003) facilitate the understanding and applicability of human values to land management by using a subset from a study on wildlife value orientations that had participants rank the acceptability of different management scenarios. Research by Vaske et al. (2007) further clarifies the 
differences in the types of recreational conflicts by using survey responses to categorize conflicts (interpersonal and social values) and determine the magnitude of conflict.

Environmental cognition seeks to explain the meaning of types of environments, including the city, rural areas, and wilderness. Rachel and Stephen Kaplan (1989) researched what information people pull from the environment in order to function effectively and described the necessity for environmental cognition as a mode of survival that informs people's behavior. Researchers have attempted to understand how people construct places by using descriptions and visualizations from study populations that represent the images in their mind that assist them in navigating specific spaces (Lynch 1960; Gould 1973). The resulting 'mental maps' represent aspects of place that people store in their memory.

The qualitative and abstract nature of human perception of the environment makes collecting this information challenging. While biophysical data can be more easily measured and analyzed to determine quantitative representations of space, human perception of place is a complicated process with no two views being the same. McLain et al. (2013a) note a number of particular issues that come into play when creating spatial data from human perceptions of place: ethics and power differentials, inequality of accessibility, ambiguities associated with spatial representations, challenges of multiple scales, and how to incorporate qualitative data into GIS technologies.

\subsection{Values Mapping}

Within the last decade sense of place researchers have been developing methods for collecting mapped values that can be analyzed using GIS. Surveys, questionnaires, 
and maps are used to record and evaluate sociocultural values that are associated with and define specific places. Brown and Reed (2000) implemented values mapping as a basis for understanding how people relate to landscapes. Data from the public about how specific landscapes are valued is important for solving land-management problems and facilitates communication with stakeholders (Fagerholm and Kayhko 2009; Sherrouse et al. 2011).

Environmental managers, planners, and local communities implement values mapping in research projects to supply sociocultural data for ecosystem-based management and planning. Theobald and Hobbs (2002) included stakeholders in a study to determine areas on a map that were valuable for habitat conservation. Before redrafting the Chugach National Forest plan in the late 1990s, Forest Service researchers administered a public values survey to nearby residents in order that local needs and expectations could be considered (Farnum and Kruger 2008). According to Brown and Reed $(2013,15)$, the potential for public land values in planning and management is evident in the U. S. Forest Service's approval for fifteen public participatory GIS studies over a three-year period.

A major challenge of values mapping research is recording interpretations of $3 \mathrm{D}$ space as 2D representations that can be incorporated for analysis using GIS (Kaplan 1974; McLain et al. 2013a). Research on values mapping can be categorized according to three main objectives: to collect and measure needed data on landscape values (Alessa et al. 2008; Donovan et al. 2009; Fagerholm and Kayhko 2009; Zhu et al. 2010; Sherrouse et al. 2011), compare landscape values with other spatial datasets (Brown and Raymond 
2007; Beverly et al. 2008; McIntyre et al. 2008; Brown and Brabyn 2012), and evaluate methodologies of landscape value collection (Pocewicz et al. 2012; Brown et al. 2013).

Brown and Reed (2000) developed a value typology based on previous studies, which has become a standard for values mapping research (for examples see Chapter 5, Table 3). Typically values mapping studies focus on residents and local stakeholders such as environmental groups or local businesses; few studies collect information from visitors of the study area (Vaske et al. 2007; Zhu et al. 2010). A majority of researchers mail surveys to residents or stakeholder groups rather than collect data in person. Recent studies have focused on developing and evaluating the use of internet-based mapping applications (Pocewicz et al. 2012; Brown and Reed 2013).

With few exceptions (Donovan et al. 2009; Fagerholm and Kayhko 2009), spatial values are recorded as names, points, or other pre-determined shapes that allow for statistical analysis of the qualitative data (Alessa et al. 2008; Zhu et al. 2010; Sherrouse et al. 2011; Brown et al. 2013). Another benefit of using points, according to Alessa et al. (2008), is that point locations do not involve making judgments on boundary locations, which makes the analysis applicable to areas with arbitrary boundaries. While it is true that points lack spatial dimension and therefore do not define boundaries, this method of data collection may be inaccurate or lack information regarding the perceived place that is being defined. Many places, such as wilderness areas, cannot be represented by points. McIntyre et al. $(2008,666)$ note that certain areas "by their very nature [can] not be delineated using concentrations of value or use points." Their study revealed that using 
points for values mapping limited the data to "activity sites" rather than measuring areas of value.

As techniques for integrating qualitative human-based data in GIS-based analysis are still experimental and undefined, there are no standard methods for analysis (McLain et al. 2013a). The most common methods used for analyzing mapped values are density calculations, correlation statistics, and proximity analyses (Alessa et al. 2008; Donovan et al. 2009; Zhu et al. 2010; Fagerholm et al. 2012). Other GIS analysis methods used include hot spot analysis (Fagerholm and Kayhko 2009; Zhu et al. 2010), regression (Brown and Raymond 2007), and extrapolation (McIntyre et al. 2008). Brown and Brabyn (2012) implement four data analysis techniques (frequency counts, residual analysis, correspondence analysis, and selected social landscape metrics) to evaluate human landscape valuation in comparison with landscape characteristics.

Values mapping has answered questions regarding how people in general associate values with places. Beverly et al. $(2008,299)$ found that landscape features, such as communities, water bodies, and roads, influence the spatial pattern of mapped values by serving as focal points or attractors for values. Zhu et al. (2010) identified a difference in the degree of clustering between what they called active values (i.e., recreational and aesthetic) and inactive values (i.e., wilderness, intrinsic, and spiritual). Donovan et al. (2009) found that several participants had a difficult time marking specific places because they consider the entire landscape important.

Despite the importance of the social and cultural dimensions of ecosystem-based planning and management, several challenges limit the application and representation of 
human ecology mapping. According to Brown and Brabyn (2012), values data is limited by participation time, effort, and cognitive abilities. Varying abilities of people to communicate meaning and interpret spatial representation is a limitation to who can successfully participate. Spatial error that results from participant misidentification of places and the effects of multi-scaled spatial data are consequences of evaluating complex human ability and perception. Another challenge is that there is no one single way to communicate the information derived from this type of research (Brown and Brabyn 2012).

While many studies include descriptions and statistics for the study population, very few evaluate the data based on different categories such as age, gender, or place of residence. Most analysis results are based solely on aggregate representations of the values mapping data. Sherrouse et al. $(2011,759)$ speculate that "[a]nalysis of the survey data describing respondents' familiarity with the study area...could prove useful for identifying selection bias that might influence how values are weighted and locations are marked on survey maps." Drawing conclusions based on composite data discounts subgroups within the whole such as level of familiarity with the area, a crucial component for identifying differences in landscape values, which are the root of controversy in land-management planning.

\subsection{The Human Ecology Mapping Project}

My research is an extension of the Human Ecology Mapping Project (HEM), a collaboration of the Forest Service Pacific Northwest Research Station, the Institute for Culture and Ecology, and Portland State University that has used values mapping to 
gather sociocultural data for land management in the Olympic Peninsula. That study evaluated mapped values and activity data collected between 2010 and 2011 at workshops in eight communities: Quilcene, Port Angeles, Port Townsend, Hoodsport, Shelton, Forks, Quinault, and Aberdeen. These workshops were held for residents of the Olympic Peninsula and focused on mapping places of importance to locals with the goal of understanding what values and where locals attach values to landscape in the Olympic Peninsula.

The HEM methodology differs from other values mapping studies in both the method of data collection and the analysis techniques. Participants mark places on the map using hand drawn shapes that are digitized into a GIS dataset and analyzed based on grid density counts and diversity of values and activities. Disaggregation of the data by zip code, demographics, and individual values, was important for revealing patterns that may be lost within the overall results. By disaggregating the data and analyzing it using GIS, HEM was able to make a number of conclusions about the mapping process. The scale and detail of the map are important details that influence how people map and should be carefully considered when designing the study. Viewing subgroups of the data reveals useful information not found in the composite. Values mapping records information from people at a specific point in time and may capture views on political debates (McLain et al. 2013b).

\subsection{Summary}

Values mapping has developed out of ideas about environmental cognition in response to the need for information about the meanings people associate with specific 
landscapes. However, several limitations need to be addressed. Most studies use predetermined shapes (usually dots) for participants to map rather than allowing the participant to define areas of importance. Results from values mapping studies are based on composite data without regard to the patterns that may be revealed by disaggregation of data. Despite the conflict between insiders and outsiders, most studies collect information from residents only and do not consider the perspective of visitors. Visitor data may be especially important when the study is about public land. I aim to address these limitations in my research on mapping visitor values of the Olympic Peninsula, Washington. 


\section{Chapter 5: Methodology}

\subsection{Field Data Collection}

To obtain information from visitors of the Olympic Peninsula, during July, August, and September of 2012, I made four trips to the Peninsula and collected survey data at fourteen different locations (Table 2). Four types of locations (visitor centers, campgrounds, trail access points, and a ferry) were chosen in order to obtain input from a variety of visitors. The sites were evenly distributed about the Peninsula with one location type in each quadrant (Figure 5). In addition, surveys were conducted in the central Peninsula at the Hoh Rain Forest and on a Puget Sound ferry travelling to and from the Peninsula.

Table 2. Data collection locations: four types of data collection locations (14 total sites) were chosen in order to capture input from a representative sample of visitors to the Olympic Peninsula.

\begin{tabular}{llcc}
\hline Name & Type & Jurisdiction & Date Day \\
\hline \hline Coho & Campground & USFS & 13-Jul Fri \\
Forks & Visitor Center & USFS/NPS & 14-Jul Sat \\
Quilcene & Visitor Center & USFS & 15-Jul Sun \\
Klahowya & Campground & USFS & 17-Jul Tue \\
\hline Port Angeles & Visitor Center & NPS & 3-Aug Fri \\
Staircase & Trail Access Point & NPS & 4-Aug Sat \\
Dosewallips & Trail Access Point & USFS & 5-Aug Sun \\
Kalaloch & Campground & NPS & 6-Aug Mon \\
Lake Quinault & Visitor Center & USFS/NPS & 7-Aug Tue \\
Sol Duc & Trail Access Point & NPS & 8-Aug Wed \\
\hline Bainbridge & Ferry & WA State & 31-Aug Fri \& \\
Island/Seattle & & 1-Sep Sat \\
\hline Seal Rock & Campground & USFS & 8-Sep Sat \\
Rialto Beach & Trail Access Point & NPS & 9-Sep Sun \\
Hoh Rain Forest & Visitor Center & NPS & 10-Sep Mon \\
\hline
\end{tabular}




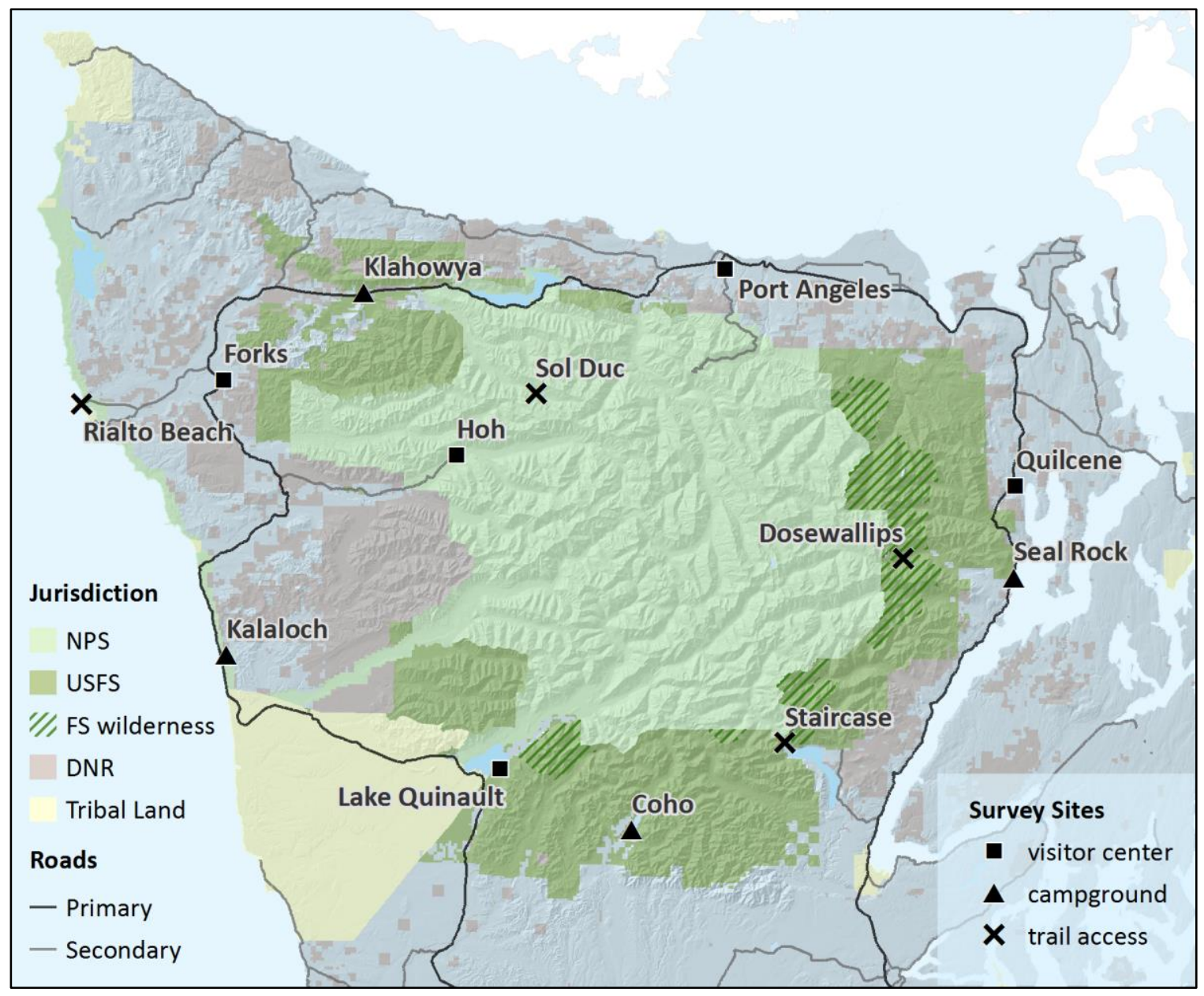

Figure 5. Map of data collection locations: the survey sites are evenly distributed around in the Olympic Peninsula, WA.

Visitor centers are located in areas of heavy use by recreationists and are places where visitors go to get information and permits. The Port Angeles Visitor Center is operated by the National Park Service and is the main Olympic National Park station. It is located directly outside the North entrance to the park in Port Angeles, which is the largest town on the Peninsula and home to a ferry that travels to/from Victoria, British Columbia, Canada. Also operated by the NPS is the Hoh Rain Forest Visitor Center that is accessible from the west side of the Peninsula. This visitor center is located within the 
national park beside a loop trail with access to the backcountry. Quilcene is a US Forest Service Ranger Station on the east side of the Peninsula. Many visitors to Quilcene seek information on eastside backpacking routes. Forks and Quinault are jointly operated NPS/USFS visitor centers. Forks Visitor Center is located in a small town on the west side of the Peninsula and serves mostly visitors headed to the coast or the Hoh Rain Forest. Quinault Ranger Station is located in the southwest of the Peninsula within the Olympic National Forest by Quinault Lake.

Campgrounds were chosen as data collection sites to access visitors who were stationary and may have had more time to respond. Kalaloch is a large coastal campground on the west side of the Peninsula located within the south coast section of Olympic National Park. Because Kalaloch is open year-round and accepts reservations between June and September, it is a popular destination for visitors. Klahowya, Seal Rock, and Coho are campgrounds located in the National Forest. Klahowya is located in the rain forest of the north Peninsula and bordered by the Sol Duc River. Coho is located in the south of the Peninsula next to Lake Wynoochee and attracts visitors who live near the Peninsula for boating and other water-based recreation. Seal Rock is located on the east side beside the Hood Canal and many visitors go there for water activities and to hunt for clams, mussels, and geoducks.

Trail access points were included to get input from active visitors (backpackers, mountain climbers, etc.) who enter the backcountry and wilderness areas. From the north of the Peninsula in the national park, Sol Duc provides access to a short trail to Sol Duc Falls as well as popular backcountry routes. Near the Sol Duc trailhead are developed hot 
spring facilities and a campground. Rialto Beach is in the coastal portion of the national park on the central west side of the peninsula and provides access to coastal backpacking routes. Staircase is located in southeast Olympic National Park where there is also a campground and ranger station. In addition to a day-use area by Lake Cushman, there are two entry points to trails and the backcountry. While Dosewallips is located in the national forest, it is the site of a washout to a road that used to provide the main national park access on the east side. Backpackers continue to walk beyond the missing road to access backpacking trails.

Given the remarkably high response rate (93 percent) of the surveying method used for researching public perception of invasive species management by the NPS (Sharp et al. 2011), my survey was administered to people traveling by ferry on Puget Sound. The Seattle/Bainbridge Island ferry, operated by the state of Washington, is a heavily traveled route during the summer. Visitors have over 30 minutes of travel time during which they can fill out the survey.

The survey consists of a map (Appendix A) and a questionnaire (Appendix B). The map includes geographic and administrative features to orient the visitor being surveyed such as major roads, lakes, and rivers, the Olympic National Park, Olympic National Forest, and wilderness areas, state parks, major cities, and major peaks. The size of the printed map was a key consideration that was addressed during the design process; it needed to be large enough for features to be discernible yet small enough to be practical for use as a field data collection tool. At twenty-two by eighteen inches, the map provided space for adequate symbolization of places and the landscape without cluttering 
the map with labels. This is important since the purpose for having visitors mark on the map is to allow them to define their own places, rather than restrict them to points or defined boundaries. So that participants understood this purpose, an example board was displayed showing a variety of ways to mark the map, including lines, points, and large and small areas. To enable the map markings to be easily identifiable, the layers of the map were given a high level of transparency.

Visitors were first asked to mark up to five meaningful places on the map and then indicate what values they attributed to each location. While this study is focused on natural areas, the participants were not restricted to marking only those locations. The values were derived from research on values mapping (for example Alessa et al. 2008) and are comparable to the values used in the Human Ecology Mapping Project (HEM) survey. Definitions of the values were included on the questionnaire (Table 3). After mapping, the participant was asked to rank the top three values for each location marked on the map.

While the values were similar to those used in the HEM survey, a few of the values differed in my survey to ensure that they were clear to the respondent. My survey included biodiversity in place of environmental health because it is a comparable word that is more frequently used in current speech, and therapeutic replaced health because its implied meaning may be more tangible (Brown and Raymond 2007; Fagerholm and Kayhko 2009). Entertainment was added to my survey because it represents what people might value outside public lands (e.g., cities). Intrinsic was removed from the value typology because results from HEM indicate the value is unclear to participants. 
Table 3. Value typology: list of values and definitions that were included in the study with corresponding resident values from the HEM workshops. Highlighted values differ between my survey and HEM.

\begin{tabular}{|c|c|c|}
\hline Values & Definition & HEM Values \\
\hline aesthetic & I value this place for the scenery, sights, smells or sounds. & aesthetic \\
\hline biodiversity & $\begin{array}{l}\text { I value this place because it provides habitat for a variety of } \\
\text { plants and animals, many of which may not be found in } \\
\text { other places. }\end{array}$ & $\begin{array}{l}\text { environmental } \\
\text { health }\end{array}$ \\
\hline economic & $\begin{array}{l}\text { I value this place because it provides income and } \\
\text { employment opportunities through industries such as forest } \\
\text { products, mining, tourism, agriculture, shellfish or other } \\
\text { commercial activity. }\end{array}$ & economic \\
\hline entertainment & $\begin{array}{l}\text { I value this place because it provides diversion, amusement } \\
\text { or cultural expression. }\end{array}$ & \\
\hline future & $\begin{array}{l}\text { I value this place because it allows generations that will } \\
\text { follow us to know and experience it as it is now. }\end{array}$ & future \\
\hline heritage & $\begin{array}{l}\text { I value this place because it has natural and human history } \\
\text { that matters to me and it allows me to pass down the } \\
\text { wisdom, knowledge, traditions, or way of life of my } \\
\text { ancestors. }\end{array}$ & heritage \\
\hline home & $\begin{array}{l}\text { I value this place because it is familiar, comfortable, and } \\
\text { welcoming. }\end{array}$ & home \\
\hline learning & $\begin{array}{l}\text { I value this place because it provides a place to learn about, } \\
\text { teach or research the natural environment. }\end{array}$ & learning \\
\hline recreation & $\begin{array}{l}\text { I value this place because it provides opportunities for } \\
\text { outdoor activities. }\end{array}$ & recreation \\
\hline social & $\begin{array}{l}\text { I value this place because it provides opportunities for } \\
\text { getting together with my friends and family or is part of my } \\
\text { family's traditional activities. }\end{array}$ & social \\
\hline spiritual & $\begin{array}{l}\text { I value this place because it is sacred, religious, or divinely } \\
\text { special to me. }\end{array}$ & spiritual \\
\hline subsistence & $\begin{array}{l}\text { I value this place because it provides food and other } \\
\text { products to sustain my life and that of my family. }\end{array}$ & subsistence \\
\hline therapeutic & $\begin{array}{l}\text { I value this place because it makes me feel better physically } \\
\text { and/or mentally. }\end{array}$ & health \\
\hline wilderness & $\begin{array}{l}\text { I value this place because it is not developed or altered } \\
\text { appreciably by people. }\end{array}$ & wilderness \\
\hline
\end{tabular}


Spaces were included on the questionnaire for the location name and activities. The backside of the questionnaire (Appendix C) prompted the participant for basic demographic information including zip code or country, age, gender, and education. These questions were presented with check boxes that categorized answers to expedite the survey since visitors were only willing to spend a limited amount of time (five to ten minutes). Finally, questions regarding familiarity with the Olympic Peninsula and federal lands in general were included. These questions were:

1. In the last five years, how often have you visited the Olympic Peninsula?

2. What is the typical length of your visit to the Olympic Peninsula?

3. In the last five years, how often have you visited National Parks and National Forests?

\subsection{Data Analysis}

To identify places visitors value and visit within the Olympic Peninsula, the individual surveys were combined using a geographic information system (GIS) to create collective information. This composite dataset was created using ArcGIS 10.1 to process and analyze the survey map data. Converting the paper maps to GIS data features was not straightforward due to the methods visitors used to mark the map. Rather than marking specific areas on the landscape, many participants circled labels or symbols on the map. By interpreting the mapped places and digitizing them based on the probable meaning rather than exact markings, I was able to reduce unintentional density that results from slivers of overlapping circles. 
To accomplish this, it was necessary to evaluate the survey maps before digitizing and classify every place marked based on how it would be represented in GIS. This evaluation entailed comparing the respondent's marks with their description of the location and the activities they listed on the survey form. If I chose to keep the map markings despite their mismatch with the questionnaire, then the study becomes more about how people mark the map than what places people value. The purpose of this study is to learn how people value places - not how they mark maps.

The four types of feature classes created were: points, point areas, lines, and areas.

- Points range from a dot or ' $\mathrm{x}$ ' on the map, to a circled label, or to a large circle surrounding a label. These points were created in GIS and buffered according to the type of location specified on the questionnaire.

- Point areas are points that encompass a specific boundary such as a lake or town and are digitized using a template of that feature. Common examples include Crescent Lake, Port Townsend, and Lake Quinault.

- Lines are based on marked or circled linear features (e.g., roads, trails, or the coast). These line features are buffered based on the size of the area as indicated by information from the questionnaire, such as the activities the respondent does there or the name they give to that location.

- Areas are the only features that are based on the exact drawing of the survey participant. These shapes are constructed by manually tracing the drawing within ArcMap. 
All feature creation was done at a scale of 1:500,000. To analyze all features together, it is necessary to convert points and lines to polygons. Point and line buffers range from 1/8 mile to one mile and are defined by four categories based on an estimated range of the perceived place (Table 4).

Table 4. Digitized buffer types categorized according to the approximate area of the place.

\begin{tabular}{lcl}
\hline Description & Buffer (miles) & Example Locations \\
\hline \hline locales & $1 / 8$ & buildings or specific locales \\
destinations & $1 / 4$ & $\begin{array}{l}\text { campgrounds, hot springs, beaches, small towns, state parks, } \\
\text { trails, highways }\end{array}$ \\
$\begin{array}{l}\text { areas } \\
\text { ambiguous }\end{array}$ & $1 / 2$ & Mt. Olympus, La Push, coast \\
\hline
\end{tabular}

Once the map features were digitized, the table with attribute data from the questionnaire was joined to the features. Table statistics such as the most common values, most common activities, and where people come from provide a general summary of the data. However, the spatial map data needed to be analyzed using GIS in order to provide any place-based information.

Density was calculated by joining the spatial data to a quarter-mile grid and obtaining a count of the number of polygons per grid cell. Attempts were made to calculate the density by overlaying the unaltered polygon shapes; however this was a much more time intensive process and the patterns produced were very similar to the grid cell method.

Another method of viewing the spatial data was to use the Getis Ord Gi hot spot analysis tool in ArcGIS to show statistically significant clustering of the density values. Hot spots are determined by a "GiScore." Scores between 1.96 and 2.58 are statistically 
significant with a confidence level of 0.05 , and scores greater than 2.58 are statistically significant with a confidence level of 0.01 . The values hot spot analysis is included because it decreases the ambiguity of data classification that makes comparison of different maps challenging. Density, hot spots, and statistics from the questionnaire complement each other and depict the visitor data from multiple angles.

In addition to analyzing the composite data, these methods were applied to subsets of the data to reveal additional patterns. I separated the data by subcategories such as individual values, visitor zip-code groups (categorized as local to the Olympic Peninsula, the Pacific Northwest region, other states in the US, and International), and type of survey location to answer questions about those topics.

Finally, I combined the data from visitors with the HEM data from residents in an attempt to create a representation of the complete human landscape of the Olympic Peninsula. 


\section{Chapter 6: Findings}

\subsection{Composite results}

Over the course of four separate trips to the Olympic Peninsula in July, August, and September of 2012, the fieldwork resulted in 345 usable surveys with varying survey collection rates from the different types of locations (Table 5). The ferry had the highest collection rate with ten surveys per hour, and campgrounds had the lowest collection rate with about two surveys per hour. Visitor centers and trail access points had comparable collection rates at about five surveys per hour.

The 345 survey maps were digitized and resulted in 1549 data features (Figure 6). When all the visitor data is analyzed as a composite dataset (Figure 7), the Olympic National Park and the east side of Olympic National Forest are delineated, with the top density class found at popular destinations within the central peninsula and along portions of the coast. Density counts range from 1-173. The only area on the Peninsula with the lowest value density (1-12) is in the northwest triangle in an area that is mostly state owned land. This class is not symbolized on the map. 
Table 5. Data collection location results.

\begin{tabular}{|c|c|c|c|c|c|}
\hline Location Type & Name & Jurisdiction & Date Day & Surveys & Features \\
\hline \multirow[t]{6}{*}{ Visitor Centers } & & & & $122^{\mathrm{a}}$ & 521 \\
\hline & Forks & USFS/NPS & 14-Jul Sat & 22 & 94 \\
\hline & Quilcene & USFS & 15-Jul Sun & 23 & 101 \\
\hline & Port Angeles & NPS & 3-Aug Fri & 31 & 133 \\
\hline & Lake Quinault & USFS/NPS & 7-Aug Tue & 20 & 89 \\
\hline & Hoh Rain Forest & NPS & 10-Sep Mon & 26 & 104 \\
\hline \multirow[t]{5}{*}{ Campgrounds } & & & & $36^{b}$ & 181 \\
\hline & Coho & USFS & 13-Jul Fri & 8 & 42 \\
\hline & Klahowya & USFS & 17-Jul Tue & 2 & 8 \\
\hline & Kalaloch & NPS & 6-Aug Mon & 17 & 100 \\
\hline & Seal Rock & USFS & 8-Sep Sat & 9 & 31 \\
\hline \multirow[t]{5}{*}{ Trail Access Points } & & & & $89^{c}$ & 421 \\
\hline & Staircase & NPS & 4-Aug Sat & 26 & 119 \\
\hline & Dosewallips & USFS & 5-Aug Sun & 17 & 82 \\
\hline & Sol Duc & NPS & 8-Aug Wed & 24 & 119 \\
\hline & Rialto Beach & NPS & 9-Sep Sun & 22 & 101 \\
\hline \multirow[t]{2}{*}{ Ferry } & & & & $98^{d}$ & 426 \\
\hline & $\begin{array}{l}\text { Seattle/Bainbridge } \\
\text { Island }\end{array}$ & WA State & $\begin{array}{c}\text { 31-Aug \& Fri \& } \\
\text { 1-Sep Sat }\end{array}$ & 98 & 426 \\
\hline TOTAL & & & & $345^{e}$ & 1549 \\
\hline
\end{tabular}

${ }^{a}$ Visitor centers resulted in an average of 5.2 surveys per hour.

${ }^{\mathrm{b}}$ Campgrounds resulted in an average of 2.2 surveys per hour.

${ }^{\mathrm{c}}$ Trail access points resulted in an average of 4.6 surveys per hour.

${ }^{\mathrm{d}}$ The ferry resulted in an average of 10 surveys per hour.

${ }^{\text {e }}$ All the survey locations combined resulted in an average of 5.5 surveys per hour. 


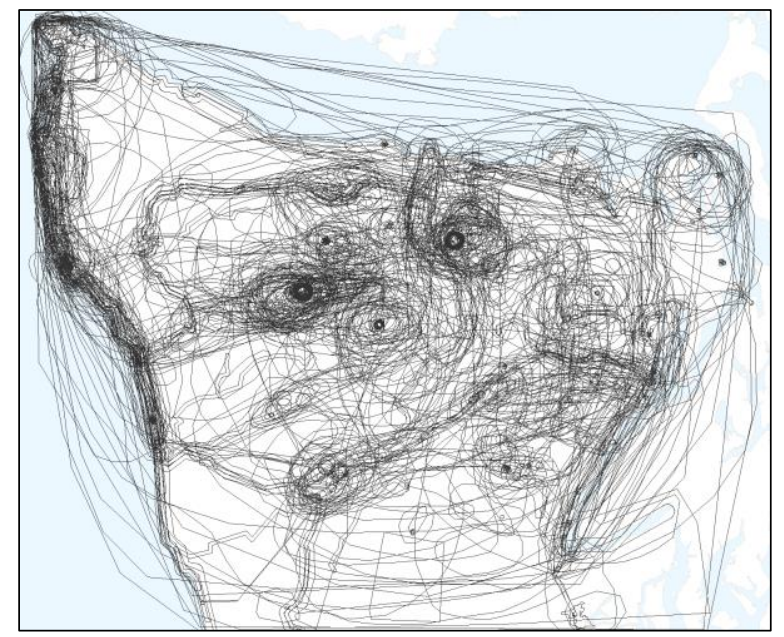

Figure 6. Digitized survey data: the raw GIS data represents a mass of overlapping features.

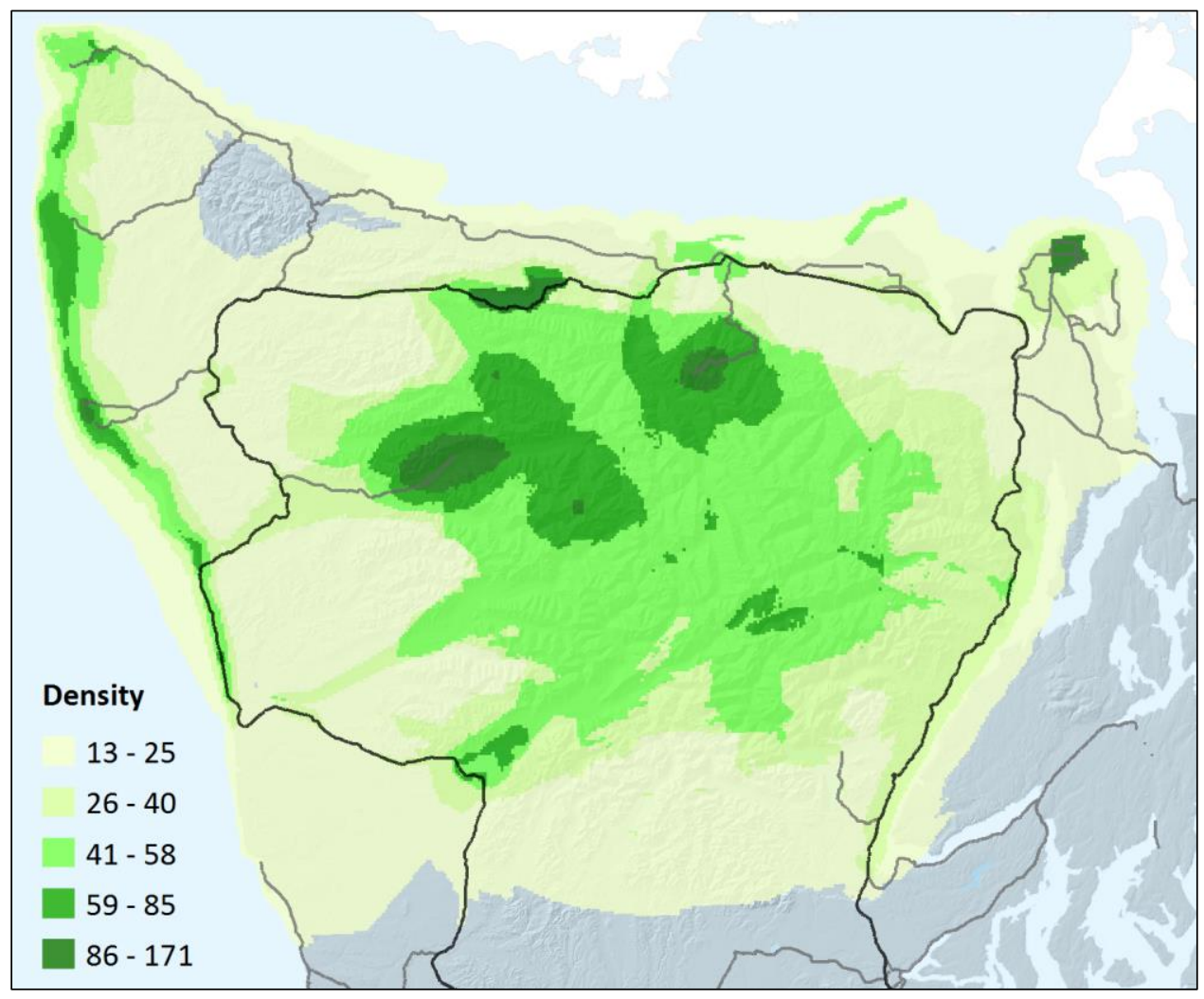

Figure 7. Map of composite visitor density is based on natural breaks classification and excludes values less than thirteen, or half the average density value. 
The hot spots (Figure 8) mostly fall within Olympic National Park and include locations that are promoted as "park destinations" by the Park Service (ONP): Hoh Rain Forest, Hurricane Ridge, Crescent Lake, Mora and Rialto Beach, Sol Duc Valley, and Quinault Valley. Other places highlighted are Mt. Olympus, Native American locales (La Push, Neah Bay, and Ozette Reservation), and Port Townsend, a historic town in the northeast of the peninsula. The only major park destinations without hot spots are Queets Rain Forest in the southwest and Staircase in the southeast. No cold spots, or statistically significant dispersion, resulted from the density data.

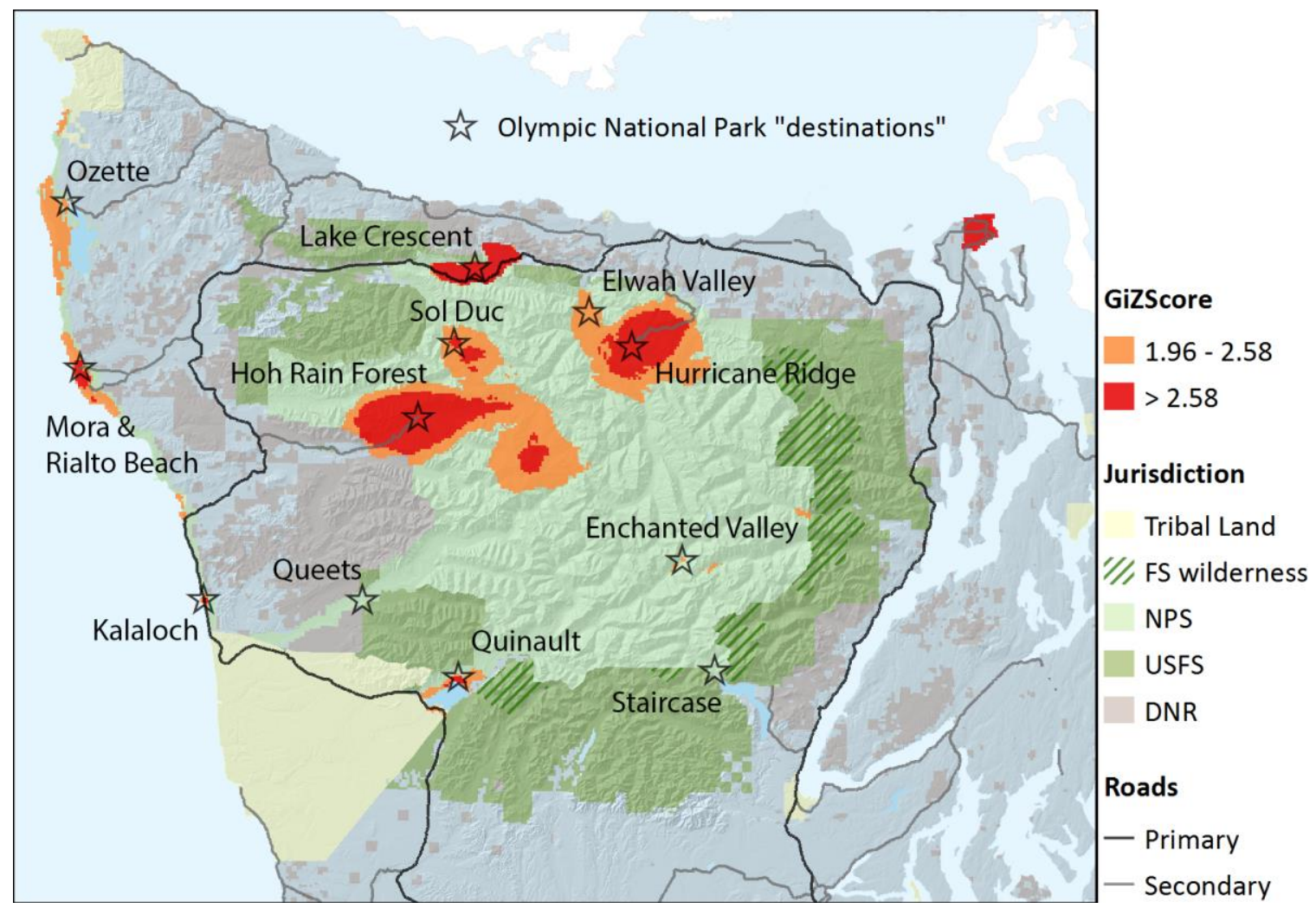

Figure 8. Map of visitor density hot spots with ONP destinations. 


\subsection{Visitors to the Olympic Peninsula}

\subsubsection{Demographics}

The majority of the survey participants were male (57 percent), between the ages 46-65 (45 percent), and educated with at least a four-year degree (75 percent) (Figure 9). The distribution of ages is fairly similar; if the dominant age group range were not twice as large as the other groupings the distribution may look like a regular bell curve.

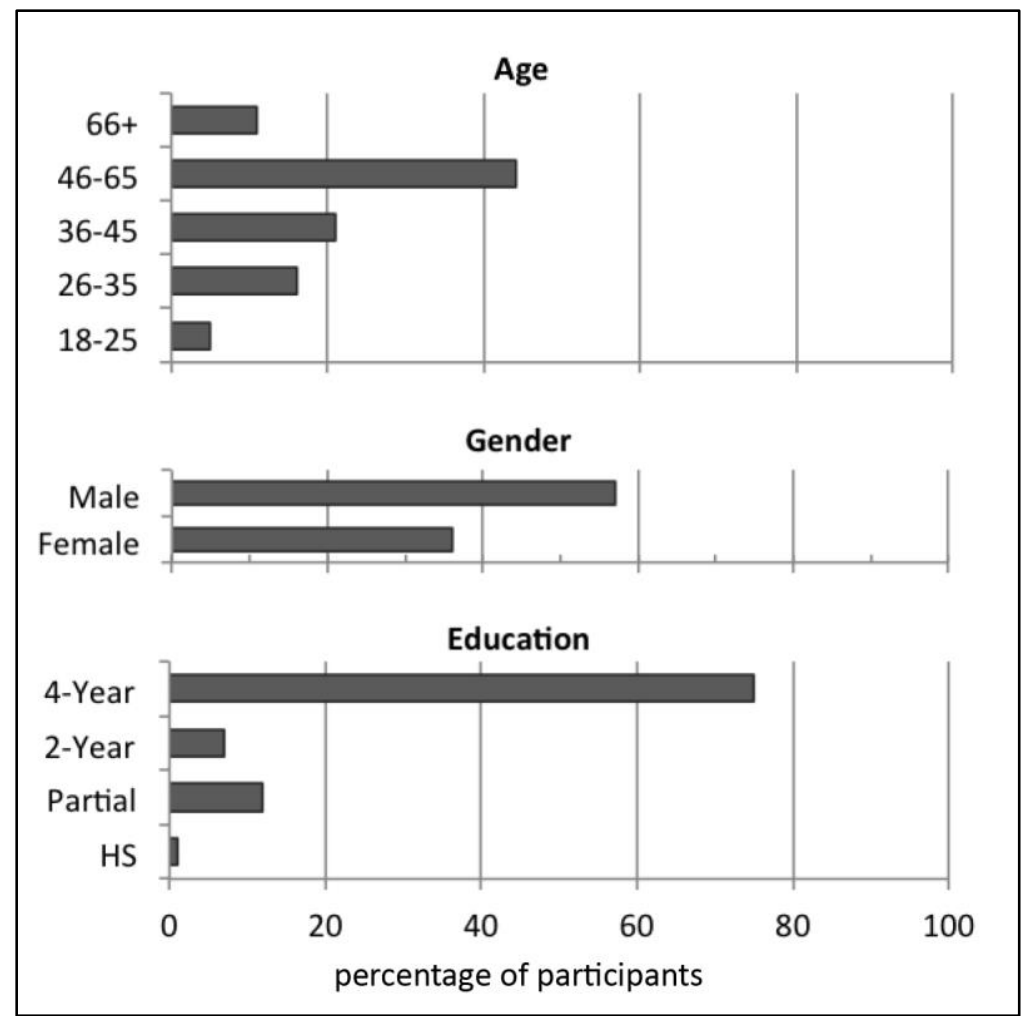

Figure 9. Charts of the visitor demographic results are based on percentage of participants. 


\subsubsection{Zip code groupings}

95 percent of survey participants were from thirty-one of the United States and 5 percent were from eight other countries. A majority of visitors (60 percent) were from the Pacific Northwest region (west of the Cascade Range) with an additional 10 percent local to the Olympic Peninsula. Figure 10 shows three zip code groupings (local, regional, and national) and maps displaying the density hot spots that result from analyzing the data divided by these zip code groupings. International visitor data analysis is not included because this small group of participants did not supply an adequate quantity of data for comparison.

The farther the visitor lives from the Olympic Peninsula, the less overall detail and variety show up in the data. Results from regional visitors closely resemble the composite data hot spots, most likely because this is the largest group of participants. The hot spots for local residents indicate those visitors marked smaller more specific places, including the coast and areas in the Olympic National Forest. In contrast to local visitors, those from outside the region mark larger areas primarily in the central part of Olympic National Park. 


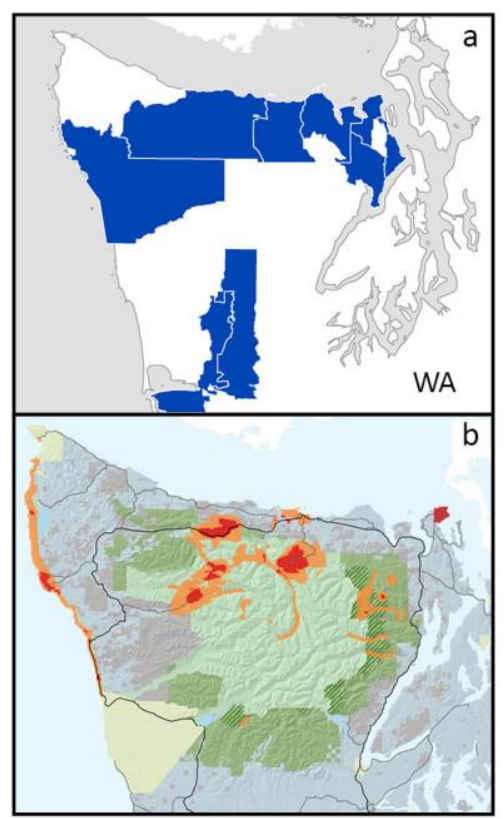

GiZScore

$1.96-2.58$

$>2.58$

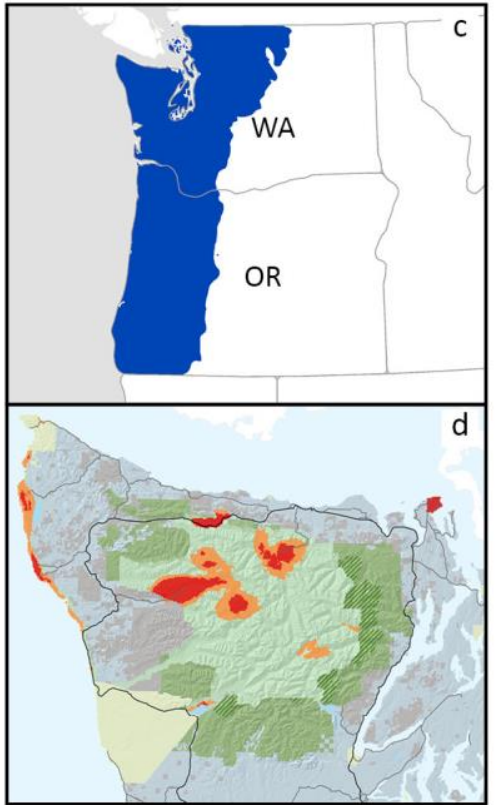

Jurisdiction

Tribal Land

V/. FS wilderness

USFS

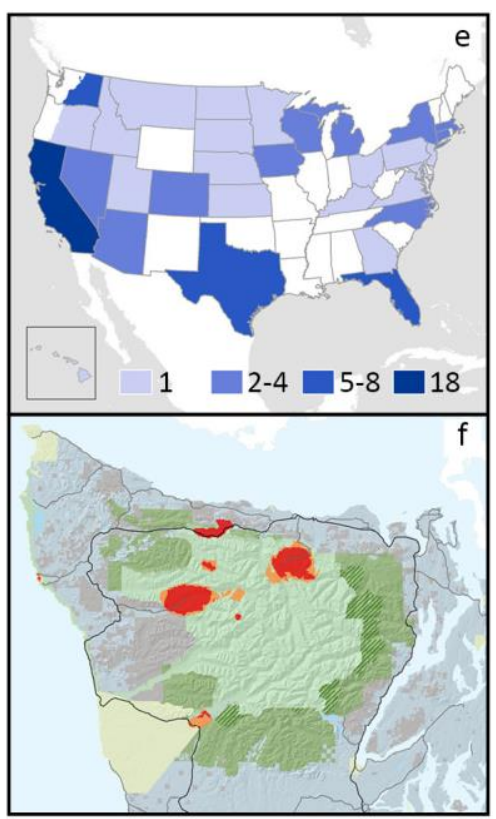

Roads

NPS DNR - Primary

- Secondary

Figure 10. Maps of visitor density hot spots by zip code group: (a) local visitor zip codes; (b) local visitor hot spots; (c) regional boundary; (d) regional visitor hot spots; (e) national visitor states by number of participants; and (f) national visitor hot spots.

\subsubsection{Familiarity}

Familiarity of participants with the Olympic Peninsula (as indicated in the survey question: "In the last five years, how often have you visited the Olympic Peninsula?") is distributed fairly equal across all the categories (Figure 11). The largest group of respondents (27 percent) visits the Olympic Peninsula many times each year and the smallest group of respondents (12 percent) have visited once or twice in the last five years. 


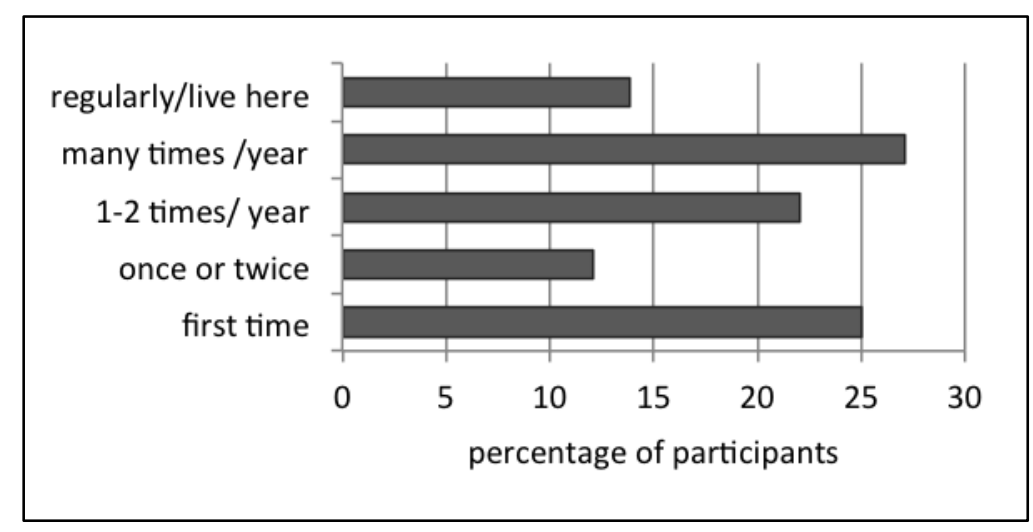

Figure 11. Chart of visitor familiarity results is based on the percentage of participants.

When the data is divided by survey site, the distribution varies noticeably (Figure 12). Participants who visit many times a year, regularly, or live on the Olympic Peninsula are grouped as familiar visitors. First-timers and participants who have only visited once or twice are grouped as unfamiliar visitors. Participants who visit once or twice a year are considered semi-familiar. The bar chart only compares unfamiliar and familiar visitors. Several locations including Bainbridge Island Ferry, Coho Campground, Dosewallips, and Klahowya Campground resulted in little or no data from unfamiliar visitors. Other locations, especially Hoh Rain Forest and Rialto Beach resulted in data mostly from unfamiliar visitors. 


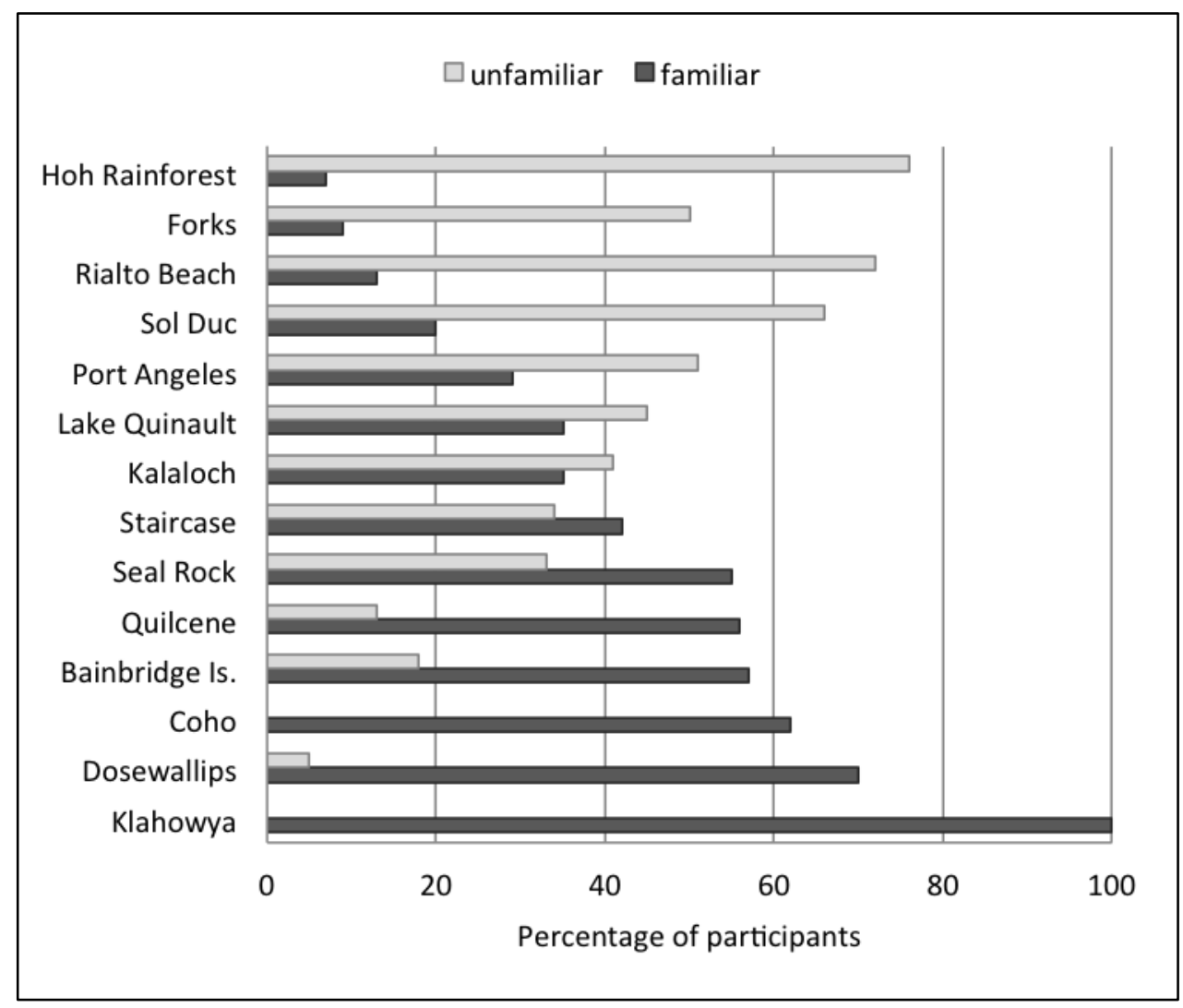

Figure 12. Chart of visitor familiarity reuslts by data collection location.

When the spatial data is analyzed based on the familiarity of the respondent, there are differences in the hot spots (Figure 13). The first time visitors' map resembles the map of out-of-state visitors. The more familiar a person is with the Peninsula, the more the coast is represented. Semi-familiar visitors are those who visit one or two times a year. Hot spots that are unique to these visitors include Lake Quinault, Ozette Lake, and Enchanted Valley. 


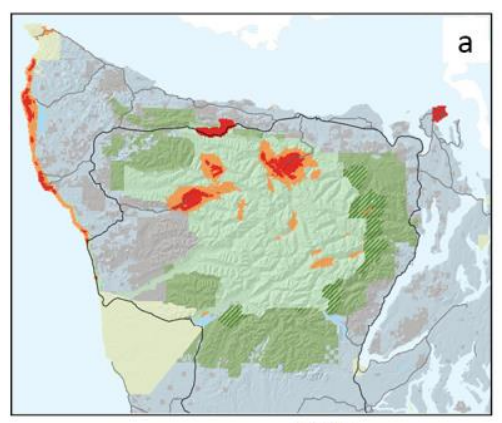

GiZScore

$1.96-2.58$

$>2.58$

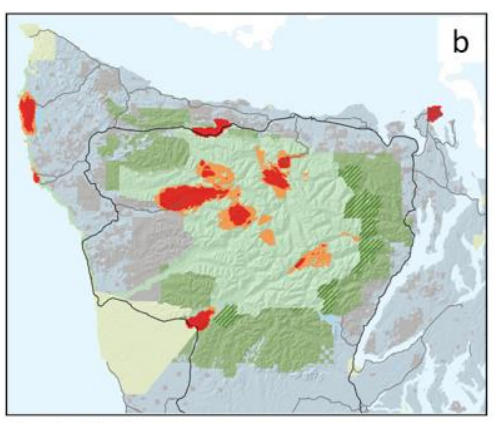

Jurisdiction

Tribal Land

Y/. FS wilderness

USFS

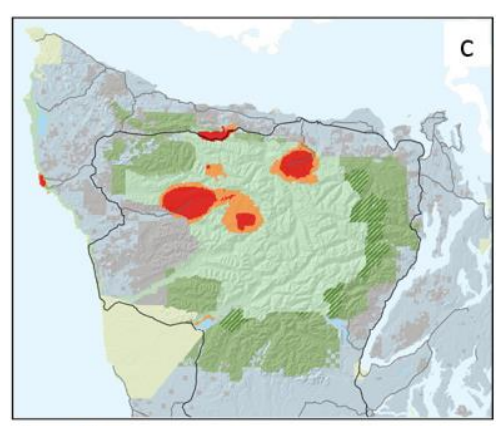

Roads

NPS DNR - Primary

- Secondary

Figure 13. Maps of visitor density hot spots by familiarity: (a) familiar, (b) semi-familiar, and (c) unfamiliar.

\subsubsection{Discussion}

Surveys from visitors of the Olympic Peninsula provided information regarding who was visiting and their familiarity with the area. Even though over three hundred visitors contributed to the research, the variety of demographics is limited. Middle-aged educated males regularly dominate in research where the study population self-selects (Alessa et al. 2008; Brown and Brabyn 2012; Pocewicz et al. 2012; Brown et al. 2013). The breakdown of demographics for this study is consistent with previous studies: mostly male, between the ages of forty-six to sixty-five, and with at least a four year degree.

Education is the most skewed value, with 75 percent of visitors having completed higher education. Only 2 percent of participants had no more than a high school degree. According to Whitesell $(2004,235)$, mainstream conservation groups target their marketing to "middle and upper class, predominantly older, well educated, and white" because these people are more likely to read promotional mail and belong to conservation 
groups. Perhaps the dominant demographic of people who visit natural areas is a product of this targeted outreach.

The demographics from this research also match the demographics reported from a survey administered to Olympic National Park visitors in 2000, with the exception of gender (Ormer et al. 2001). The national park survey reported a majority of female visitors (52 percent) whereas this research had mostly male participants (57 percent) with only 38 percent female participants. Based on observations during the data collection, many couples consisting of a man and a woman participated together. Some couples marked both genders on the survey, but in many cases the man filled out the survey with his demographic information while the woman provided input on places and values.

Familiarity with aspects of the research or the study area contributed to selfselection. Certain people were attracted to the research table where a banner hung with the words "Department of Geography/Portland State University" and two large example maps of the Olympic Peninsula were displayed. A number of visitors who volunteered to participate shared that they had a background in geography, lived in Portland or attended Portland State University, worked in land management, or had a lot of experience within the Olympic Peninsula. These people recognized a direct connection to the research.

Examples of the people who did not readily participate are families with young children, people in large groups, and migrants or foreign visitors. Based on observation during the data collection, these groups did not participate because their circumstances restricted their ability to participate. Children often require attention and do not have patience to wait while their parent(s) focus on the survey (Figure 14). Similarly, large 
groups usually have an objective and the level of interest varies among the individuals. Foreign visitors often do not participate because there is a language barrier.

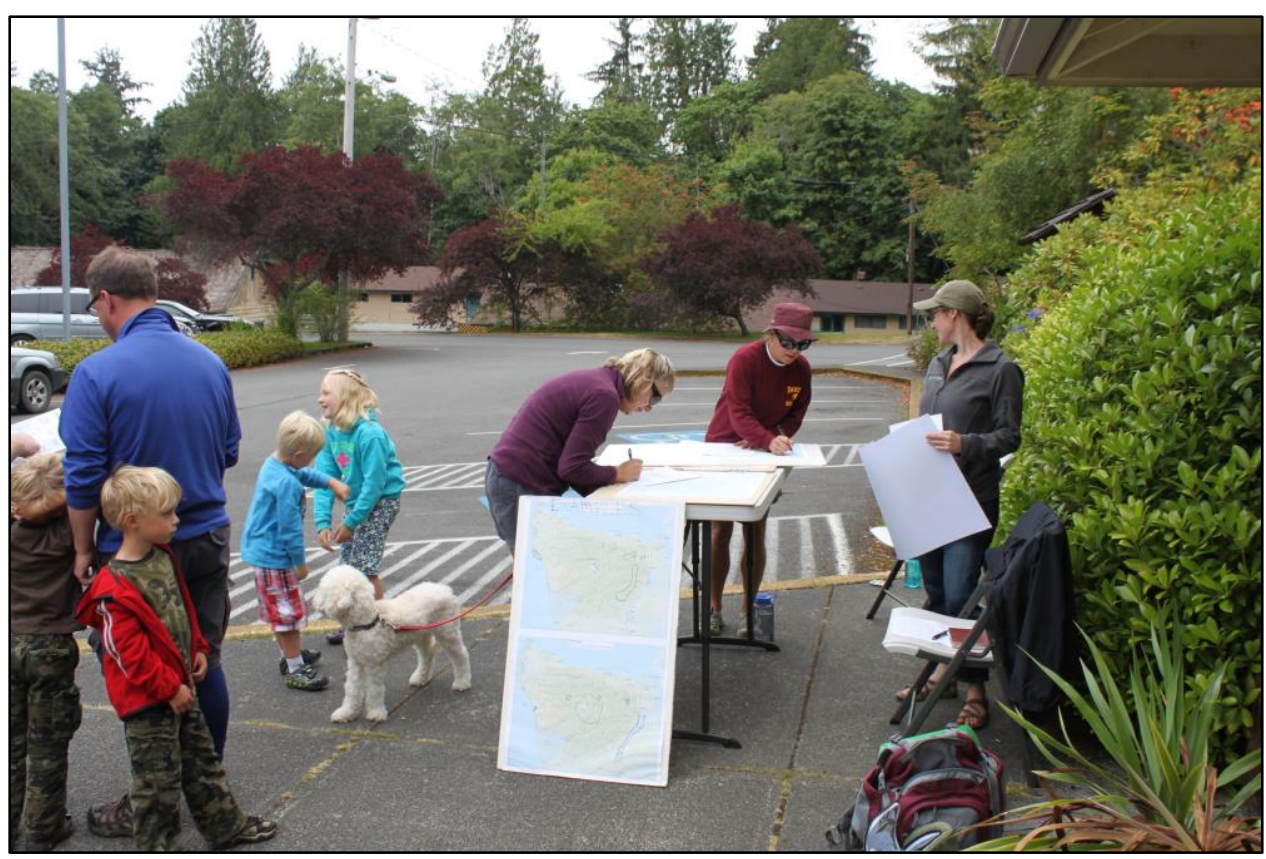

Figure 14. Photo of data collection: in this example of a family group that took the time to participate at Quinault Ranger Station, it is apparent there are potential distractions, including several children and a dog.

First timers were also reluctant to participate. Most justified not participating because they had "never been places" or they "don't know." A visitor at the Lake Quinault Ranger Station responded to my request for his contribution to my study of personally important places with, "That's why I'm here [at the visitor center]; to find out what places are important." Even though the research seeks to learn what people think, most first-timers believe they don't have information to contribute. 
Many people say they cannot value a place unless they've been there. If so, what motivated first-timers to come there? According to the National Park Service statistics, in 2012 nearly three million people visited Olympic National Park (NPS). Without input from people with little familiarity, the study would lack information about what brings people to the Olympic Peninsula in the first place.

With the inclusion of zip code or country on the survey, I was able to determine how far a person lives from the study area. Nearly a third of the visitors who participated in the research traveled to the Olympic Peninsula from outside the Pacific Northwest region. That people spend time, money, and energy travelling to the Olympic Peninsula indicates there is perceived value in the area that extends beyond the region. Getting people who live different distances from the Olympic Peninsula to participate offers additional information for analysis. The perception of local visitors differs from national or international visitors. Since much of the peninsula consists of federally owned land, public opinion from outside the area can influence management decisions.

Visitors from outside the region often have less familiarity with the Olympic Peninsula. Based on the hot spot maps, it appears they travel to the central part of Olympic National Park that is dominated by mountains and rainforest. The destinations that are located in large areas of significant density include Hoh Rain Forest, Hurricane Ridge, Sol Duc Valley, Lake Crescent, Mt Olympus, and Quinault Valley. Larger marked areas may be the result of less personal knowledge of a place, making the location more abstract to the visitor. 
Most data collection locations had participants that were either mostly familiar or mostly unfamiliar with the Olympic Peninsula. Survey participants at Hoh Rain Forest, Rialto Beach, Port Angeles, Forks, and Sol Duc consisted of over 50 percent visitors with little familiarity (first time visitors or had visited once or twice in the last five years). These locations all fall along the major tourist route from Port Angeles to Lake Quinault on the west side of the Peninsula. Survey participants on the Bainbridge Island Ferry, Coho, Dosewallips, Klahowya, Quilcene, and Seal Rock consisted of over 50 percent visitors with high familiarity. With the exception of Klahowya, these are locations that fall on the east side of the Peninsula. Klahowya differs from the west side Olympic National Park destinations, because it is located in Olympic National Forest. None of the locations dominated by familiar visitors are managed by the National Park Service. Only three locations (Kalaloch, Lake Quinault, and Staircase) had a similar number of familiar and unfamiliar visitors. These places are all located in the southern part of the Peninsula. The distribution of people with different levels of familiarity indicates jurisdictional locations within the Olympic Peninsula attract different types of visitors (Figure 15). 


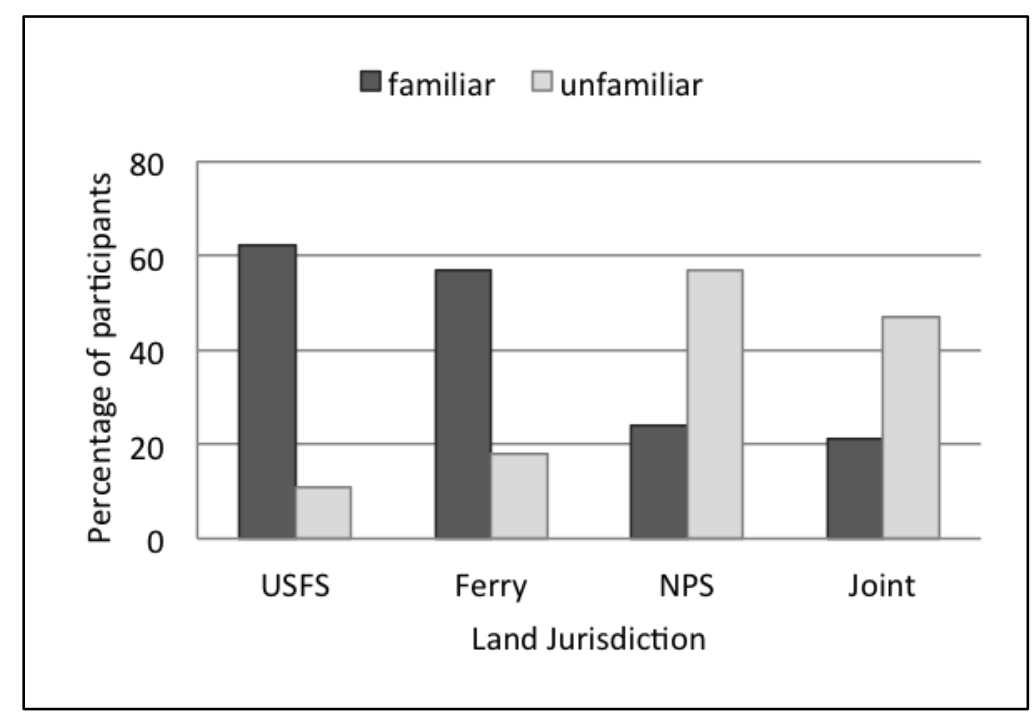

Figure 15. Chart of visitor familiarity results by land jurisdiction.

Assuming people have visited places they consider valuable, varying familiarity with places may have different impacts on the meaning of those locations. Consider the first time you encounter a landscape. What is the first thing you see? Most likely you visually pan the area and take in the setting. Sensory qualities of this new space draw your attention as you explore the area: the cool breeze moving toward you from the shore, rocky sand slipping between your toes, people meandering at varying paces up and down the coast. Do you make associations between what you see and how it makes you feel to past experiences in other places?

Now compare your experience of a new space with your experience in a favorite destination. Is your attitude any different? You may unintentionally search for qualities from your memories in the physical space. Maybe you notice slight differences. Are you more aware of yourself and your thoughts in this familiar place? Like Tuan (1974), I 
argue that the more time a person spends in a space, the more individual the meaning of that place is to that person. Layers of memories and personal growth merge with the physical qualities of the environment. A person in this environment for the first time may appreciate the space as much as a person who has been there many times, but the relationship to that space is different.

The survey locations where a majority of first-time visitors participated in the survey are within areas on the map that resulted in the highest density, for example Olympic National Park destinations such as Hoh Rain Forest and Hurricane Ridge. Since these popular locations host mostly unfamiliar visitors yet were marked by both unfamiliar and familiar participants, it would appear these are places that create strong first impressions on visitors. To many people, destinations within the national park are iconic places that serve as introductions to the Olympic Peninsula. Meanings associated with these destinations are provided by external sources such as NPS documentation available at visitor centers and online (ONP). This was observed when first time visitors sought information from the NPS about why the Olympic Peninsula is important.

Places where visitors are more familiar may have stronger place attachment because the meaning of that place is personal to those people. Many familiar visitors commented that they go to places in the Olympic Peninsula to enjoy an environment that is not populated by many people. For example, a visitor at Coho Campground said he goes to the Olympic Peninsula to "get away from the rat race." At Quilcene, someone remarked they value the Olympic Peninsula for a place to "get away." The locations where a majority of familiar visitors participated display lower density when the 
important places for all visitor surveys are compiled, suggesting there are fewer visitors. Just because a place is not significant when combined with all places people visit, does not mean it is not as meaningful to people. Less popular destinations offer a place for frequent visitors to develop a personal connection with the environment.

\subsection{Meaningful Places}

\subsubsection{Values}

The top three values listed by participants overall are aesthetic, recreation, and wilderness (Figure 16). From the total counts, the values break into four groups with a relatively close range of counts: 1) aesthetic, recreation, and wilderness have high counts ( 747 to 547 , or 52 to 38 percent of features); 2) biodiversity and therapeutic have moderately high counts (368 and 326, or 25 to 22 percent of features); 3) learning, spiritual, social, entertainment, future, and heritage have medium counts (214 to 152, or

14 to 10 percent of features); and 4) economic, home, and subsistence have low counts (94 to 47 , or 6 to 3 percent of features). 


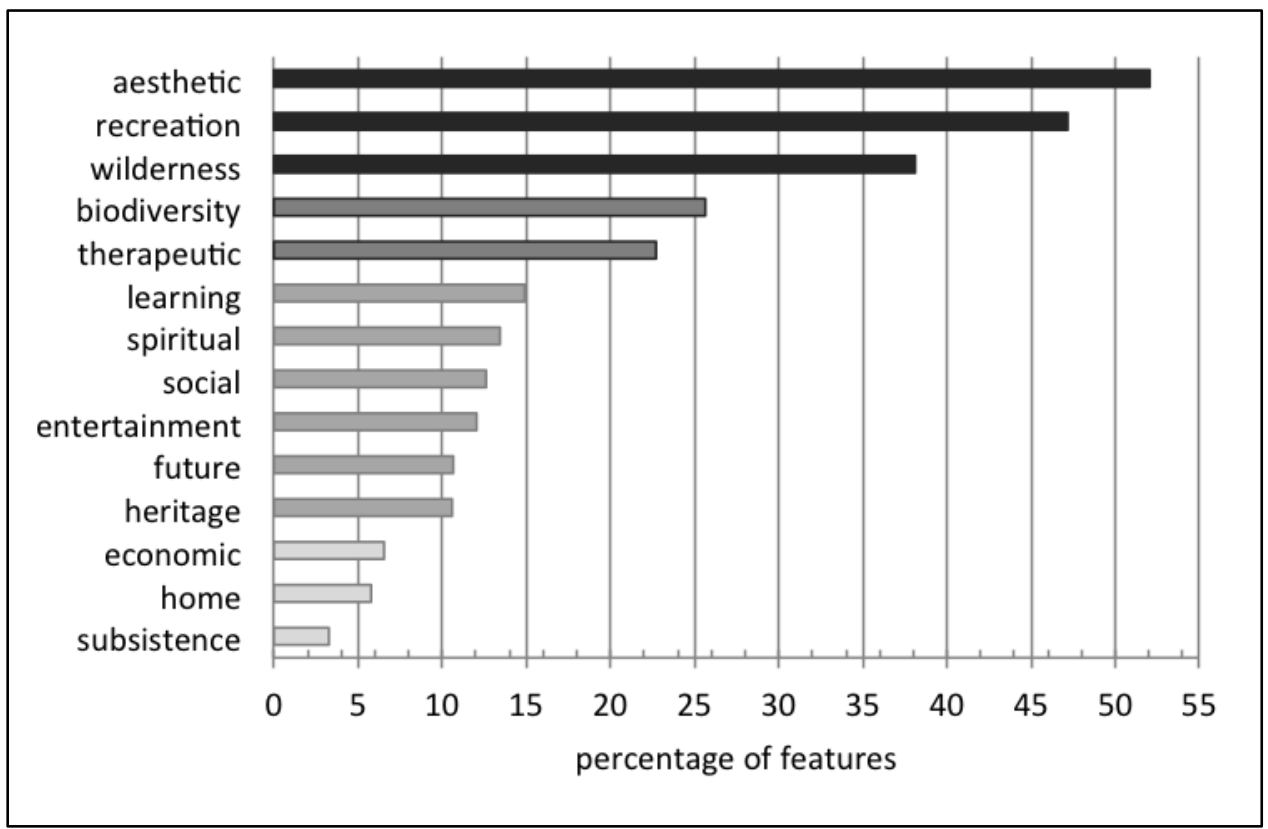

Figure 16. Chart of visitor value percentages. Values with similar percentages are grouped using different tones.

Comparing the density of individual values can be misleading because the top density counts for these individual values range from 6-56. Visualizing the value hot spots alleviates this problem, because it is based on statistical significance within each dataset. However, it is important to keep in mind that individual values with fewer features may have significant density counts that would not be considered significant for values with more features. There are two ways of viewing the values' hot spot maps: by the first value listed; and all the times the value is listed (as the first, second, or third value). Both sets of values are considered in the analysis, but the hot spot maps for the features where all the times the value is listed are shown (Figure 17). 

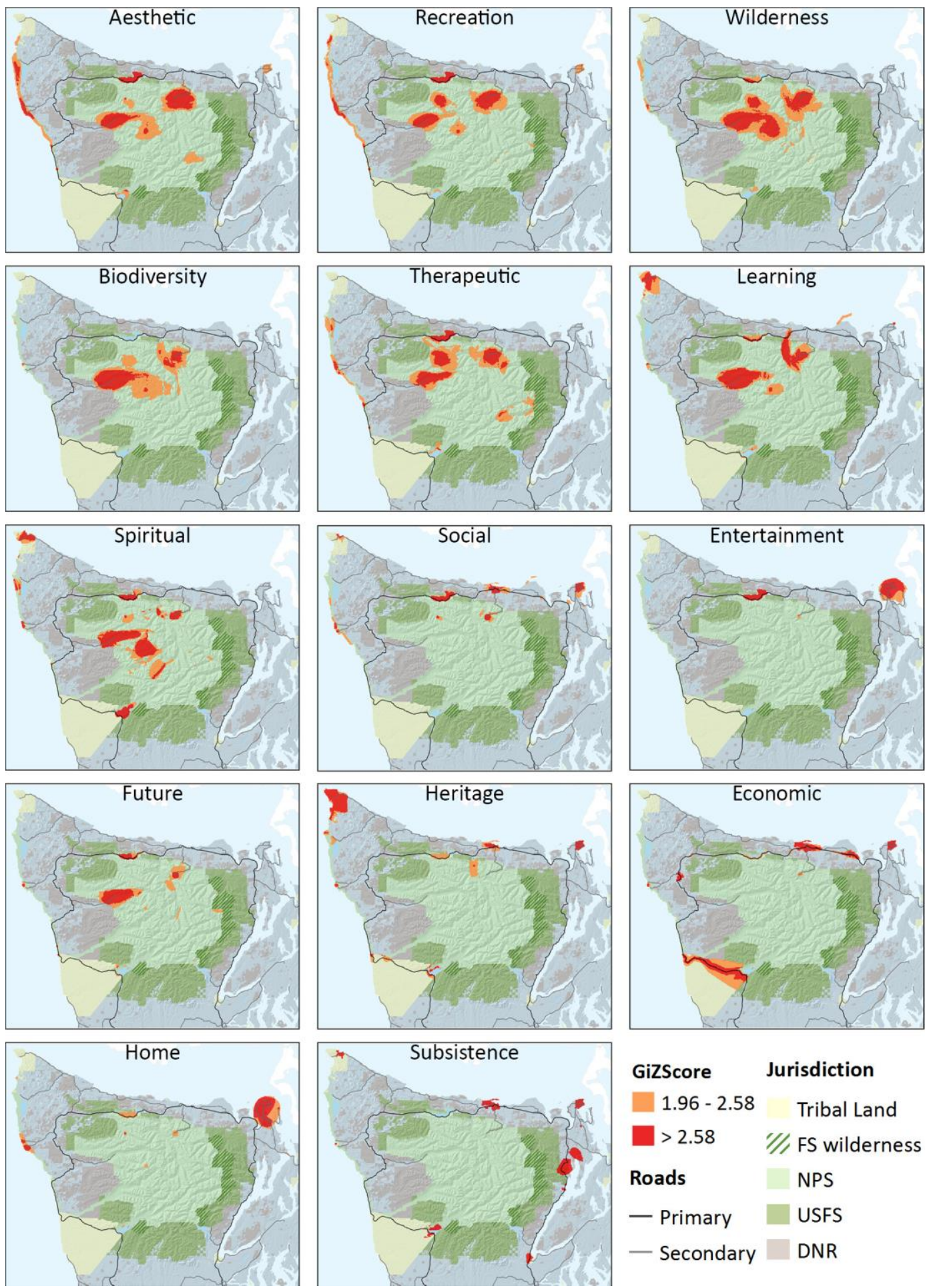

GiZScore Jurisdiction

1.96-2.58 Tribal Land

$>2.58 \quad 1 / /$, FS wilderness

Roads NPS

- Primary USFS

- Secondary DNR

Figure 17. Maps of visitor value density hot spots. 
When viewing the top values side-by-side, while there are commonalities, apparent differences are evident that makes certain values stand out. Densities representing aesthetic and recreation both closely resemble the overall density with few exceptions - aesthetic extends to the east by Hood Canal and around Quinault Lake, and recreation has less concentration on the coast. Out of all the values, wilderness displays the largest marked areas with high levels of density in central areas of the Peninsula. Biodiversity concentrates around the Hoh Rain Forest and Hurricane Ridge. Heritage and entertainment are different from the overall density; heritage is concentrated on the northwest corner of the Peninsula or the Makah Indian Reservation, and entertainment is concentrated around Port Townsend. Entertainment and social are the only values that are displayed as small areas. The area for therapeutic is larger than all other values of high density around Sol Duc where there is a popular hot springs resort. Learning clearly highlights the Elwha River around the recently removed dams and also has the largest area of concentration out of all the values around the Hoh Rain Forest. Spiritual is centrally focused and shows several hot spots in the mountains (in particular Mt. Olympus) and the rain forests.

When the data is viewed by the location where the surveys were collected, the top value for ten out of the fourteen locations is aesthetic. The four locations (Coho, Klahowya, Quilcene, and Seal Rock) that have a different top value are all within the Olympic National Forest. 


\subsubsection{Activities}

Visitors listed their own activities, and categorization was necessary before any analysis was possible. The activities are grouped into ten categories based on the general focus and level of exertion (Table 6). Figure 18 shows the activity groups by the percentage of features included from most to least. Hiking is its own category due to the large number of surveys that included this activity (45 percent). The other major category is non-cardio recreation with 29 percent. Activity classes with moderate counts (5-12 percent) include sociocultural, observation, water sports, active recreation, forage, and rest and relaxation. Education, travel, and work are the least common activities with a combined percentage of 7 percent.

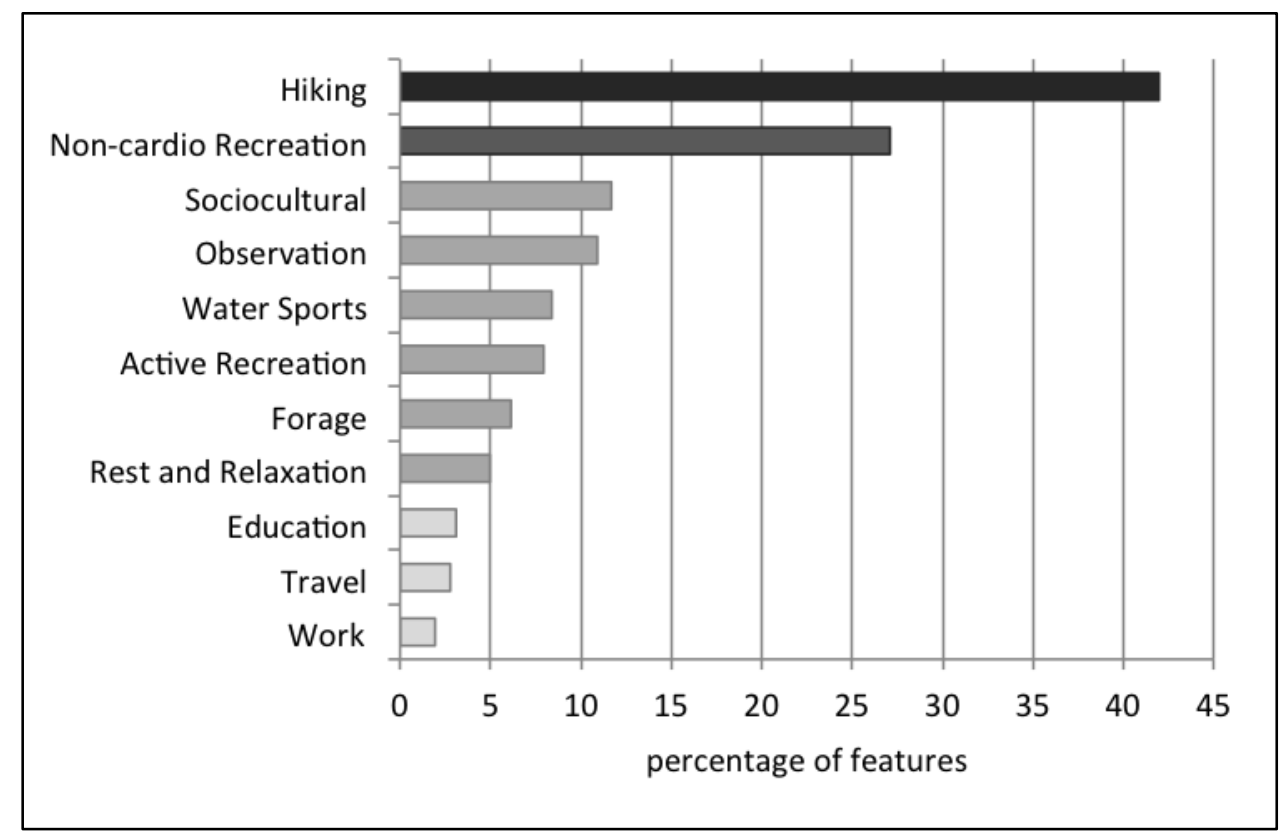

Figure 18. Chart of visitor activity group percentages of features for each activity category. 
Table 6. Activity classification groups, listed with examples from the surveys and the total number of times each is included. Because many participants listed multiple activities for each location, the counts differ from the number of features.

\begin{tabular}{|c|c|c|}
\hline Activity class & Examples from surveys & Count \\
\hline Hiking & hiking & 650 \\
\hline $\begin{array}{l}\text { Non-cardio } \\
\text { Recreation }\end{array}$ & $\begin{array}{l}\text { camping, picnicking, soak, walking, beach-combing, } \\
\text { collecting, golfing, recreation, exploring, beach }\end{array}$ & 419 \\
\hline Sociocultural & $\begin{array}{l}\text { sightseeing, tourism, event/festival, Twilight, shopping, } \\
\text { eating, socializing, drinking, gambling, knitting, music, } \\
\text { agriculture, living, heritage, dinner, visit(ing friends), } \\
\text { "place ashes on the glacier", economic, family vacation, } \\
\text { preserve }\end{array}$ & 181 \\
\hline Observation & viewing, photography, birding, observati on, tide pool & 169 \\
\hline Water Sports & $\begin{array}{l}\text { kayaking, boating, sailing, surfing, snorkeling, diving, } \\
\text { canoeing, rowing, swimming }\end{array}$ & 130 \\
\hline $\begin{array}{l}\text { Active } \\
\text { Recreation }\end{array}$ & $\begin{array}{l}\text { backpacking, climbing, mountain biking, running, } \\
\text { snowshoeing, geocaching, snowboarding, skiing }\end{array}$ & 123 \\
\hline Forage & $\begin{array}{l}\text { fishing, shellfishing, oystering, shrimping, crabbing, } \\
\text { mushrooming, hunting }\end{array}$ & 95 \\
\hline $\begin{array}{l}\text { Rest and } \\
\text { Relaxation }\end{array}$ & $\begin{array}{l}\text { relaxing, resting, hanging-out, being, staying, getaway, } \\
\text { vacation, retreat, meditating, spiritual, enjoying, lodging, } \\
\text { sitting, "stop over", communing, cabin living }\end{array}$ & 77 \\
\hline Education & $\begin{array}{l}\text { learning, museum, history, research, teaching, archeology, } \\
\text { junior ranger }\end{array}$ & 48 \\
\hline Travel & travel, ferry, driving, motorcycling, biking, access & 43 \\
\hline Work & $\begin{array}{l}\text { working, trail maintenance, volunteering, training, } \\
\text { restoration }\end{array}$ & 30 \\
\hline
\end{tabular}


The hot spot maps for the top activity groups show different patterns (Figure 19). The hiking map has large hot spots in the most popular places from the composite hot spot maps, including Hoh Rain Forest, Hurricane Ridge, and Lake Crescent. Non-cardio recreation is heavy on the coastal portion of Olympic National Park. Sociocultural hot spots occur in populated areas including the towns of Port Townsend and Port Angeles, Lake Crescent, Hurricane Ridge, and a small area of Hoh Rain Forest. Observation is broadly significant around Hurricane Ridge. Water sports are centered on the main water features within the Peninsula, including Ozette Lake, Lake Crescent, Lake Quinault, and Hood Canal but not along rivers. Active recreation takes place in the central part of the Peninsula away from roads.

When the activity group hot spots are compared with the recreation value hot spots, an assumption can be made about what types of recreation is important in each place. Places that are valued for their hiking recreation include Hoh Rain Forest, Hurricane Ridge, Sol Duc, Crescent Lake, and Ozette. Hoh Rain Forest and Hurricane Ridge are also valued for sociocultural, observation, active, and non-active recreation. Crescent Lake is valued for all but active recreation. Port Townsend is valued for sociocultural recreation and water sports. The area around Mt Olympus is valued for active recreation. Sol Duc is valued for all but sociocultural recreation. 

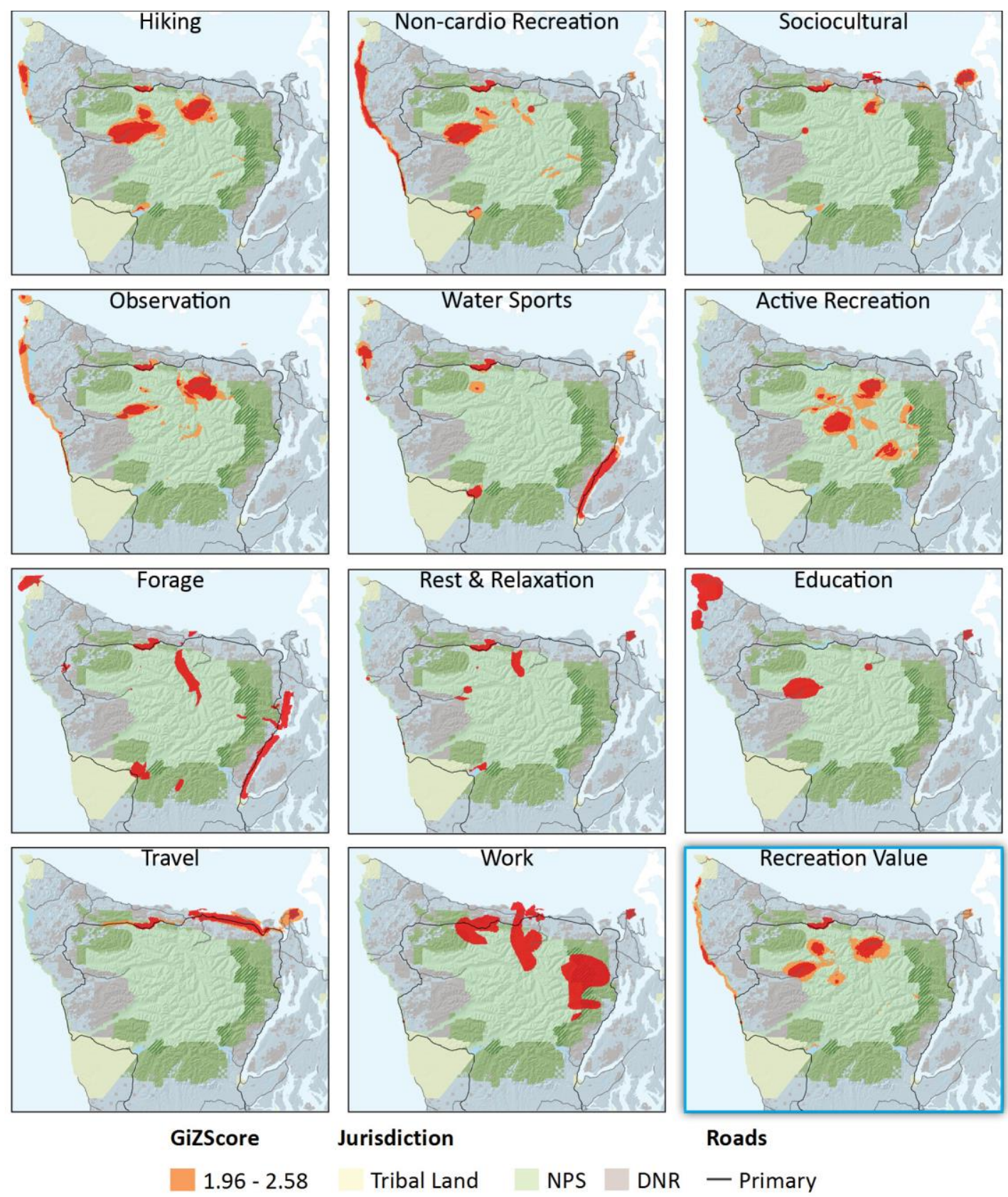

Jurisdiction

Roads

> $2.58 \quad$ W/. FS wilderness U USFS - Secondary

Figure 19. Maps of visitor activity density hot spots, as well as the recreation value density hot spots (shown with a blue border) for comparison. 


\subsubsection{Discussion}

When asked to identify areas in the Olympic Peninsula that are important, most visitors responded by enthusiastically talking about their experiences. First time visitors described places they recently encountered, regular visitors recounted meaningful experiences in their favorite places, and local visitors listed where they normally go. These memories are associated with places. Without necessarily knowing it, people draw information from their experiences that inform the meaning of places (Tuan 1974). Reciprocally, these place meanings affirm people's environmental values.

Values that were included most often in the survey are aesthetic, recreation, and wilderness. Based on the definitions provided with these values, the Olympic Peninsula is important to visitors for how the environment looks and feels, for opportunities to participate in outdoor activities, and because there is a lack of human development.

Aesthetic dominates all values as the first listed. While the counts remain high as the second and third value, it ranks below other values, including recreation, wilderness, and therapeutic. The only data collection sites where visitors did not rank aesthetic highest are located within Olympic National Forest. Visitors who participated in these locations had greater familiarity of the Olympic Peninsula. Therapeutic has moderate counts for the first and second value, but ranks third behind recreation and wilderness as the third value. Overall, therapeutic ranks fifth out of the fourteen values based on total counts.

To explore the relationship between values and places in the Olympic Peninsula, I compared the individual value hot spot maps with the composite hot spots (Table 7). The 
range of each value was determined based on how significant the value was for each of these hot spots. Values are considered highly significant and given a score of 2 for places where hot spots appear for the first value and all values. Values are considered significant and given a score of 1 for places where hot spots appear in either the first value or all values map.

Some values are associated with a wide range of places, and other values are more place-specific. In many cases, the range of a value corresponds with the number of features. Aesthetic is the most popular value and it has an equally high range. Certain values stand out because the rank in range differs from the popularity. For example, therapeutic is fifth in feature counts, yet it is second in range to aesthetic, meaning it is a significant value for many places in the Olympic Peninsula. Biodiversity is the fourth most common value, but it ties for eighth in range indicating it is more place specific than therapeutic. 
Table 7. Hot spot value significance is based on the individual value hot spot maps. Highly significant values have a hot spot in the location for both the map with all features and the map with features where that value is ranked first. Significant values show a hot spot in the location for only one of these maps.

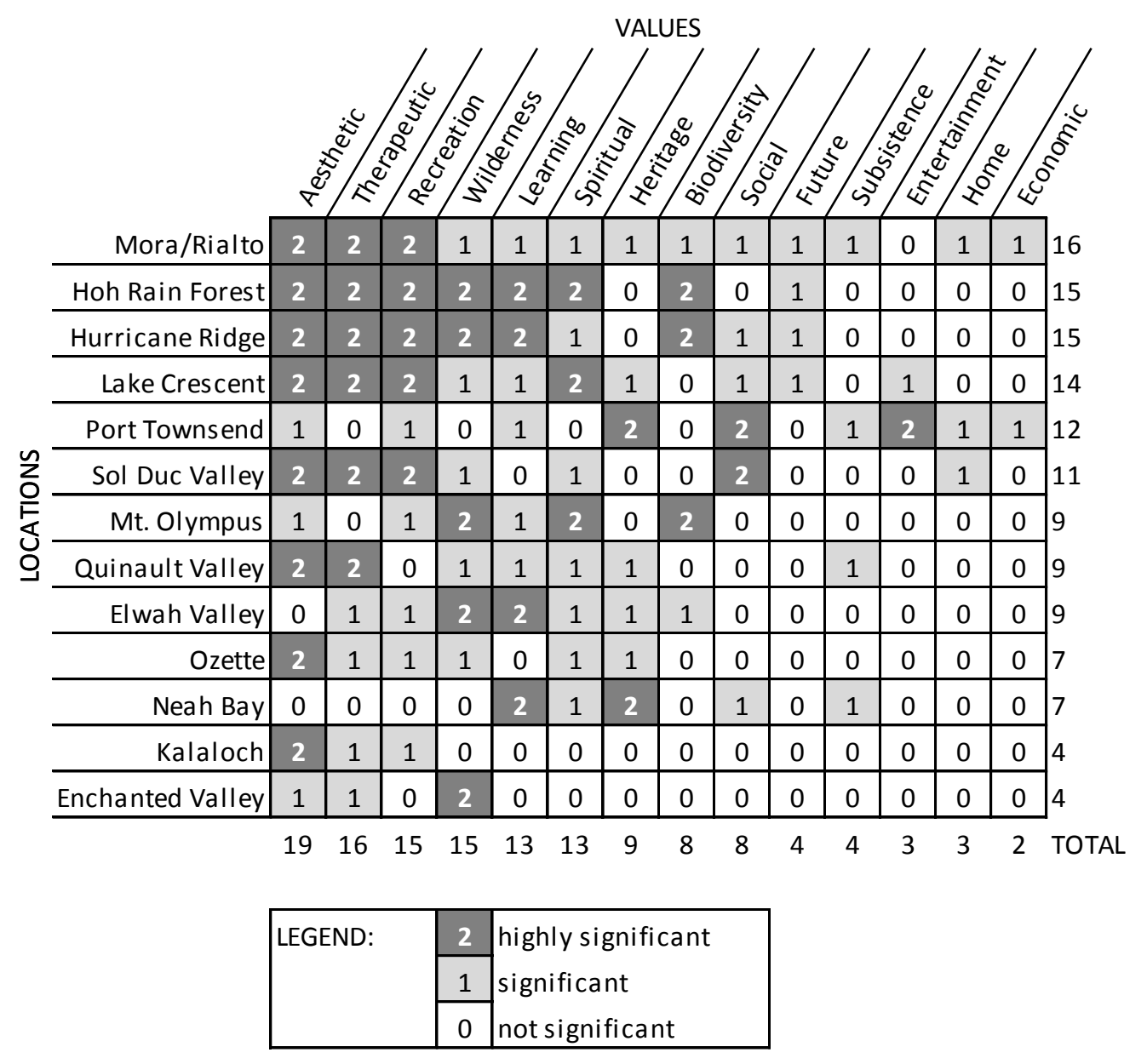


Certain values are associated with specific places, as observed in the hot spot maps. Places within the Olympic Peninsula that are highlighted by the composite hot spot map (Figure 8) have been charted with their associated values as a means for understanding how places differ and what they mean to visitors (Figure 20). For instance, Neah Bay and Elwah Valley both are places valued for learning, but Neah Bay is also valued for heritage while Elwah Valley is valued for wilderness. These combinations suggest each place offers a different type of education. Learning is also an important value for Hurricane Ridge and Hoh Rain Forest in addition to several other values: aesthetic, recreation, wilderness, biodiversity, and therapeutic. Hoh Rain Forest differs from Hurricane Ridge because it has spiritual value. Another way of understanding places is by the values that are not significantly associated. Hoh Rain Forest is not a place that is important for social value; Hurricane Ridge has some social value. Similar places can be compared based on what values are significant and not significant to recognize what qualities make them different.

Another way to view the hot spot by values chart is to compare similar types of locations. Kalaloch, and Mora/Rialto are located on the coast. These locations are important for different values. Mora/Rialto has the greatest diversity of meanings (Figure 24) out of all the hot spot locations with entertainment being the only value that is not significant. Kalaloch is a location with one of the lowest diversity of values (aesthetic, recreation, and therapeutic). The complexity of meanings associated with these places reflects the land uses. In a small area around Mora/Rialto are a beach, entry points for backpacking routes, a campground, and an Indian Reservation that has received attention 
for being the set for a recently popular American movie (Twilight). In contrast, Kalaloch is the site of a coastal campground and lodge without other surrounding attractions.

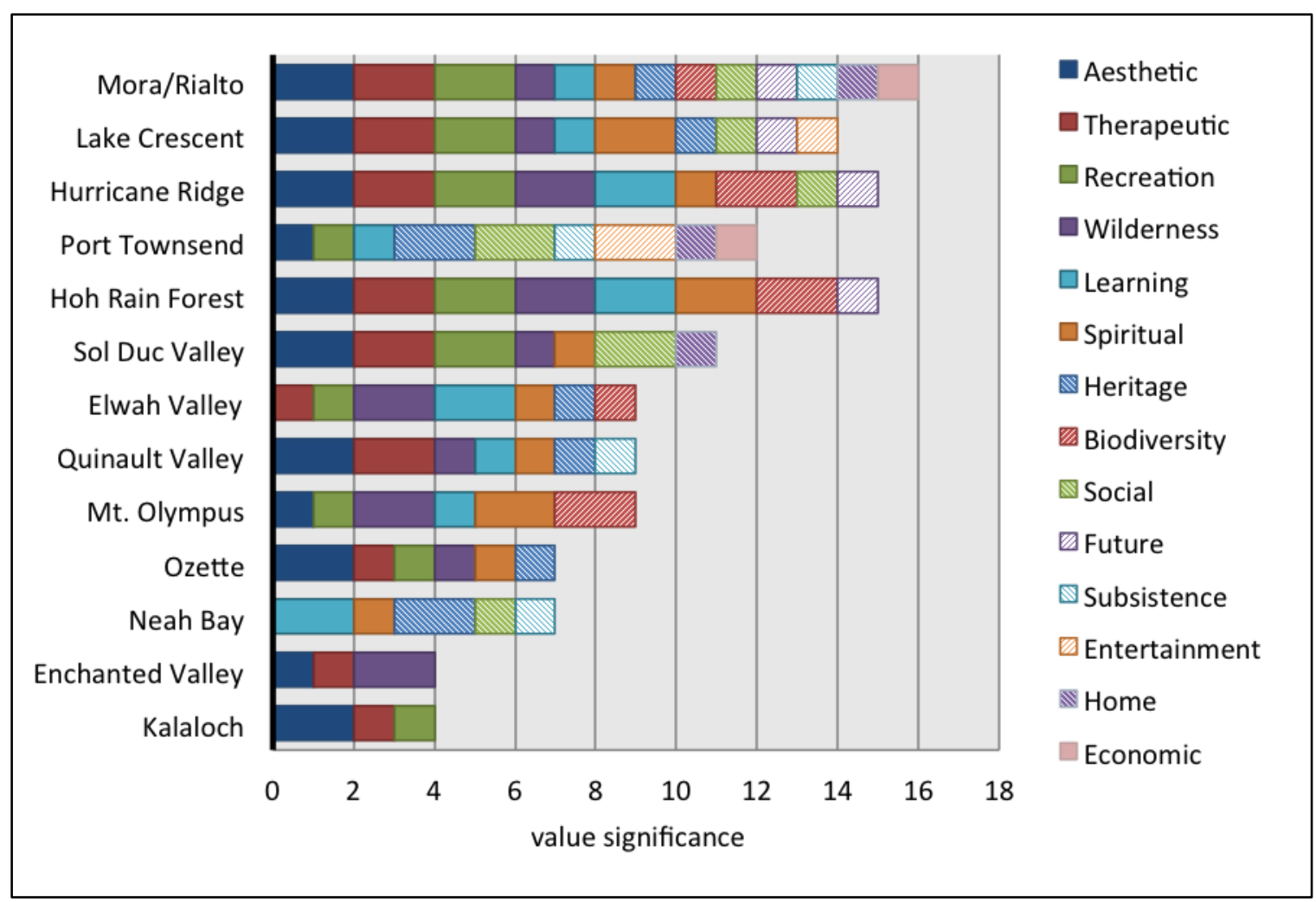

Figure 20. Chart of value diversity (high to low) for the density hot spots.

Wilderness ranks as the third most common value included by visitors in the survey. Rarely does any part of the forest service wilderness areas show up in hot spot maps. The wilderness value that people include in the survey is associated with areas in Olympic National Park and many of those areas are accessible by paved roads. Out of the eleven destinations listed on the Olympic National Park website as "places to go," Staircase and Queets are the only two that do not appear in any of the hot spot maps. These are the only two places from the list that necessitate driving on unpaved roads in 
order to get there. But wilderness is important to people as defined by "it is not developed or altered appreciably by people." The lack of connection between wilderness as a value and actual wilderness areas brings into question the meaning of wilderness. How do the designated wilderness areas differ from the places participants marked as important?

Wilderness and access are related concepts that can have a negative correlation. Places with greater access receive more people. Wilderness is defined as an environment that has not been altered appreciably by people. By logic, the more people that are in a place means the less that place is wilderness. Places that get the most attention for wilderness qualities contain more development than other wilderness areas. People lack direct access to wilderness because roads are not permitted in designated wilderness areas. Since these areas are restrictive, they get less attention from casual visitors.

Access is a value that was brought up in conversations with participants on numerous occasions that may need to be included the value typology. People stated that access is crucial in order for them to value places. At Lake Quinault a visitor described how access to natural areas is needed for people to appreciate them, yet the impact of people threatens the existence of these natural areas. Roads to many people mean access to places, thus they provide opportunity to care about those place. Other people think roads restrict access by removing elements that they seek, like a sense of wilderness or solitude. A regular visitor at the Coho Campground reflected on the increase in visitors to places in the National Forest where roads have recently been paved. Now there is not enough room for everyone to stay and the people who have been going there over time 
have to compete for access to their favorite places. Other people oppose restrictions, such as those proposed by Wild Olympics that would limit access by closing roads.

The contrasting views on access were observed at Dosewallips in regards to the road there that washed out years ago. Many visitors think the road should remain closed because the lack of vehicles provides more opportunity for immersion with wildlife. Others want the road to be repaired so that they can access areas on that side of the park. Because this road is now surrounded by designated wilderness, alternatives cannot be constructed as a solution to the washout. This example demonstrates how wilderness may limit access.

\subsection{Visitors and Residents}

\subsubsection{Comparison of Visitors and Residents}

When viewing the visitor data density next to the local resident data density from the Human Ecology Mapping Project (HEM), the overall patterns are dramatically different (Figure 21). An overlay of the hotspots with land jurisdiction shows that visitors recognize Olympic National Park, while residents mark Olympic National Forest and Department of Natural Resources land. 


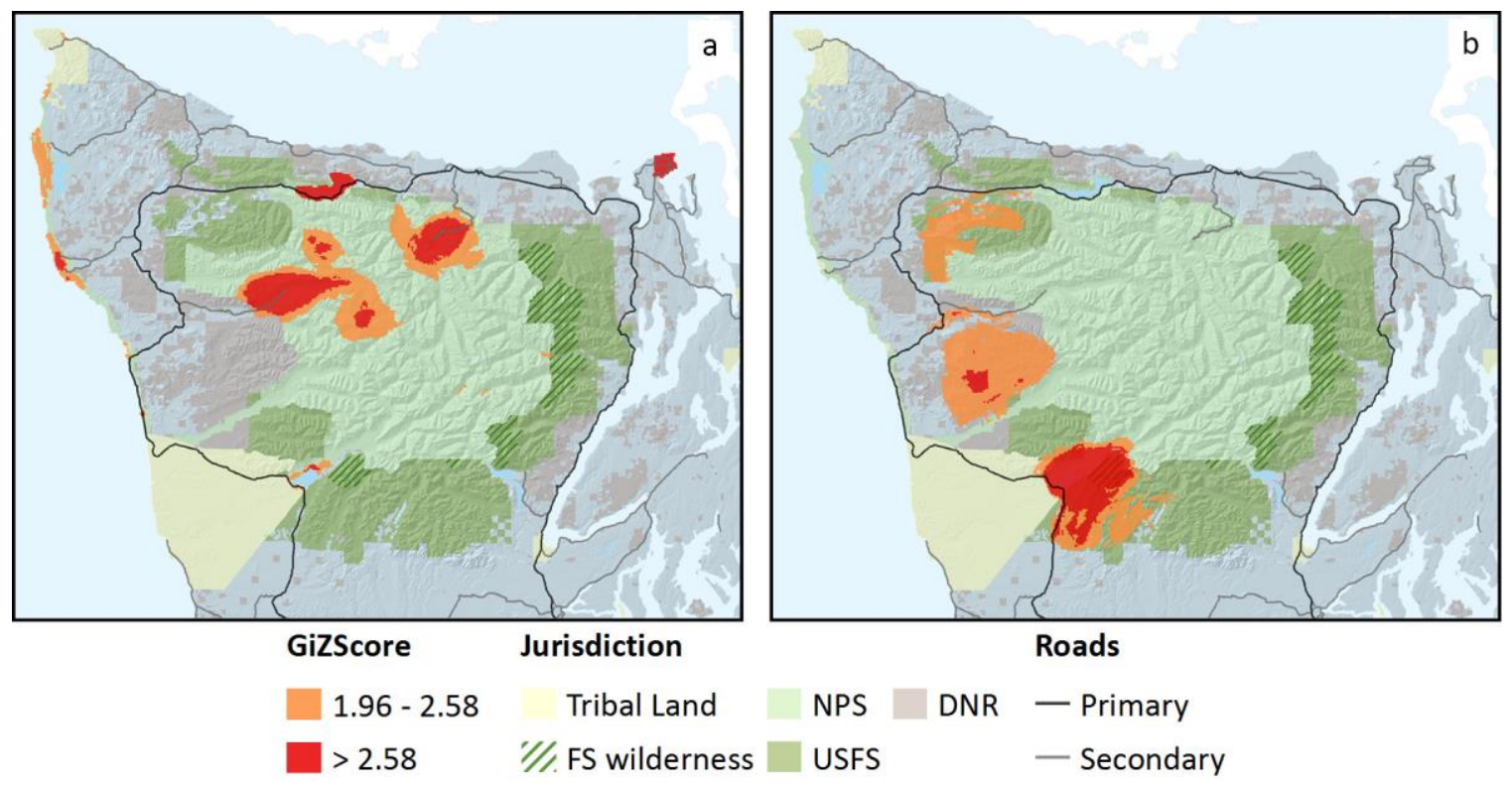

Figure 21. Maps showing (a) all visitor and (b) resident value density hot spots.

The top values of the surveyed visitors and residents of the Olympic Peninsula are partially similar; aesthetic and recreation are important values to both (Figure 22). Recreation has a much higher percentage for residents than any other value. In contrast, the top three values for visitors (aesthetic, recreation, and wilderness) are closer in percentage. The values with the greatest difference between visitors and residents are economic and wilderness; residents value economic highly, while visitors value wilderness highly. The two values that differ from the HEM survey (biodiversity and therapeutic) have higher percentages for visitors than residents by at least double the percentage. Future, social, and spiritual have similarly low percentages for both groups. Visitors value learning a little more than residents, and residents value heritage, home, and sustenance a little more than visitors. 


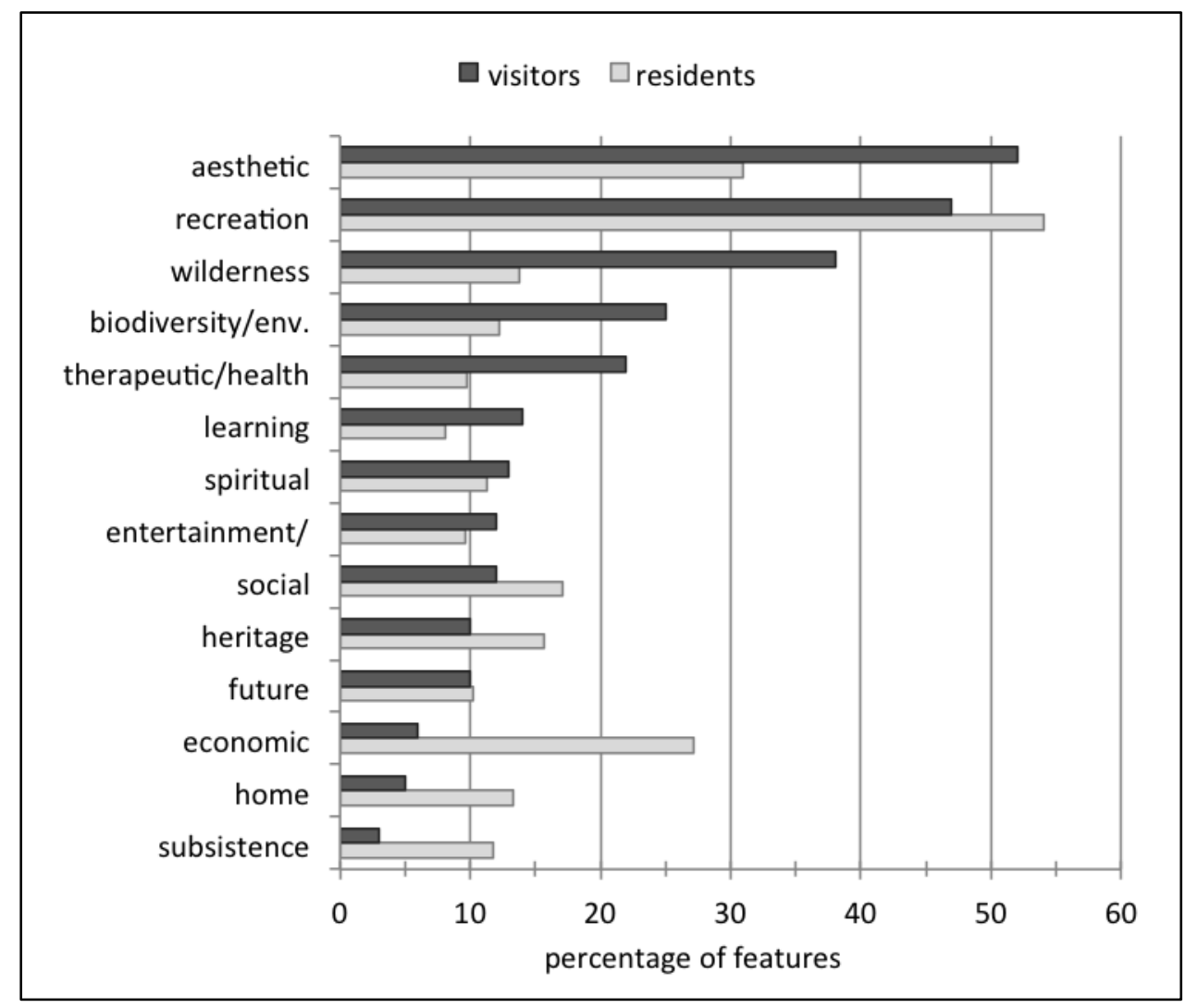

Figure 22. Chart comparing visitor and resident value percentages.

\subsubsection{Combination of visitor and resident data}

The combination of values data from visitors and residents portrays an image of the human perceived landscape in the Olympic Peninsula (Figure 23). I combined the visitor data (1549 features) with the resident values data (818 features) and used the same methods of analysis. While there is more visitor data than resident data, there are also more people who visit the Olympic Peninsula than who live there. The combined density hot spots lean to the west side of the Olympic Peninsula with the exception of Port Townsend in the northeast. The largest significant areas surround Quinault, the Hoh Rain Forest, Hurricane Ridge, and Sol Duc. This map differs from the visitor hot spot map in 
the significant areas to the west and southwest of the Olympic National Park boundary within state and forest service lands, and increased significance of the Lake Quinault area.

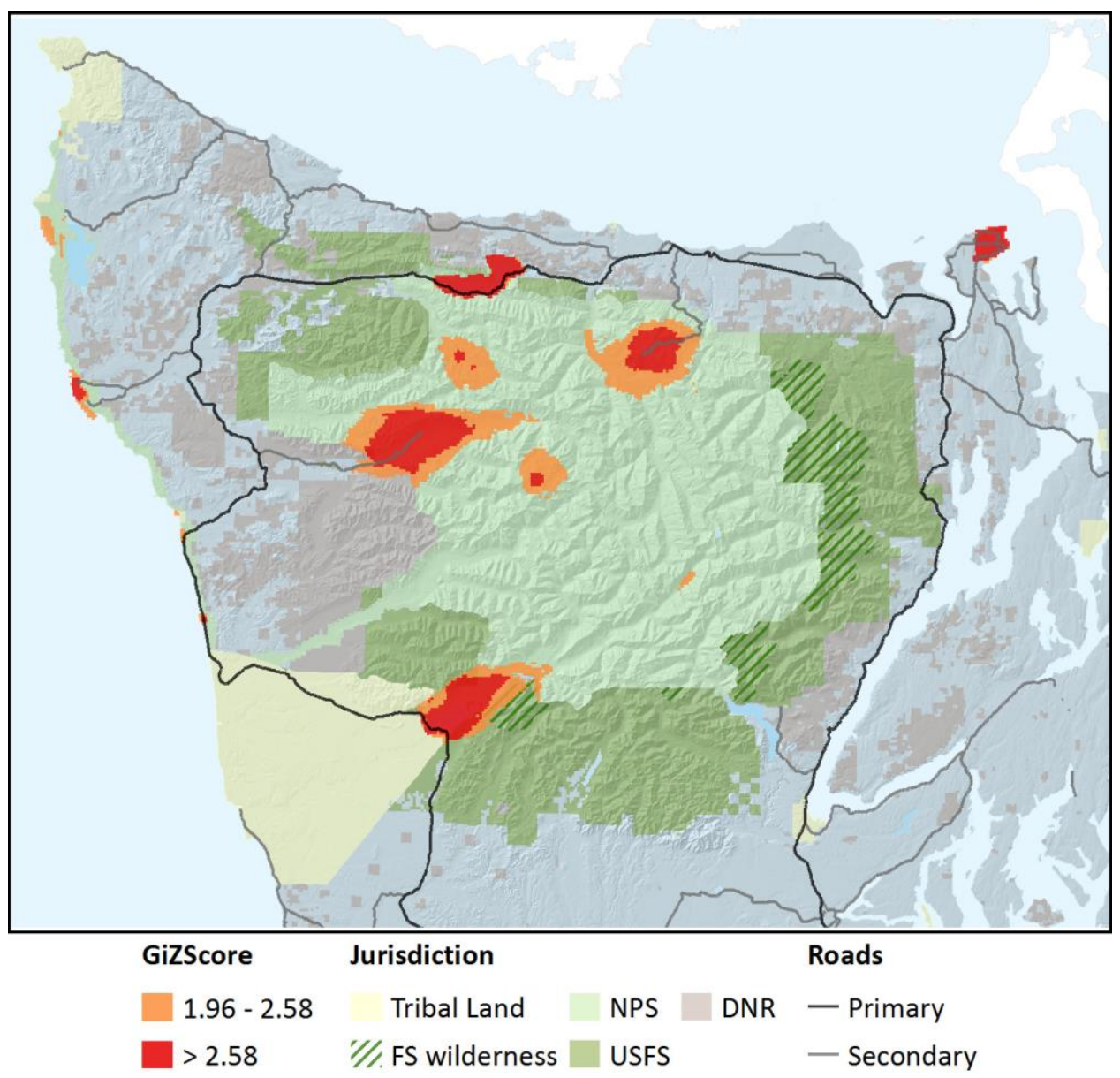

Figure 23. Map of the composite visitor and resident density hot spots.

When the percentages of the values are calculated for all the visitor and resident features, the distribution of values differs from both the visitor and the resident totals (Figure 24). Recreation leads over aesthetic with 50 percent of all the features. Economic 
ranks third to last for visitors and third for residents. When the values are combined economic ranks in the middle and is associated with about 15 percent of features.

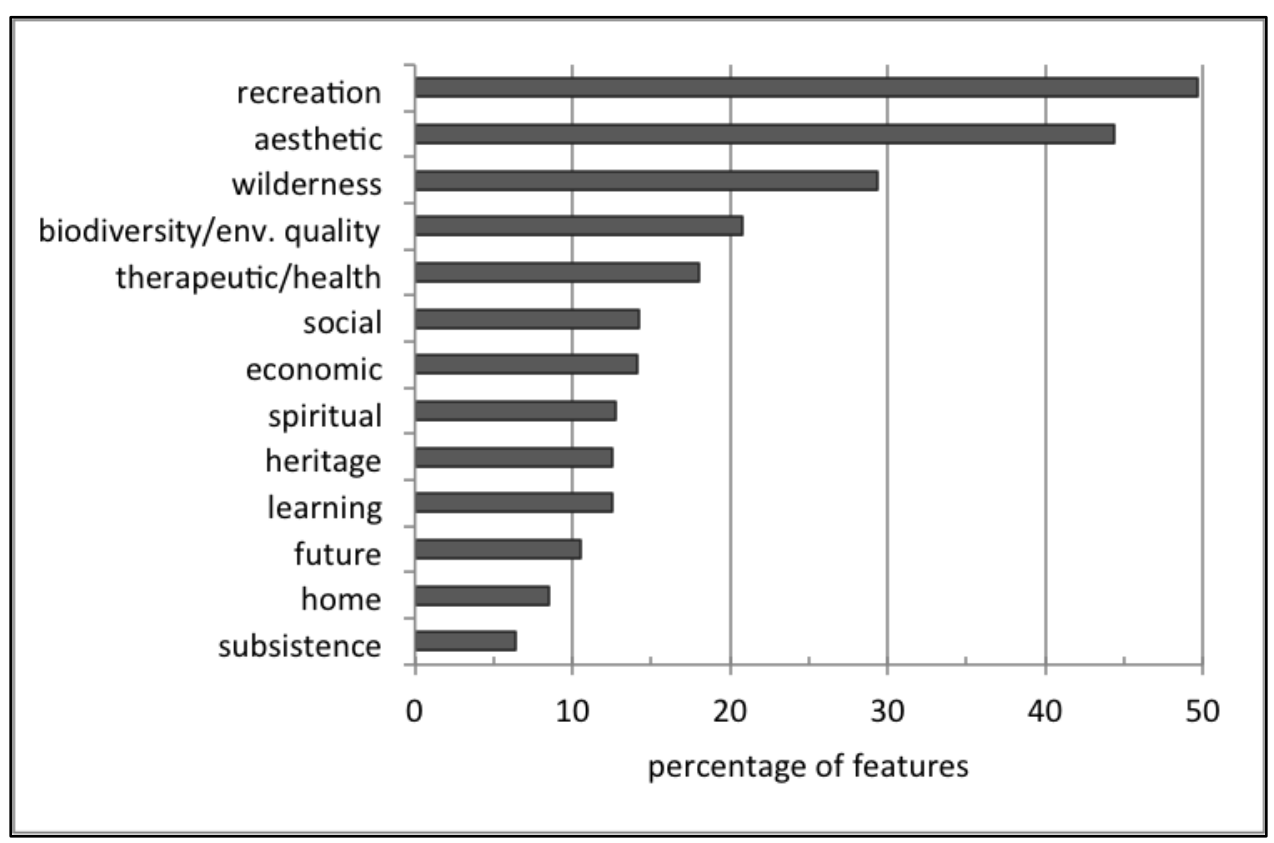

Figure 24. Chart of combined visitor and resident value percentages.

\subsubsection{Discussion}

Comparing visitor data with resident data reveals significant differences in places and values. The stark difference between the resident and visitor perspectives of the Olympic Peninsula indicates that the two groups receive their information about the place from different sources and may bring different politics. These differences substantiate Buttimer's (1980) writing about the contrast between outsider (visitors) and insider (residents) conception of place identity. Values with higher percentages for visitors (aesthetic, wilderness, biodiversity, therapeutic, learning, spiritual) are more conceptual in nature and values with higher percentages for residents (economic, home, subsistence, recreation, social, heritage) are generally more physical in nature. The difference in these 
values between visitors and residents may represent the "traps" that influence perspectives of outsiders and insiders.

The values that were adjusted from HEM (biodiversity and therapeutic) were included in visitor surveys more often than residents included the alternatives (environmental quality and health). Biodiversity ranks fourth with visitors whereas environmental health ranks eighth with residents. Therapeutic ranks fifth with visitors and health ranks thirteenth with residents. These results may demonstrate the influence of word choices. The words I used to introduce the research to visitors had an influence on how participants understood the survey. For example, when describing what I wanted marked on the map, visitors interpreted words such as 'place,' 'location,' and 'area' differently.

Collecting data at multiple locations around the Olympic Peninsula allowed me to get input from residents who did not participate in the scheduled HEM workshops. Residents who were visiting locations on the Peninsula mapped different places and values than residents who participated in the workshops (Figure 25). These local visitors value areas within the Olympic National Park and Olympic National Forest for mostly wilderness, recreation, aesthetic, biodiversity, and learning. Residents at workshops value areas within Olympic National Forest and DNR lands for mostly recreation, aesthetic, economic, social and heritage. The greatest difference in values between local visitors and resident workshop participants include wilderness, economic, biodiversity, learning, and recreation (Figure 26). Since the places and the values these participants mark differ, the groups do not necessarily view places differently, but they place greater importance 
on different places and values. By collecting data from visitors who just happen to be visiting a particular location, this research is able to get input from residents who normally do not participate in workshops.

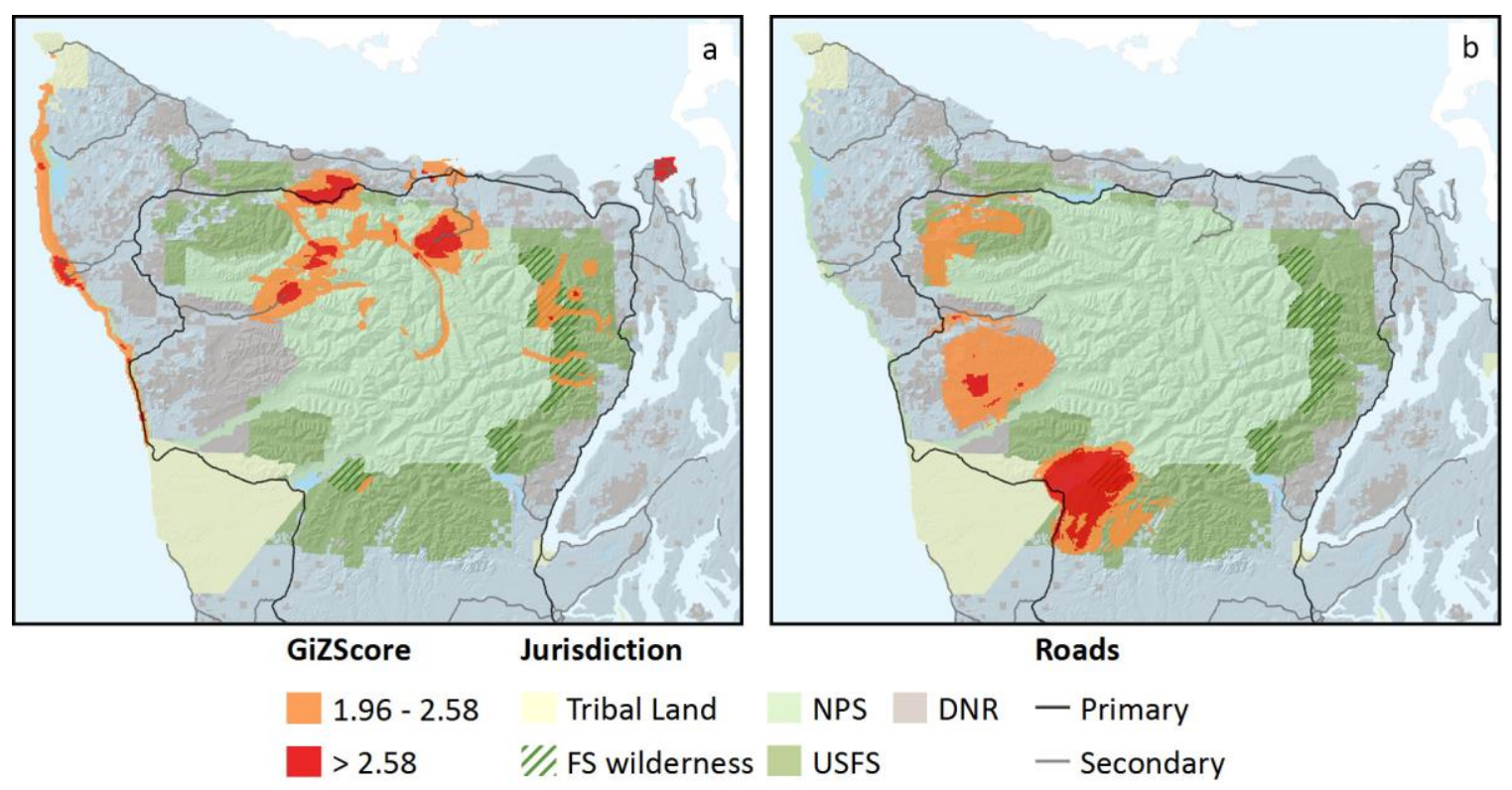

Figure 25. Maps showing (a) local visitor and (b) resident value density hot spots. 


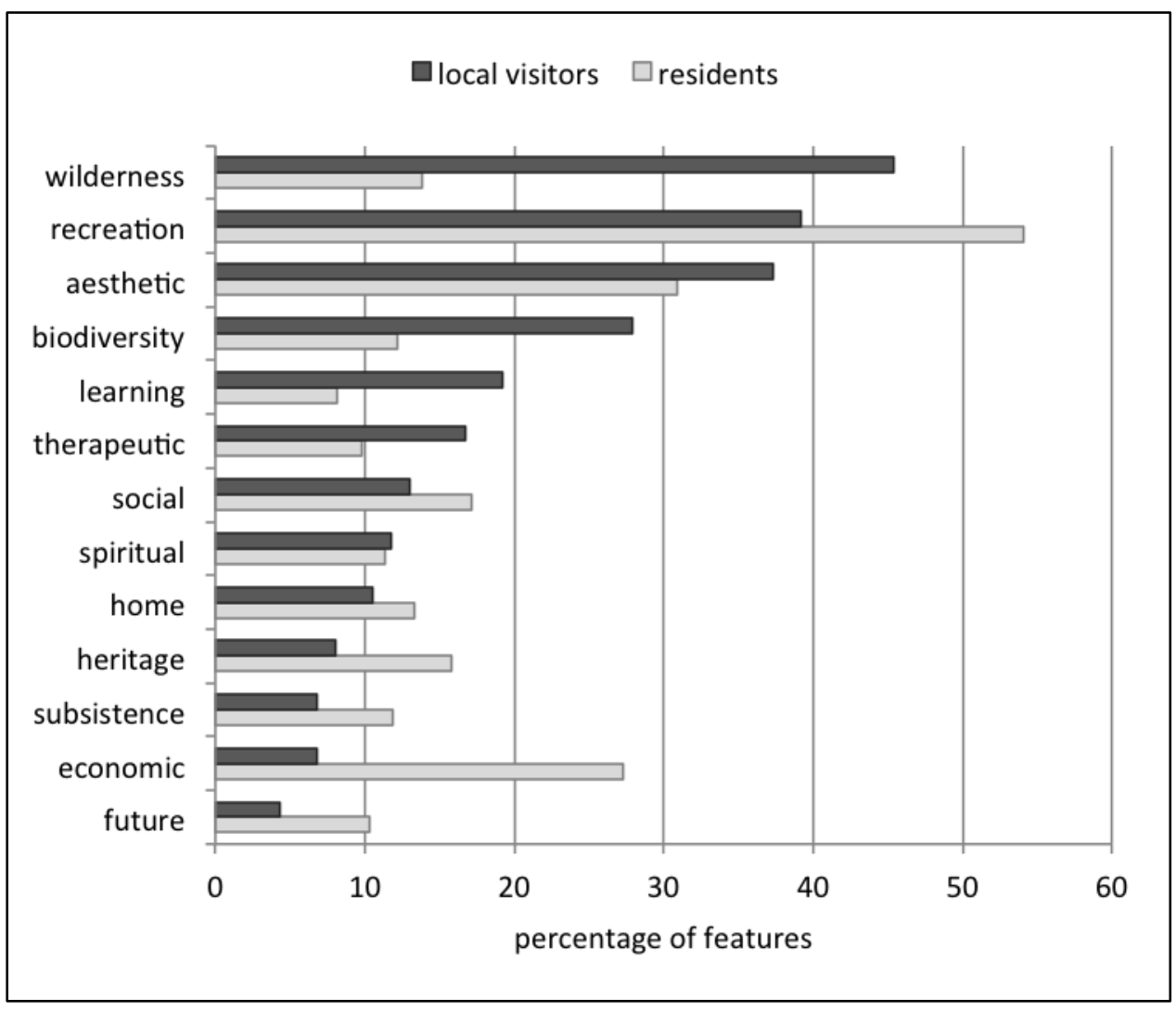

Figure 26. Chart comparing local visitor and resident value percentages.

Perhaps the similarities in values for both residents and visitors validate them as universal descriptors of the Olympic Peninsula. In contrast, the dissimilar values may better describe the survey participant groups as they relate to their respective hot spots identified within the Olympic Peninsula. The visitor response corresponds with the NPS educational material depicting Olympic National Park as an important place for wilderness and biodiversity. Similarly, much of the local dialogue depicts the working forests of Olympic National Forest and Department of Natural Resources as important to residents for economic and home. 
Local visitors at Coho Campground claimed they were unable to mark meaningful places because the map "doesn't have any roads on it." On the other hand, many visitors had difficulty marking the map because "the whole Peninsula is important!" These contrasting views of the Olympic Peninsula describe the difference between familiar and unfamiliar knowledge. People, who are very familiar, such as these local visitors, understand the Peninsula in greater detail than the map shows. People, who are less familiar, including first time visitors, do not know the area well enough to mark specific areas on the map. Like Tuan (1974) writes about environmental cognition, the range of perception reflects different sources of knowledge. Residents have a small-scale perception based on intimate experiences within the landscape. Visitors have large-scale perception based on sociocultural information. The results demonstrate a difference in the scale of perception between residents and visitors. 


\section{Chapter 7: Methodology Assessment}

\subsection{Random Visitor Surveys versus Resident Workshops}

Residents who participated at the Human Ecology Mapping Project (HEM) workshops marked shared maps with others sitting at the same table. Results indicate residents who marked the same map were often influenced by what others marked. In some cases, residents may have collaborated on the mapping to voice political views (McLain et al. 2013b). Collaborative input emphasizes a certain response by repetition. When people plan to provide certain information, they are contributing a composite response rather than individual perspectives. Adding that composite response to the average does not allow equal consideration of diverging responses. These examples from HEM demonstrate that collaborative mapping influences the overall results.

While this research is structured to be comparative to HEM, many details of the survey methodology were altered. Rather than organizing workshops, this research collected surveys from random people at typical visitor locations around the Olympic Peninsula. This method of data collection allowed me to obtain information from participants who do not plan for or think about the survey in advance. In order to prevent biased input in this research, visitors marked individual maps. In some cases, visitors collaborated as a couple or group to fill out the survey and map, but generally each survey included information that represented an individual participant. Some maps even included unusual individualistic mapping symbols such as squares or dotted lines. 
There are number of ways to collect data in surveys, including ranking or rating options and answering yes/no questions. This research implements options (values) for the participants to choose from and rank. On the survey form, visitors were asked to choose the top three values from a list of options. Many participants found this portion of the survey challenging because they had to choose between many values that they consider important. In contrast, the HEM survey allowed residents to include as many values from the list as they choose for each place. By restricting the number of values that a participant can include for each place, this research places greater emphasis on the values rather than the place. The participant chooses what values are most important for a place rather than describe the place using values.

Due to time restraints in the field, this survey combined activities and values for each place marked. Activities were collected as filled-in blanks. The resulting visitor composite maps place greater emphasis on values than activities. This differs from HEM, in which residents marked places for values separately from places for activities. The activities that visitors included on the survey needed to be categorized in order to analyze this data. Results may vary depending on how the activities are interpreted and grouped. Also, because in most of the surveys participants included more than one activity, the features are repeated for many categories of activities and the resulting patterns are not distinct. 


\subsection{Spatial Misrepresentation}

Methodologies that are the same between this research and HEM contrast from other studies. A majority of values mapping research distributes and collects surveys through the mail (Beverly et al. 2008; Zhu et al. 2010; Brown et al. 2013). In the Olympic Peninsula, the visitor field data collection and resident workshops were facilitated in person by researchers. Even though thorough instructions were printed on the surveys and explained by the researchers, participants still needed to be coached through the process to correctly complete the surveys. For a majority of people conceptualizing places was challenging. One participant observed, "You're really making us think!" It would seem that people are used to being told why places are important, rather than deciding for themselves.

The maps people are accustomed to seeing represent places as points. In order to ensure participants provided personal interpretations of space rather than choosing from conventional places, most participants needed additional explanation about how the data would be analyzed. Based on this observation of the data collection, I am skeptical that surveys distributed to visitors without guidance would be interpreted correctly.

After visitors acknowledge that the map can be marked in a number of ways, many still draw circles around labels on the map. Drawings that do not indicate landscape features are likely the product of map illiteracy, unfamiliarity with the Olympic Peninsula, or hasty reflection. According to McLain et al. (2013a), "sense of place mapping is...highly susceptible to locational errors and ambiguities in spatial representations." Interpretation of mapped places as points, lines, feature areas, or 
polygons is a solution to this misrepresentation. The resulting data includes 805 points or point areas, 115 lines, and 640 polygons. Even though many participants did not mark the map as expected, nearly half the features characterized areas that cannot be represented by points. These areas combined with the buffered points result in representations of places in the Olympic Peninsula that vary in size.

\subsection{Data Collection Locations}

The types of data collection locations (visitor center, campground, trail access point, and ferry) had different success rates. Visitor centers are the most obvious type of location for collecting data from visitors (Ormer et al. 2001). At visitor centers, many visitors seeking information approached us. To their surprise, we switched roles by requesting information from the visitor. It was common for people at visitor centers to initially respond to the research with skepticism. Many asked what the data would be used for, assuming there was a political objective. After we explained the purpose and methodology of the research, visitors expressed interest and appreciation for the study. Dispelling misguided judgments is another benefit of collecting the data in person.

Although it was expected campgrounds would be a good location to collect surveys, they resulted in the least amount of participation. Most campgrounds do not have a main center for setting up and addressing a volume of visitors. The exception was Kalaloch, a campground with greater capacity where there was a space in front of the main restroom to collect data. This location resulted in the most surveys out of all the campgrounds (seventeen). Campers at their sites were not interested in interacting. It was apparent that people in the campground were either enjoying downtime or taking care of 
daily routines like preparing food or suiting-up for an activity. Approaching people at their campsite was like going door-to-door perhaps because people relate their camp to something like their home.

Trail access points were unexpectedly successful as data collection sites. My presence was unexpected and as a result many people were curious about what I was doing. Most visitors who participated at trailheads had just returned from recreating in natural areas so their impressions were fresh in their minds. Visitors at trail access points had different attitudes about the research than at other types of locations. While people were skeptical at other locations, at trail access points people assumed the research was for a good purpose and thanked me for my work.

The ferry proved to be an excellent location for collecting large quantities of surveys. Several factors contributed to the efficiency of this location: ferry passengers are waiting to arrive at their destination and many seek something to occupy their time; the ferry crew made an announcement at the start of the trip to invite passengers to participate in the research; and additional researchers (four total) administered surveys aboard the ship thus increasing capacity.

While I collected double the number of surveys aboard the ferry in the same amount of time as other types of survey locations, more surveys do not necessarily provide additional information about who visits the Olympic Peninsula. The demographics for the ferry are similar to the overall demographics but with more extreme skewing - about 10 percent more male and people with a four-year degree (Figure 27). 


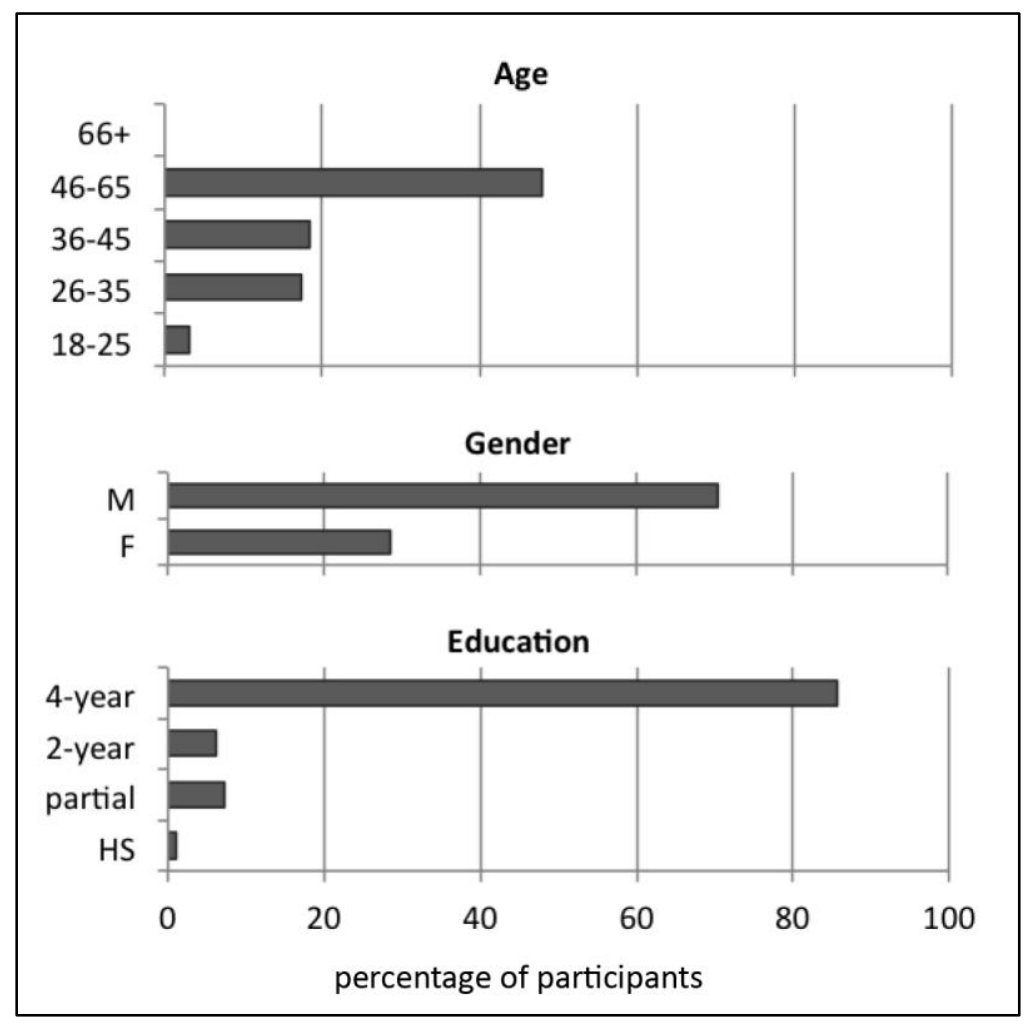

Figure 27. Charts of the Bainbridge Island visitor demographic results by percentage of total participants for that data collection location.

Several ferry lines cross the Puget Sound from different locations. Five routes directly connect to the Olympic Peninsula. According to employees of Washington State Department of transportation, each ferry route generally transports passengers who are traveling for different purposes, and the peak travel times vary. For example, they noted that on the weekend, day-trippers - many local to Seattle and surrounding towns - travel the Seattle/Bainbridge Island route. In contrast, blue-collar workers local to Puget Sound travel the Seattle/Bremerton route during the week. Collecting surveys on several ferries during the route's peak travel time may result in surveys from a greater variety of people. 


\section{Chapter 8: Conclusion}

\subsection{Typology of Visitors}

Older males with higher education dominated the visitors who participated in this research. Even though the demographics of the participants seem skewed, they may be representative of visitors to the Olympic Peninsula. The people who visit natural areas are predominantly older and well educated. Attempting to specifically target alternative populations such as youth or minority groups may provide new information for analysis, but that would be a different study. Getting input from a wider variety of visitors may depend on the marketing tactics of conservation initiatives to promote outdoor recreation to a broader range of people.

The level of familiarity of visitors with the Olympic Peninsula greatly influenced places marked. The overall density and hot spot maps show patterns that match those for visitors who are less familiar and visit from farther distances. These visitors account for nearly a third of all the participants. Local visitors and visitors with greater familiarity also mark popular destinations, but also map areas that are lost within the composite dataset. Recognizing these areas helps to understand how and by whom differing perspectives of the Olympic Peninsula are formed.

It is useful collecting data from first time visitors because regardless of the familiarity of people at the time of the survey, everyone was at some point new to the Olympic Peninsula. From a look at historic land management, change is the cause of differing perspectives. A visitor's familiarity has an influence on the places and values s/he includes in the survey. Because I collected surveys from anyone who would 
participate, I have only approximate information on people visiting the Olympic Peninsula.

My survey included visitors with different levels of familiarity from different parts of the Olympic Peninsula. The results emphasize the importance of the tourist route in the north part of the Peninsula where there are Olympic National Park destinations. Familiar visitors spend more time on the east side of the Peninsula and a mix of visitors spends time in the southern part of the Peninsula.

\subsection{Values and Activities in the Olympic Peninsula}

Aesthetic far outweighs all other values for visitors. This indicates that landscape appearance is crucial for people. Since recreation is an important value to visitors, access is necessary. However, wilderness is also a popular value, which by federal definition has limited access. Visitors associate wilderness value with areas that are not designated wilderness. Therefore there is a necessary difference between perceived wilderness where people can recreate and preserved wilderness that supports ecosystem function. Meaning from the values data is more robust when the values are combined with place characteristics. Places can be better understood when they are evaluated based on significant values. 


\subsection{Comparison of Visitors and Residents}

Visitors respond differently than residents to this type of survey of the Olympic Peninsula. These results validate the assumption that there is a difference in perspective between visitors and residents. Visitors marked areas in the National Park while residents marked national forest and state lands. Data that shows different perspectives and uses may provide supportive information for explaining potential conflict between outsiders and insiders.

However, even local visitors responded differently than residents at workshops. The method of collecting data from unsuspecting people at popular visitor locations enabled me to get input from people who would not otherwise participate in this type of research. While participants at the workshops had time to prepare and consider what information to contribute, participants from visitor locations provided information from a different mindset and/or without time to plan an objective.

\subsection{Methodology}

Overall, the methodology worked as planned; however, some details may be altered in future studies to result in stronger data for analysis. Campgrounds were not a good location to collect data. Rather than collect data at campgrounds, time would be better spent at active recreation locations. Because data collection on the ferry was a success, adding additional ferry routes may result in more data to compare.

There are benefits and limitations to collecting spatial data as freeform drawings rather than as points. Allowing participants to draw the areas that they refer to in the survey reveals information regarding the extent of values on the landscape. For example, 
places associated with wilderness often were drawn as larger areas. In contrast places associated with social and therapeutic values were drawn as smaller more specific areas.

Digitizing the data was challenging because many participants circled labels on the map rather than marking polygons to represent area. A lack of familiarity or simple map illiteracy exhibited by many visitors prevented them from marking the map any differently than if they were given a predefined shape. The buffered circles are essentially points that do not translate precisely as spatial data. As a result of hastily drawn shapes, features needed interpretation and many were not entered exactly as they were drawn. The resident data collected by HEM were digitized exactly as they were drawn. As a consequence of this exact digitizing, the data included slivers of high density that are not necessarily associated with any specific location in the Olympic Peninsula. Classifying the features may result in more useful and accurate information.

I was able to answer the research objectives of this study by disaggregating the data, a method which differs from that of other research (Tyrvainen et al. 2007; McIntyre et al. 2008; Sherrouse et al. 2011). The process of analysis used for this study combines many individual perspectives. This composite is an average of the whole. Details are lost when one result is produced from samples of widely ranging input. The composite does not describe the whole story and meanings may be misinterpreted. To better understand the visitor participants, I dissected the data to see what information is hidden within the average. 


\subsection{Study Implications}

A strength of this research is that it produced expected results. The results not only substantiate knowledge about specific places in the Olympic Peninsula, but also support theories about environmental cognition (Tuan 1974; Buttimer 1980). From the participant demographics to the locations of hot spots to the differences between visitors and residents, the outcomes from the participant surveys are logical and intuitive. These results may have been observed prior to the data collection, however, now there is data to support those claims.

Scale of the area affects the level of detail mapped and limits the analysis to regional results. This needs to be accounted for in the study expectations. Perhaps this form of study is best suited as a precursor to more specific study of highly impacted areas. Given the scale of the map, participants were only able to draw general areas or circle labels. Even people highly familiar with the area drew general shapes. Just as a map of the Olympic Peninsula can show limited data, participants can only map general information. The data collected represents the perspective of the participants, and participants provided data using the map as a guide. Therefore, information can only accurately be derived at the same scale as the study map. For regional scaled research, an appropriate use of values data is to provide general spatial patterns of values and activities. Patterns that the data reveals include the counts and distribution of features and values.

A difference was observed between the visitors to Olympic National Park and those to Olympic National Forest not only in the field, but also in the data those 
participants contributed to the research. In this study, visitors who participated while on national forest lands contributed results that vary from the overall composite results. Because there were more participants in Olympic National Park locations, the responses had greater influence on the overall results. In order to collect a comparative number of surveys from people in both areas, I recommend that future studies add additional survey locations within national forest land.

\subsection{Future Research}

The Forest Service initiated this form of study in the Olympic Peninsula because they need sociocultural data for land-use planning. Stakeholder groups may provide useful information for considering specific uses of the land and subcultures of people. When there are conflicting ideas about how land should be managed, it is usually organized groups that have strong opinions and voice complaints, as observed on signs advocating and discrediting Wild Olympics.

The data collected in this research reflects the views of participants at a specific point in time. To get the most use out of this type of data, surveys should be administered regularly so that the changing perspectives of visitors and residents can be observed and evaluated.

During the summer of 2013, colleagues and I conducted follow-up research in the Olympic Peninsula. The purpose of this additional research was to better understand the responses from visitors, since much of this study required making assumptions about the places participants marked and the value they associate with those places. We administered the same survey in locations on the east side of the Peninsula and collected 
fifty surveys. In addition, my colleague and I conducted ten in-depth interviews with participants after they filled out the surveys. Questions sought to understand why participants used certain mapping methods and how they interpret the value meanings. My first impression after speaking with participants is that the combination of values chosen by a person provides additional meaning.

\subsection{Concluding Remarks}

Accounting for different opinions and experiences is challenging but necessary. Nigerian author, Chimamanda Ngozi Adichie (2009), presented The Danger of a Single Story as a TED Talk addressing the problem with judging people based on one piece of information, what she calls the "single story." Adichie asserts, "The single story creates stereotypes, and the problem with stereotypes is not that they are untrue, but that they are incomplete. They make one story become the only story." The single story is a onedimensional representation of humanity that divides people rather than bringing them together by revealing connections. This is evident in the Olympic Peninsula where people divide over the Wild Olympics proposal and view the other as either an environmental extremist or anti-government logger. However, there are numerous and more complex issues that justify the support of or opposition to the proposal. The more stories we can derive from the sociocultural data collected by values mapping, the better we can understand how people relate to places. 
Adichie, C. N. 2009. "The Danger of a Single Story". TED Conferences, LLC website. http://www.ted.com/talks/chimamanda_adichie_the_danger_of_a_single_story.ht ht (last accessed 10 January 2014).

Alessa, L. N., Kliskey, A. A., Brown, G. 2008. Social-ecological hotspots mapping. A spatial approach for identifying coupled social-ecological space. Landscape and Urban Planning 85: 27-39.

Allen, E. T. 1911. Practical forestry in the Pacific Northwest: protecting existing forests and growing new ones, from the standpoint of the public and that of the lumberman, with an outline of technical methods. Portland, OR: Western Forestry \& Conservation Association.

ArcMap 10.1. Esri: Redlands, CA.

Beverly, J. L., K. Uto, J. Wilkes, and P. Bothwell. 2008. Assessing spatial attributes of forest landscape values: an internet-based participatory mapping approach. Canada Journal of Forest Research 38: 289-303.

Boyd, E. J. ca. 1939. "Lapoel Auto Camp showing a log truck with a large fir log parked near a small building, Clallam County”. University of Washington, Digital Libraries website. http://content.lib.washington.edu/cdm4/item_viewer.php?CISOROOT=/cchs\&CI CISOP=45\&CISOBOX=1\&REC=33 (last accessed 10 January 2014).

Brown, G. and L. Brabyn. 2012. An analysis of the relationships between multiple values and physical landscapes at a regional scale using public participation GIS and landscape character classification. Landscape and Urban Planning 107: 317-331.

Brown, G., M. Kelly, and D. Whitall. 2013. Which 'public'? Sampling effects in public participation GIS (PPGIS) and colunteered geographic information (VGI) systems for public lands management. Journal of Environmental Planning and Management 57(2): 190-214.

Brown, G. and C. Raymond. 2007. The relationship between place attachment and landscape values: Toward mapping place attachment. Applied Geography 27: 89111.

Brown, G. and P. Reed. 2013. Social landscape metrics: measures for understanding place values from public participation geographic information systems (PPGIS). Landscape Research: forthcoming. http://www.landscapemap2.org/publicationsv1.html (last accessed 10 January 2014).

. 2000. Validation of a forest values typology for use in national forest planning. Forest Science 46(2): 240-247.

Buttimer, A. 1980. Home, reach, and the sense of place. In The Human Experience of Space and Place, ed. A. Buttimer, and D. Seamon, 166-187. New York, NY: St. Martin's Press. 
Buttolph, L.P., W., Kay, S. Charnley, C. Moseley, and E. M. Donoghue. 1996. Northwest Forest Plan - the first 10 years (1994-2003): Socioeconomic monitoring of the Olympic National Forest and three local communities. Gen. Tech. Rep. PNWGTR-679. Portland, OR: U.S. Department of Agriculture, Forest Service, Pacific Northwest Research Station.

Center for the Study of the Pacific Northwest. "Seeing the Forest for the Trees: Placing Washington's Forests in Historical Context." Center for the Study of the Pacific Northwest, University of Washington website. http://www.washington.edu/uwired/outreach/cspn/Website/Classroom\%20Materi als/Curriculum\%20Packets/Evergreen\%20State/Section\%20II.html (last accessed 10 January 2014).

Chickowski, E. 2009. Moon spotlight: the Olympic Peninsula. Berkeley, CA: Avalon Travel Publishing.

Cresswell, T. 2004. Place: a short introduction. Malden, MA: Blackwell Publishing.

Donovan, S. S., C. Looney, T. Hanson, Y. Sanchez de Leon, J. Wilfhorst, S. D. Eigenbrode, M. Jennings, J. Johnson-Maynard, and N. A. Bosque Perez. 2009. Reconciling social and biological needs in an endangered ecosystem: the Palouse as a model for bioregional planning. Ecology and Society 14(1):9.

DeLyser, D. 2001. When less is more: absence and landscape in a California ghost town. In Textures of place: exploring human geographies, ed. P. C. Adams, S. Hoelscher, and K. E. Tills, 24-40. Minneapolis: Minnesota Press.

ECC (Emergency Conservation Committee). 1934. The proposed Olympic National Park: an opportunity of which we must take advantage now or never. New York, NY: Emergency Conservation Committee.

Fagerholm, N., N. Kayhko, F. Ndumbaro, and M. Khamis. 2012. Community stakeholders' knowledge in landscape assessments: mapping indicators for landscape services. Ecological Indicators 18: 421-433.

Fagerholm, N. and N. Kayhko. 2009. Participatory mapping and geographical patterns of the social landscape values of rural communities in Zanzibar, Tanzania. Fennia 187(1): 43-60.

Farnum, J. O., and L. E. Kruger. 2008. Place-based planning: innovations and applications from four western forests. Gen. Tech. Rep. PNW-GTR-741. Portland, OR: US Department of Agriculture, Forest Service, Pacific Northwest Research Station.

Gerrard, M. 2007. Global climate change and U.S. law. Chicago, IL: American Bar Association.

Gould, P. R. 1973. "On mental maps." In Image and environment: cognitive mapping and spatial behavior, ed. R. M. Downs, and D. Stea. Chicago: Aldine Pub. Co. 
Kaplan, R. and S. Kaplan. 1989. The Experience of Nature: A Psychological Perspective. New York, NY: Cambridge University Press.

Kaplan,S. 1979. "Perception and landscape: conceptions and misconceptions." Proceedings of the National Conference on Applied Techniques for Analysis and management of the Visual Resource, Incline Village, NV, 23-25 April 1979.

Lindstrom, M. J. 2011. Encyclopedia of the U.S. government and the environment: history, policy, and politics. Santa Barbara, CA: ABC-CLIO, LLC.

Lynch, K. 1960. The image of the city. Cambridge, Massachusetts: MIT Press.

Manfredo, M. J., J. J. Vaske, and T. L. Teel. 2003. The potential for conflict index: a graphic approach to practical significance of human dimensions research. Human Dimensions of Wildlife 8: 219-228.

Marshall, R. 1933. The people's forests. Iowa City, IA: University of Iowa Press.

McDonald, K. and R. McLain. 2003. "The integration of community well-being and forest health in the Pacific Northwest”. In Forest communities, community forests, ed., J. Kusel and E. Adler, 221-256. Lanham, MD: Rowman \& Littlefield Publishers, Inc.

McIntyre, N., J. Moore, and M. Yuan. 2008. A place-based, values-centered approach to managing recreation on Canadian crown lands. Society and Natural Resources 21: 657-670.

McLain, R., Poe, M., Biedenweg, K., Cerveny, L., Besser, D., and D. Blahna. 2013a. Making sense of human ecology mapping: an overview of approaches to integrating sociocultural data into GIS-based environmental planning. Human Ecology 41(1): author's copy.

McLain, R., L. Cerveny, D. Besser, D. Banis, K. Biedenweg, A. Todd, C. KimballBrown, and S. Rhody. 2013b. Mapping human-environment connections on the Olympic Peninsula: an atlas of landscape values. http://www.pdx.edu/geography/presentations (last accessed 10 January 2014).

McNulty, T. 2009. Olympic National Park: a natural history, revised edition. Seattle, WA: University of Washington Press.

Miles, J. C. 2000. "Three national parks of the Pacific Northwest". In National parks and rural development: practice and policy in the United States, ed., G. E. Machlis and D. Field, 91-109. Washington, DC: Island Press.

Morgan, Murray. 1955. The last wilderness. Revised and expanded ed. Seattle: University of Washington Press.

Nash, R. 1982. Wilderness and the American mind, third edition. New Haven, CT: Yale University Press. 
NPS (National Park Service). "National Park Service Visitor Use Statistics" National Park Service website. https://irma.nps.gov/Stats/Reports/Park (last accessed 10 January 2014).

National Park Service Organic Act. 25 August 1916. 16 USC $§ 1$.

Oakes, T. S. and P. L. Price. 2008. The cultural geography reader. New York, NY: Routledge.

Oberthur, S. and H. E. Ott. 1999. The Kyoto Protocol: international climate policy for the 21st Century. New York, NY: Springer.

Ollikainen, R. 2011. “Anti-Wild Olympics resolution presented.” Peninsula Daily News website.

http://www.peninsuladailynews.com/article/20111201/news/312019997/anti-

wild-olympics-resolution-presented (last accessed 10 January 2014).

ONP (Olympic National Park). "Olympic National Park: Places to go". Olympic National Park website. http://www.nps.gov/olym/planyourvisit/places-to-go.htm (last accessed 10 January 2014).

Ormer, C. V., Littlejohn, M., and J. H. Gramann. 2001. Olympic National Park visitor study: Summer 2000. National Park Service website. http://www.nps.gov/olym/parkmgmt/upload/ONPvisitorstudy2000.pdf (last accessed 10 January 2014).

Pendley, W. P. 1995. War on the West: government tyranny on America's great frontier. Washington, DC: Regnery Publishing, Inc.

Pinchot, G. 1910. The fight for conservation. New York, NY: DoubleDay, Page \& Company.

Pocewicz, A., M. Nielsen-Pincus, G. Brown, and R. Schnitzer. 2012. An evaluation of internet versus paper-based methods for public participation geographic information systems (PPGIS). Transactions in GIS 16(1): 39-53.

Proctor, J. D. 1996. Whose nature? The contested moral terrain of ancient forests. In Uncommon ground: rethinking the human place in nature, ed. W. Cronon, 269297. New York, NY: W. W. Norton \& Company.

Proctor, J. D. 1998. Environmental values and popular conflict over environmental management: a comparative analysis of public comments on the Clinton Forest Plan. Environmental Management 22(3): 347-358.

Sharp, R., L. Larson, and G. Green. 2011. Factors influencing public preferences for invasive alien species management. Biological Conservation 144: 2097-2104.

Sherrouse, B. C., J. M. Clement, and D. J. Semmens. 2011. A GIS application for assessing, mapping, and quantifying the social values of ecosystem services. Applied Geography 31: 748-760. 
Stipe, R. E. and A. J. Lee. 1997. The American mosaic: preserving a nation's heritage. Detroit, MI: Wayne State University Press.

The Morning Leader. 3 May 1911. University of Washington, Digital Libraries website. http://content.lib.washington.edu/cdm4/item_viewer.php?CISOROOT=/ptleader $\& \mathrm{CISOPTR}=5844 \& \mathrm{CISOBOX}=1 \& \mathrm{REC}=12$ (last accessed 10 January 2014).

Theobald, D. M., and N. T. Hobbs. 2002. A framework for evaluating land use planning alternatives: protecting biodiversity on private land. Conservation Ecology 6(1): 5. http://consecol.org/vol6/iss1/art5 (last accessed 10 January 2014).

Tuan, Y. 1974. Topophilia: a study of environmental perception, attitudes, and values. Englewood Cliffs, NJ: Prentice-Hall.

Tyrvainen, L., Makinen, K., and J. Schipperijn. 2007. Tools for mapping social values of urban woodlands and other green areas. Landscape and Urban Planning 79: 5-19.

USDA (U.S. Department of Agriculture). 1997. Establishment and modification of national forest boundaries and national grasslands, a chronological record: 18911996. Washington D.C. . 1990. Land and Resource Management Plan: Olympic National Forest.

USGS (U.S. Geological Survey). 1902. Forest conditions in the Olympic Reserve, Washington. Washington D.C.

Vaske, J. J., M. D. Needham, and R. C. Cline Jr. 2007. Clarifying interpersonal and social values conflict among recreationists. Journal of Leisure Research 39(1): 182-195.

Whitesell, E. A. 2004. Defending wild Washington: A Citizen's Action Guide. Seattle, WA: The Mountaineers Books.

Wilderness Act. 3 September 1964. 16 USC § 1131-1136.

Wilderness.net. "What is 'Wilderness'?" Wilderness.net website. http://www.wilderness.net/NWPS/WhatIsWilderness (last accessed 10 january 2014).

Wilkinson, C. F. 1992. Crossing the next meridian: land, water, and the Future of the West. Washington D. C: Island press.

Wild Olympics. 'Wild Olympics Conservation Vision'. Wild Olympics website. http://www.wildolympics.org/vision (last accessed 10 January 2014).

Wisman, P. 1985. "EPA History (1970-1985).” U.S. Environmental Protection Agency website. http://www2.epa.gov/aboutepa/epa-history-1970-1985 (last accessed 10 January 2014).

Wood, R. L. 2000. Olympic Mountains Trail Guide: national park and national forest, Third Edition. Seattle, WA: The Mountaineers.

Wray, J. 2002. Native peoples of the Olympic Peninsula: who we are. Norman, OK: University of Oklahoma Press. 
Zhu, X., S. Pfueller, and P. Whitelaw. 2010. Spatial differentiation of landscape values in the Murray River region of Victoria, Australia. Environmental Management 45: 896-911. 


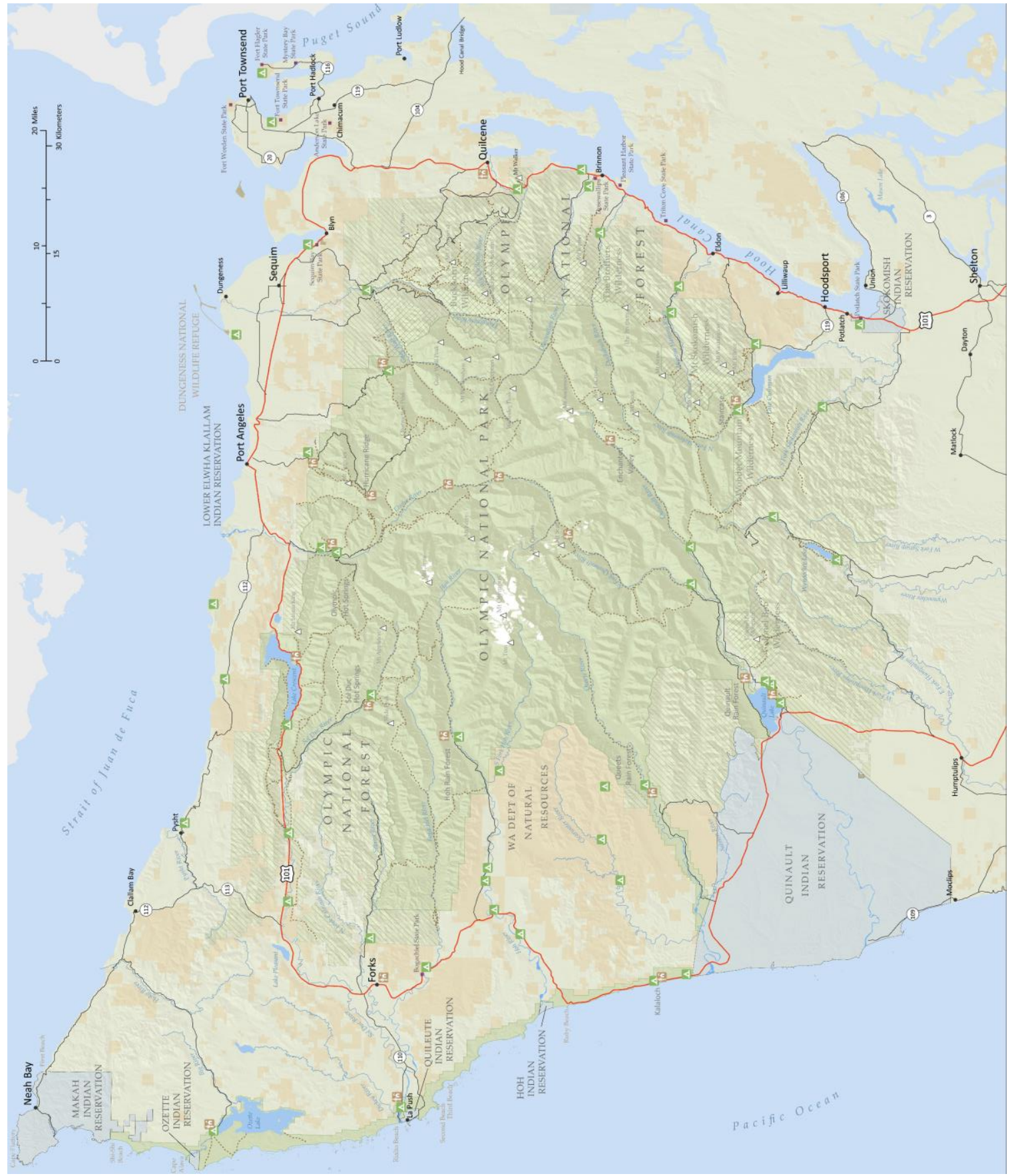




\section{Appendix B. Data Collection Questionnaire: Values Mapping}

Mapping Visitor Perspectives

Questionnaire

A) Location:

Activities:

Value 1: Comments:

Value 2:

Value 3

B) Location:

Activities:

Value 1: Comments:

Value 2:

Value 3

C) Location:

Activities:

Value 1: Comments:

Value 2:

Value 3:

D) Location:

Activities:

Value 1: Comments:

Value 2:

Value 3

E) Location:

Activities:

Value 1

Value 2:

Value 3
Values

1 AESTHETIC (scenic beauty) - I value this place for the scenery, sights, smells or sounds.

2 BIODIVERSITY - I value this place because it provides habitat for a variety of plants and animals, many of which may not be found in other places.

3 ECONOMIC - I value this place because it provides income and employment opportunities through industries such as forest products, mining, tourism, agriculture, shellfish, or other commercial activity.

4 ENTERTAINMENT - I value this place because it provides diversion, amusement or cultural expression.

5 FUTURE - I value this place because it allows generations that will follow us to know and experience it as it is now.

6 HERITAGE - I value this place because it has natural and human history that matters to me and it allows me to pass down the wisdom, knowledge, traditions, or way of life of my ancestors.

7 HOME - I value this place because it is familiar, comfortable, and welcoming.

8 LEARNING - I value this place because it provides a place to learn about, teach or research the natural environment.

9 RECREATION - I value this place because it provides opportunities for outdoor activities.

10 SOCIAL - I value this place because it provides opportunities for getting together with my friends and family.

11 SPIRITUAL - I value this place because it is sacred, religious, or divinely special to me.

12 SUBSISTENCE (products used but not sold) - I value this place because it provides food and other products to sustain my life and that of my family.

13 THERAPEUTIC - I value this place because it makes me feel better physically and/or mentally.

14 WILDERNESS - I value this place because it is not developed or altered appreciably by people. 


\section{Appendix C. Data Collection Questionnaire: Demographics}

For each question, please fill in the blank or mark the box that most closely resembles your situation.

1) zip code or country (of your primary address)

2) In the past 5 years, how often have you visited the Olympic Peninsula?

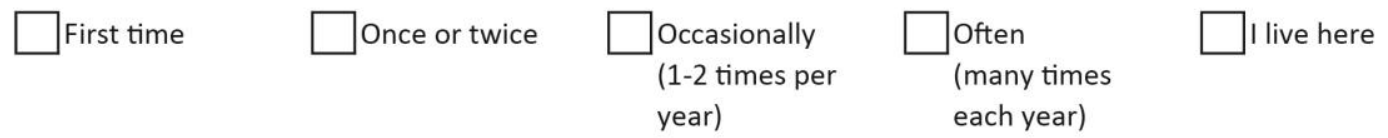

3) What is the typical length of your visit in the Olympic Peninsula?

$\begin{array}{lll}\square \text { Day trip } & \square \text { Overnight } \quad \square \text { Weekend } \square \text { Week } \\ \square \text { Month } & \square \text { For a season }\end{array}$

4) In the last 5 years, how often have you visited National Parks/ National Forests?

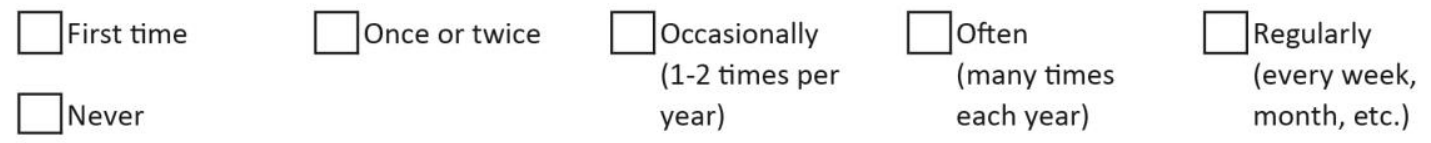

5) Age

18-25

$\square 26-35$

$36-45$

46-65

\66 or greater

6) Gender
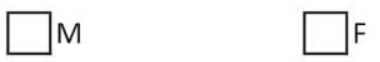

7) Education

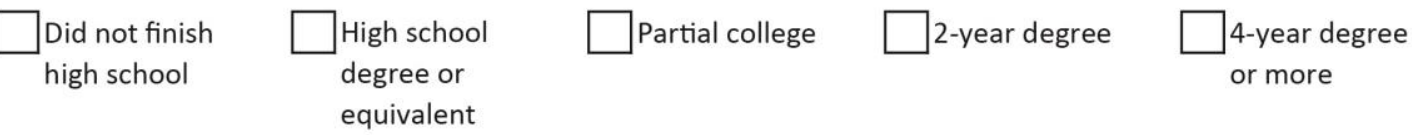

